\title{
Computerised cognitive training for 12 or more weeks for maintaining cognitive function in cognitively healthy people in late life (Review)
}

Gates NJ, Rutjes AWS, Di Nisio M, Karim S, Chong LY, March E, Martínez G, Vernooij RWM

Gates NJ, Rutjes AWS, Di Nisio M, Karim S, Chong LY, March E, Martínez G, Vernooij RWM.

Computerised cognitive training for 12 or more weeks for maintaining cognitive function in cognitively healthy people in late life.

Cochrane Database of Systematic Reviews 2020, Issue 2. Art. No.: CD012277.

DOI: 10.1002/14651858.CD012277.pub3.

www.cochranelibrary.com 
TABLE OF CONTENTS

HEADER 1

ABSTRACT

PLAIN LANGUAGE SUMMARY

SUMMARY OF FINDINGS

BACKGROUND

OBJECTIVES

METHODS

RESULTS

Figure 1.

Figure 2.

Figure 3.

Figure 4.

Figure 5.

Figure 6.

Figure 7.

Figure 8.

Figure 9.

Figure 10.

DISCUSSION

AUTHORS' CONCLUSIONS

ACKNOWLEDGEMENTS

REFERENCES

CHARACTERISTICS OF STUDIES

DATA AND ANALYSES

Analysis 1.1. Comparison 1 Computerised cognition-based training versus active control, Outcome 1 Global cognitive function.

Analysis 1.2. Comparison 1 Computerised cognition-based training versus active control, Outcome 2 Episodic memory. .........

Analysis 1.3. Comparison 1 Computerised cognition-based training versus active control, Outcome 3 Speed of processing. ....

Analysis 1.4. Comparison 1 Computerised cognition-based training versus active control, Outcome 4 Executive function. .......

Analysis 1.5. Comparison 1 Computerised cognition-based training versus active control, Outcome 5 Working memory. ........

Analysis 2.1. Comparison 2 Computerised cognition-based training versus inactive control, Outcome 1 Episodic Memory. .....

Analysis 2.2. Comparison 2 Computerised cognition-based training versus inactive control, Outcome 2 Executive function. ....

Analysis 2.3. Comparison 2 Computerised cognition-based training versus inactive control, Outcome 3 Speed of processing. ..

Analysis 2.4. Comparison 2 Computerised cognition-based training versus inactive control, Outcome 4 Working memory. .....

Analysis 2.5. Comparison 2 Computerised cognition-based training versus inactive control, Outcome 5 Verbal fluency. .......... APPENDICES

FEEDBACK

WHAT'S NEW

CONTRIBUTIONS OF AUTHORS

DECLARATIONS OF INTEREST

SOURCES OF SUPPORT

DIFFERENCES BETWEEN PROTOCOL AND REVIEW

INDEX TERMS 
[Intervention Review]

\section{Computerised cognitive training for 12 or more weeks for maintaining cognitive function in cognitively healthy people in late life}

Nicola J Gates ${ }^{1}$, Anne WS Rutjes 2,3 , Marcello Di Nisio4, Salman Karim5, Lee-Yee Chong6, Evrim March7 , Gabriel Martínez ${ }^{8}$, Robin WM Vernooij 9

${ }^{1}$ Centre for Healthy Brain Ageing (CHeBA), University of New South Wales, Sydney, Australia. 2Institute of Social and Preventive Medicine (ISPM), University of Bern, Bern, Switzerland. 3Institute of Primary Health Care (BIHAM), University of Bern, Bern, Switzerland. ${ }^{4}$ Department of Medicine and Ageing Sciences, University "G. D'Annunzio" of Chieti-Pescara, Chieti Scalo, Italy. ${ }^{5}$ Psychiatry, Lancashire Care NHS Foundation Trust, Preston, UK. 6UK Cochrane Centre, Oxford, UK. 7St Vincent's Adult Mental Health, St Vincent's Hospital (Melbourne), Fitzroy, Australia. ${ }^{8}$ Faculty of Medicine and Dentistry, Universidad de Antofagasta, Antofagasta, Chile. ${ }^{9}$ Department of Nephrology and Hypertension and Julius Center for Health Sciences and Primary Care, University Medical Center Utrecht, Utrecht, Netherlands

Contact address: Robin WM Vernooij, Department of Nephrology and Hypertension and Julius Center for Health Sciences and Primary Care, University Medical Center Utrecht, Heidelberglaan 100, Utrecht, 3584 CX, Netherlands. robinvernooij@gmail.com.

Editorial group: Cochrane Dementia and Cognitive Improvement Group

Publication status and date: Edited (conclusions changed), published in Issue 2, 2020.

Citation: Gates NJ, Rutjes AWS, Di Nisio M, Karim S, Chong LY, March E, Martínez G, Vernooij RWM. Computerised cognitive training for 12 or more weeks for maintaining cognitive function in cognitively healthy people in late life. Cochrane Database of Systematic Reviews 2020, Issue 2. Art. No.: CD012277. DOI: 10.1002/14651858.CD012277.pub3.

Copyright ( 2020 The Cochrane Collaboration. Published by John Wiley \& Sons, Ltd.

\section{A B S T R A C T}

\section{Background}

Increasing age is associated with a natural decline in cognitive function and is the greatest risk factor for dementia. Cognitive decline and dementia are significant threats to independence and quality of life in older adults. Therefore, identifying interventions that help to maintain cognitive function in older adults or that reduce the risk of dementia is a research priority. Cognitive training uses repeated practice on standardised exercises targeting one or more cognitive domains and may be intended to improve or maintain optimal cognitive function. This review examines the effects of computerised cognitive training interventions lasting at least 12 weeks on the cognitive function of healthy adults aged 65 or older and has formed part of a wider project about modifying lifestyle to maintain cognitive function. We chose a minimum 12 weeks duration as a trade-off between adequate exposure to a sustainable intervention and feasibility in a trial setting.

\section{Objectives}

To evaluate the effects of computerised cognitive training interventions lasting at least 12 weeks on cognitive function in cognitively healthy people in late life.

\section{Search methods}

We searched to 31 March 2018 in ALOIS (www.medicine.ox.ac.uk/alois), and we performed additional searches of MEDLINE, Embase, PsycINFO, CINAHL, ClinicalTrials.gov, and the WHO Portal/ICTRP (www.apps.who.int/trialsearch), to ensure that the search was as comprehensive and as up-to-date as possible to identify published, unpublished, and ongoing trials.

\section{Selection criteria}

We included randomised controlled trials (RCTs) and quasi-RCTs, published or unpublished, reported in any language. Participants were cognitively healthy people, and at least $80 \%$ of the study population had to be aged 65 or older. Experimental interventions adhered to the following criteria: intervention was any form of interactive computerised cognitive intervention - including computer exercises, computer 
games, mobile devices, gaming console, and virtual reality - that involved repeated practice on standardised exercises of specified cognitive domain(s) for the purpose of enhancing cognitive function; the duration of the intervention was at least 12 weeks; cognitive outcomes were measured; and cognitive training interventions were compared with active or inactive control interventions.

\section{Data collection and analysis}

We performed preliminary screening of search results using a 'crowdsourcing' method to identify RCTs. At least two review authors working independently screened the remaining citations against inclusion criteria. At least two review authors also independently extracted data and assessed the risk of bias of included RCTs. Where appropriate, we synthesised data in random-effects meta-analyses, comparing computerised cognitive training (CCT) separately with active and inactive controls. We expressed treatment effects as standardised mean differences (SMDs) with 95\% confidence intervals (CIs). We used GRADE methods to describe the overall quality of the evidence for each outcome.

\section{Main results}

We identified eight RCTs with a total of 1183 participants. The duration of the interventions ranged from 12 to 26 weeks; in five trials, the duration of intervention was 12 or 13 weeks. The included studies had moderate risk of bias, and the overall quality of evidence was low or very low for all outcomes.

We compared CCT first against active control interventions, such as watching educational videos. Negative SMDs favour CCT over control. Trial results suggest slight improvement in global cognitive function at the end of the intervention period ( 12 weeks) (standardised mean difference (SMD) - $0.31,95 \%$ confidence interval ( $\mathrm{Cl}$ ) -0.57 to $-0.05 ; 232$ participants; 2 studies; low-quality evidence). One of these trials also assessed global cognitive function 12 months after the end of the intervention; this trial provided no clear evidence of a persistent effect (SMD - $0.21,95 \% \mathrm{Cl}-0.66$ to $0.24 ; 77$ participants; 1 study; low-quality evidence). CCT may result in little or no difference at the end of the intervention period in episodic memory (12 to 17 weeks) (SMD $0.06,95 \% \mathrm{Cl}-0.14$ to $0.26 ; 439$ participants; 4 studies; low-quality evidence) or working memory (12 to 16 weeks) (SMD $-0.17,95 \% \mathrm{Cl}-0.36$ to $0.02 ; 392$ participants; 3 studies; low-quality evidence). Because of the very low quality of the evidence, we are very uncertain about the effects of CCT on speed of processing and executive function.

We also compared CCT to inactive control (no interventions). We found no data on our primary outcome of global cognitive function. At the end of the intervention, CCT may lead to slight improvement in episodic memory (6 months) (mean difference (MD) in Rivermead Behavioural Memory Test (RBMT) -0.90 points, $95 \%$ confidence interval (CI) -1.73 to $-0.07 ; 150$ participants; 1 study; low-quality evidence) but can have little or no effect on executive function (12 weeks to 6 months) (SMD $-0.08,95 \% \mathrm{Cl}-0.31$ to $0.15 ; 292$ participants; 2 studies; low-quality evidence), working memory (16 weeks) (MD - $0.08,95 \% \mathrm{Cl}-0.43$ to $0.27 ; 60$ participants; 1 study; low-quality evidence), or verbal fluency ( 6 months) (MD -0.11, 95\% Cl -1.58 to 1.36; 150 participants; 1 study; low-quality evidence). We could not determine any effects on speed of processing because the evidence was of very low quality.

We found no evidence on quality of life, activities of daily living, or adverse effects in either comparison.

\section{Authors' conclusions}

We found low-quality evidence suggesting that immediately after completion of the intervention, small benefits of CCT may be seen for global cognitive function when compared with active controls, and for episodic memory when compared with an inactive control. These benefits are of uncertain clinical importance. We found no evidence that the effect on global cognitive function persisted 12 months later. Our confidence in the results was low, reflecting the overall quality of the evidence. In five of the eight trials, the duration of the intervention was just three months. The possibility that more extensive training could yield larger benefit remains to be more fully explored.

We found substantial literature on cognitive training, and collating all available scientific information posed problems. Duration of treatment may not be the best way to categorise interventions for inclusion. As the primary interest of older people and of guideline writers and policymakers involves sustained cognitive benefit, an alternative would be to categorise by length of follow-up after selecting studies that assess longer-term effects.

\section{PLAIN LANGUAGE SUMMARY}

\section{Computerised cognitive training for maintaining cognitive function in cognitively healthy people in late life}

\section{Background}

The terms 'cognition' and 'cognitive function' describe all of the mental activities related to thinking, learning, remembering, and communicating. Normal changes in cognition occur with ageing. There are also diseases that affect cognition, principally dementia, which becomes increasingly common with increasing age from about 65 years onwards. It is known that being mentally active throughout life is associated with lower risk of dementia. Therefore, it has been suggested that encouraging mental activity might be an effective way of maintaining good cognitive function as people age. Cognitive training comprises a set of standardised tasks intended to 'exercise the brain' in various ways. Programmes of cognitive training are often delivered by computers or mobile technology, so that people can do this training on their own at home. Increasingly, these are available as commercial packages that are advertised to the general public. 
We wanted to know whether long-term use of computerised cognitive training (CCT) is an effective way for people aged 65 and older to maintain good cognitive function as they age.

\section{What we did}

We searched the medical literature up to 15 March 2018 for trials that compared cognitive function of people aged 65 or older who had taken part in computerised cognitive training for a minimum of 12 weeks with cognitive function of a control group that had not done so. All participants should have been cognitively healthy at the start of the trials. For the comparison to be as fair as possible, it should have been decided randomly whether participants were in the cognitive training group or in the control group. We were primarily interested in overall measures of cognition. The choice of three months for the intervention was somewhat arbitrary, but we thought very short interventions were unlikely to have lasting effects, and we were interested in interventions that could be sustained over time.

\section{What we found}

We found eight trials with a total of 1183 participants to include in the review. Five trials provided CCT for three months, two for four months, and one for six months. We compared CCT with other activities, such as watching educational videos, and with no activity. We looked for effects on overall cognitive function and on specific cognitive functions, such as memory and thinking speed. All of the included studies had some design problems, which could have biased the results. Overall, we thought the quality of the evidence that we found was low or very low. This means we cannot be confident in the results, and that future research might well find something different. CCT may slightly improve overall cognitive function after 12 weeks of training; however, we found no evidence of a persistent effect 12 months after the intervention. We were unable to comment or found little evidence that CCT when compared with other activities may have a relevant effect on most of the specific cognitive functions that we examined. The longest trial found that compared to doing nothing, completing six months of CCT may have had a beneficial effect on memory. None of the included trials reported effects of cognitive training on quality of life or on daily activities, and none reported harmful effects of training.

\section{Our conclusions}

Compared to other activities, CCT may lead to slightly better overall cognitive function at the end of 12 weeks of training, but we found no evidence that the effect persists a year later. Compared to doing nothing, CCT may slightly improve memory at the end of six months of training. Although we excluded trials with less than 12 weeks of training, the trials that we included were still quite short for examining long-term effects as people age. A limitation of our review is that we did not include some trials with shorter training periods that did look for long-lasting effects, so it is possible that we missed some useful evidence. Many published studies have looked at computer training. Making sense of this substantial literature is difficult. It may be more helpful in the future to categorise trials by the duration of effects of training rather than by the duration of the training itself. 
SUMMARY OF FINDINGS

\section{Summary of findings for the main comparison.}

\section{Computerised cognitive training compared with active control intervention in cognitively healthy people in late life}

Patient or population: cognitively healthy people in late life

Settings: general population

Intervention: computerised cognitive training

Comparison: active control intervention

\begin{tabular}{|c|c|c|c|c|}
\hline Outcomes & $\begin{array}{l}\text { Difference be- } \\
\text { tween } \mathrm{CCT} \text { and } \\
\text { control }(95 \% \mathrm{Cl})^{a^{*}}\end{array}$ & $\begin{array}{l}\text { No. of par- } \\
\text { ticipants } \\
\text { (studies) }\end{array}$ & $\begin{array}{l}\text { Quality of } \\
\text { the evi- } \\
\text { dence } \\
\text { (GRADE) }\end{array}$ & Comments \\
\hline $\begin{array}{l}\text { Global cognitive function measured at the } \\
\text { end of the intervention period ( } 12 \text { weeks) }\end{array}$ & $\begin{array}{l}\text { SMD } 0.31 \text { lower } \\
\text { (0.57 lower to } 0.05 \\
\text { lower) }\end{array}$ & $\begin{array}{l}232 \text { partici- } \\
\text { pants } \\
\text { ( } 2 \text { studies) }\end{array}$ & $\begin{array}{l}\oplus \oplus \ominus \ominus \\
\text { lowb }\end{array}$ & $\begin{array}{l}\text { CCT may improve global cogni- } \\
\text { tive function slightly compared } \\
\text { with active control }\end{array}$ \\
\hline $\begin{array}{l}\text { Cognitive subdomain: episodic memory } \\
\text { measured at the end of the intervention pe- } \\
\text { riod ( } 12 \text { to } 17 \text { weeks) }\end{array}$ & $\begin{array}{l}\text { SMD } 0.06 \text { higher } \\
\text { ( } 0.14 \text { lower to } 0.26 \\
\text { higher) }\end{array}$ & $\begin{array}{l}439 \text { partici- } \\
\text { pants } \\
\text { ( } 4 \text { studies) }\end{array}$ & $\begin{array}{l}\oplus \oplus \ominus \ominus \\
\text { lowb }\end{array}$ & $\begin{array}{l}\text { CCT may result in little to no } \\
\text { difference in episodic memory } \\
\text { compared with active control }\end{array}$ \\
\hline $\begin{array}{l}\text { Cognitive subdomain: speed of processing } \\
\text { measured at the end of the intervention pe- } \\
\text { riod ( } 12 \text { to } 16 \text { weeks) }\end{array}$ & $\begin{array}{l}\text { SMD } 0.63 \text { lower } \\
\text { (1.14 lower to } 0.12 \\
\text { lower) }\end{array}$ & $\begin{array}{l}138 \text { partici- } \\
\text { pants } \\
\text { ( } 2 \text { studies) }\end{array}$ & $\begin{array}{l}\oplus \ominus \ominus \ominus \\
\text { very lowc }\end{array}$ & $\begin{array}{l}\text { It is uncertain whether CCT } \\
\text { maintains speed of processing } \\
\text { better than active control }\end{array}$ \\
\hline $\begin{array}{l}\text { Cognitive subdomain: executive functioning } \\
\text { measured at the end of the intervention pe- } \\
\text { riod ( } 12 \text { to } 17 \text { weeks) }\end{array}$ & $\begin{array}{l}\text { SMD } 0.04 \text { lower } \\
(0.61 \text { lower to } 0.53 \\
\text { higher }\end{array}$ & $\begin{array}{l}230 \text { partici- } \\
\text { pants } \\
\text { ( } 3 \text { studies) }\end{array}$ & $\begin{array}{l}\oplus \ominus \ominus \ominus \\
\text { very lowc }\end{array}$ & $\begin{array}{l}\text { It is uncertain whether } \mathrm{CCT} \\
\text { maintains executive functioning } \\
\text { better than active control }\end{array}$ \\
\hline $\begin{array}{l}\text { Cognitive subdomain: working memory } \\
\text { measured at the end of the intervention pe- } \\
\text { riod ( } 12 \text { to } 16 \text { weeks) }\end{array}$ & $\begin{array}{l}\text { SMD } 0.17 \text { lower } \\
\text { (0.36 lower to } 0.02 \\
\text { higher }\end{array}$ & $\begin{array}{l}392 \text { partici- } \\
\text { pants } \\
\text { ( } 3 \text { studies) }\end{array}$ & $\begin{array}{l}\oplus \oplus \ominus \ominus \\
\text { lowb }\end{array}$ & $\begin{array}{l}\text { CCT may result in little to no } \\
\text { difference in working memory } \\
\text { compared with active control }\end{array}$ \\
\hline $\begin{array}{l}\text { Quality of life at the end of the intervention } \\
\text { period }\end{array}$ & \multicolumn{3}{|c|}{ Not reported using a validated measure } & \\
\hline $\begin{array}{l}\text { Number of participants experiencing } 1 \text { or } \\
\text { more serious adverse events at the end of } \\
\text { the intervention period }\end{array}$ & \multicolumn{3}{|c|}{ Not reported using a validated measure } & \\
\hline
\end{tabular}

* The risk in the intervention group (and its $95 \%$ confidence interval) is based on the assumed risk in the comparison group and the relative effect of the intervention (and its $95 \% \mathrm{Cl}$ ).

СCT: computerised cognitive training; $\mathrm{Cl}$ : confidence interval; SMD: standardised mean difference.

GRADE Working Group grades of evidence.

High quality: further research is very unlikely to change our confidence in the estimate of effect.

Moderate quality: further research is likely to have an important impact on our confidence in the estimate of effect and may change the estimate.

Low quality: further research is very likely to have an important impact on our confidence in the estimate of effect and is likely to change the estimate.

Very low quality: we are very uncertain about the estimate.

${ }^{a}$ The direction of the difference in effect was standardised so that lower values favour CCT and higher values favour control.

Computerised cognitive training for 12 or more weeks for maintaining cognitive function in cognitively healthy people in late life 
bDowngraded two levels for imprecision (confidence interval included effects that are not clinically relevant) and risk of bias.

cDowngraded three levels for imprecision (confidence interval included effects that are not clinically relevant), inconsistency (high heterogeneity), and risk of bias.

\section{Summary of findings 2.}

\section{Computerised cognitive training compared with inactive control in cognitively healthy people in late life}

Patient or population: cognitively healthy people in late life

Settings: general population

Intervention: computerised cognitive training

Comparison: inactive control intervention

\begin{tabular}{|c|c|c|c|c|}
\hline Outcomes & $\begin{array}{l}\text { Difference be- } \\
\text { tween CCT and } \\
\text { control ( } 95 \% \\
\mathrm{CI})^{\mathrm{a}^{*}}\end{array}$ & $\begin{array}{l}\text { No. of par- } \\
\text { ticipants } \\
\text { (studies) }\end{array}$ & $\begin{array}{l}\text { Quality of } \\
\text { the evi- } \\
\text { dence } \\
\text { (GRADE) }\end{array}$ & Comments \\
\hline $\begin{array}{l}\text { Global cognitive function measured at the end } \\
\text { of the intervention period }\end{array}$ & \multicolumn{3}{|c|}{ Not reported using a validated measure } & \\
\hline $\begin{array}{l}\text { Cognitive subdomain: episodic memory mea- } \\
\text { sured at the end of the intervention period ( } 6 \\
\text { months) }\end{array}$ & $\begin{array}{l}\text { MD } 0.90 \text { lower } \\
\text { (1.73 lower to } 0.07 \\
\text { lower) }\end{array}$ & $\begin{array}{l}150 \text { partici- } \\
\text { pants } \\
\text { (1 study) }\end{array}$ & $\begin{array}{l}\oplus \oplus \odot \odot \\
\text { lowb }\end{array}$ & $\begin{array}{l}\text { CCT may improve slightly } \\
\text { episodic memory when com- } \\
\text { pared to inactive control }\end{array}$ \\
\hline $\begin{array}{l}\text { Cognitive subdomain: speed of processing mea- } \\
\text { sured at the end of the intervention period ( } 12 \text { to } \\
16 \text { weeks) }\end{array}$ & $\begin{array}{l}\text { SMD } 0.28 \text { lower } \\
\text { (0.82 lower to } 0.26 \\
\text { higher) }\end{array}$ & $\begin{array}{l}204 \text { partici- } \\
\text { pants } \\
\text { ( } 2 \text { studies) }\end{array}$ & $\begin{array}{l}\oplus \odot \odot \ominus \\
\text { very lowc }\end{array}$ & $\begin{array}{l}\text { It is uncertain whether CCT } \\
\text { maintains speed of processing } \\
\text { better than inactive control }\end{array}$ \\
\hline $\begin{array}{l}\text { Cognitive subdomain: executive functioning } \\
\text { measured at the end of the intervention period } \\
\text { (12 weeks to } 6 \text { months) }\end{array}$ & $\begin{array}{l}\text { SMD } 0.08 \text { lower } \\
\text { ( } 0.31 \text { lower to } 0.15 \\
\text { higher) }\end{array}$ & $\begin{array}{l}292 \text { partici- } \\
\text { pants } \\
\text { ( } 2 \text { studies) }\end{array}$ & $\begin{array}{l}\oplus \oplus \odot \ominus \\
\text { lowb }\end{array}$ & $\begin{array}{l}\text { CCT may lead to little or no im- } \\
\text { provement in executive func- } \\
\text { tioning when compared to in- } \\
\text { active control }\end{array}$ \\
\hline $\begin{array}{l}\text { Cognitive subdomain: working memory mea- } \\
\text { sured at the end of the intervention period ( } 16 \\
\text { weeks) }\end{array}$ & $\begin{array}{l}\text { MD } 0.08 \text { lower } \\
\text { (0.43 lower to } 0.27 \\
\text { higher) }\end{array}$ & $\begin{array}{l}60 \text { partici- } \\
\text { pants } \\
\text { ( } 1 \text { study) }\end{array}$ & $\begin{array}{l}\oplus \oplus \odot \ominus \\
\text { lowb }\end{array}$ & $\begin{array}{l}\text { CCT may lead to little or no im- } \\
\text { provement in working memo- } \\
\text { ry when compared to inactive } \\
\text { control }\end{array}$ \\
\hline $\begin{array}{l}\text { Cognitive subdomain: verbal fluency measured } \\
\text { at the end of the intervention period ( } 6 \text { months) }\end{array}$ & $\begin{array}{l}\text { MD } 0.11 \text { lower } \\
\text { (1.58 lower to } 1.36 \\
\text { higher) }\end{array}$ & $\begin{array}{l}150 \text { partici- } \\
\text { pants } \\
\text { (1 study) }\end{array}$ & $\begin{array}{l}\oplus \oplus \ominus \ominus \\
\text { lowb }\end{array}$ & $\begin{array}{l}\text { CCT may lead to little or no im- } \\
\text { provement in verbal fluency } \\
\text { when compared to inactive } \\
\text { control }\end{array}$ \\
\hline $\begin{array}{l}\text { Quality of life at the end of the intervention peri- } \\
\text { od }\end{array}$ & \multicolumn{3}{|c|}{ Not reported using a validated measure } & \\
\hline $\begin{array}{l}\text { Number of participants experiencing } 1 \text { or more } \\
\text { serious adverse events at the end of the inter- } \\
\text { vention period }\end{array}$ & \multicolumn{3}{|c|}{ Not reported using a validated measure } & \\
\hline
\end{tabular}

* The risk in the intervention group (and its $95 \%$ confidence interval) is based on the assumed risk in the comparison group and the relative effect of the intervention (and its $95 \% \mathrm{Cl}$ ).

CCT: computerised cognitive training; $\mathrm{Cl}$ : confidence interval; MD: mean difference; SMD: standardised mean difference.

GRADE Working Group grades of evidence. 
High quality: further research is very unlikely to change our confidence in the estimate of effect.

Moderate quality: further research is likely to have an important impact on our confidence in the estimate of effect and may change the estimate.

Low quality: further research is very likely to have an important impact on our confidence in the estimate of effect and is likely to change the estimate.

Very low quality: we are very uncertain about the estimate.

aThe direction of the difference in effect was standardised so that lower values favour CCT and higher values favour control. bDowngraded two levels for imprecision (confidence interval included effects that are not clinically relevant) and risk of bias. cDowngraded three levels for imprecision (confidence interval included effects that are not clinically relevant), inconsistency (high heterogeneity), and risk of bias. 


\section{B A C K G R O U N D}

\section{Description of the condition}

\section{Cognitive health, dementia, and reserve}

'Cognitive health' broadly refers to the absence of cognitive impairment and the preservation of cognitive structure. Maintaining cognitive health in later life is essential to allow older adults to achieve active ageing (Depp 2012; Hendrie 2006). 'Active ageing' refers to the process of optimising opportunities for health, participation, and security in later life (WHO 2016). Older adults themselves are increasingly interested in managing their own health and have expectations of positive ageing and a high quality of life (Brown 2004). Retirement age in many countries is being extended past age 65 , and many older adults want to extend their working lives, requiring them to maintain cognitive health as long as possible. Cognitive decline and dementia are significant threats to independence and active ageing, and are significant concerns of older adults (Deary 2009; Lustig 2009).

Dementia is now one of the biggest global health challenges and may affect up to 135 million adults worldwide by 2050 (Prince 2013). The global cost of caring for people with dementia is currently estimated at USD315 billion (Wimo 2010). The World Health Organization 2017 Dementia Action Plan identifies reducing dementia risk as a major health objective (who.int/mental_health/ neurology/dementia/action_plan_2017_2025/en/). In most cases, the onset of clinical dementia is gradual, with the underlying disease process probably starting years, or even decades, before symptoms present. Pharmacological treatments at present are very limited, and none are curative (Aisen 2011). The long prodromal and preclinical periods before dementia onset offer an opportunity to intervene to maintain cognitive function, thereby preventing or postponing the onset of clinical dementia (Leifer 2003). Postponing the onset of clinical dementia by just five years could potentially reduce disease prevalence by $50 \%$ (Brookmeyer 1998). Differences in individual susceptibility to the development of clinical dementia may in part be due to exposure to a number of positive and negative factors. Multiple potentially modifiable factors have been identified, including physical exercise, diet, and mentally stimulating activities (World Alzheimer Report 2014). Accordingly, new non-pharmacological lifestyle interventions are being investigated for their potential to prevent or delay dementia onset (Acevedo 2007; Dresler 2013).

Research evidence indicates that maintenance of cognitive health requires the development of optimal levels of brain and cognitive reserve across the lifespan (Stern 2012). 'Brain reserve' refers to structural tolerance of the brain to disease processes. 'Cognitive reserve' refers to functional differences in cognitive processes that may affect the way cognitive tasks are performed, which may in turn enhance resilience against threats to cognitive health. Thus, reserve provides a theoretical explanation for the differences between individuals with the same degree of disease in the brain who succumb to clinical dementia and are functionally impaired, and those who tolerate the pathology and maintain function (Stern 2012). Consistent with this notion of reserve is evidence from epidemiological and prospective studies that a lower incidence of Alzheimer's disease is found in people who have engaged in mentally stimulating activities (Marioni 2014; Marquine 2012; Stern 2012; Verghese 2003; Wilson 2002). Therefore, one intervention that has been proposed to increase cognitive health and improve cognitive function in older adults is the introduction of novel mental activity (Park 2007).

\section{Age-related cognitive decline}

In cognitively healthy adults, some non-pathological changes in cognitive function naturally occur with increasing age (Salthouse 2003). Cognitive changes associated with normal ageing may contribute to deterioration in quality of life and may compromise functional capacity. Large variations in cognitive health and function are observed at a population level, and trajectories of decline are highly variable (Salthouse 2011). Cross-sectional and longitudinal comparisons indicate that whilst acquired knowledge generally increases until about age 60 , there is a decrease in information processing efficiency from early adulthood, and beyond age 60 , increasing age is associated with general negative cognitive change (Salthouse 2011). When cognitive difficulties are beyond those associated with normal ageing but performance of daily activities is not significantly affected, the term 'mild cognitive impairment' ( $\mathrm{MCl})$, or its synonym 'mild neurocognitive disorder', is applied. $\mathrm{MCl}$ is associated with an increased risk of progression to dementia (Petersen 2018).

\section{Risk and protective factors}

Although increasing age is the greatest risk factor for dementia, additional risk and protective factors have been linked with dementia in general, and with Alzheimer's disease in particular (World Alzheimer Report 2014). It has recently been suggested that after accounting for non-independence between risk factors, around a third of cases of dementia due to Alzheimer's disease worldwide might be attributable to potentially modifiable risk factors (Norton 2014). Accordingly, there is growing interest in addressing lifestyle factors to combat age-related cognitive decline, enhance cognitive function, and prevent the onset of clinical dementia (Barnes 2011; Dresler 2013). Addressing preventable risks, as by promoting cognitively stimulating activities, is a global health priority according to the World Health Organization 2017 Health Report Dementia Action Plan.

The links between stimulating leisure pursuits and cognitive health are strong. Epidemiological evidence indicates that the risk of developing dementia due to Alzheimer's disease is significantly reduced in individuals with higher educational or occupational attainment (Marioni 2012; Marquine 2012; Stern 2012). Cognitive lifestyle variables such as education, midlife occupation, and late life social engagement may also be associated with cognitive trajectories and morbidity (Marioni 2012; Marioni 2014). A broad spectrum of activities, including those with mental, physical, and social components, contribute to reducing risk for dementia (Karp 2006). Prospective studies also indicate that mental activity, even when commenced late in life, has positive benefits, with lowered rates of decline and lowered dementia incidence reported (Beydoun 2014; Geda 2012; Verghese 2003; Wilson 2002; Wilson 2012). In contrast, lack of cognitive stimulation, particularly across an individual's life course, is a significant risk factor (Norton 2014; World Alzheimer Report 2014). Therefore, introducing cognitively stimulating interventions - even in late life - has the potential to reverse the effects of reduced participation, promote cognitive health and active ageing, and improve quality of life (Amoyal 2012). 


\section{Description of the intervention}

Cognitive interventions are diverse treatments based upon the distinct theoretical constructs of maintenance and improvement for the purposes of preventing decline, restoring reduced function, and compensating for impairment (Gates 2014). The clinical research literature refers to three forms of cognitive intervention based upon these theoretical models: cognitive training, cognitive stimulation, and cognitive rehabilitation (Baher-Fuchs 2013; Clare 2004; Gates 2014; Woods 2012).

Cognitive training is increasingly being applied in research and clinical settings for prevention of cognitive decline, and commercial training packages are widely available. 'Cognitive training' is defined as an intervention consisting of repeated practice on standardised exercises, targeting a specific cognitive domain or domains, for the purpose of benefiting cognitive function (Gates 2010). In cognitively healthy older adults, it is intended to maintain cognitive function, reduce age-related decline, and prevent or delay the development of clinical dementia. Recent investigations suggest that cognitive training may improve cognitive function (Petersen 2018). Computer-based cognitive training tasks, including computer exercises and computer games (which may involve mobile devices, gaming consoles, and virtual reality), offer a highly accessible low-cost, standardised means of training in specified cognitive domain(s) for the purpose of enhancing cognitive function. Computerised cognitive training can be provided in different ways, including individual exercises or games, group games, online games, and on-site games.

Several meta-analyses and randomised clinical trials of cognitive training in cognitively healthy adults and those at risk of dementia have reported significant benefits across multiple cognitive domains, global cognition, and composite measures of cognitive function (Alves 2013; Kelly 2014; Kueider 2012; Lampit 2014a; Shao 2015). Other meta-analyses of cognitive interventions in longitudinal trials have indicated that such interventions may reduce the risk of developing dementia and may reduce the rate of cognitive decline (Valenzuela 2006a; Valenzuela 2006b; Valenzuela 2009). Researchers investigating cognitive training in adults with subtle cognitive changes and $\mathrm{MCl}$ have concluded that it could improve global cognitive function and increase performance on domain-specific outcome measures, with some studies also reporting reduced rates of incident dementia (Cheng 2012; Gates 2011a; Herrera 2012; Hoyer 2006; Unverzagt 2012; Zehnder 2009). Additionally, some clinical trial results indicate that computerised and online cognitive training in adults without dementia may improve daily functioning and psychological wellbeing (Gordon 2013; Kueider 2012; Rebok 2014; Zelinski 2009), and some systematic reviews indicate that computerised cognitive training (CCT) might be beneficial for cognitive outcomes (Lampit 2014a), and even for non-cognitive outcomes such as well-being and functional outcomes (Edwards 2018).

In this review, we focus on primary prevention, that is, maintenance of cognitive function in cognitively healthy adults in late life (> 65 years of age) by means of CCT. Companion reviews have investigated the effects of CCT on cognitively healthy adults in midlife (40 to 65 years) and among people with MCl (Gates 2019a; Gates 2019b). We reviewed randomised controlled trials (RCTs) investigating the effects of CCT interventions over at least 12 weeks on cognitive performance, quality of life, and daily functioning. For any intervention designed to maintain or improve health, the effect will be dependent on the exposure. For example, the effect of a drug, an exercise programme, or a dietary intervention would be influenced, respectively, by drug dose, time spent exercising, or proportion of meals meeting prescribed nutritional standards. For CCT, no consensus has been reached about the minimum or optimum exposure required to achieve cognitive effects. When the protocol for this review was designed, a minimum exposure was selected based on the judgement that it was implausible that short training courses would have long-term cognitive benefits. After discussion, an inclusion criterion of 12 weeks of exposure was chosen. This was an arbitrary threshold, as any threshold of duration or dose would be in this field, which was considered to represent an acceptable trade-off between biologically plausible effects and feasibility within a trial setting. This review forms part of a suite of reviews on modifiable risk factors for dementia and cognitive decline. Harmonisation of inclusion criteria with the other reviews in the suite was also a consideration.

\section{How the intervention might work}

Computerised programmes have been delivered in individual sessions and within groups, with supervision or privately at home, and there is wide variation in the 'dose' or length of each training session, the frequency of sessions, and the duration of training programmes, leading to significant heterogeneity in the literature (Gates 2014). However, the unifying theoretical premise behind cognitive training is that it will stimulate neuroplasticity, increase brain and cognitive reserve, and thereby maintain or improve cognitive function. It has also been suggested that cognitive stimulation may result in neural compensation, which is the development of compensatory networks maintaining cognitive performance, potentially masking or preventing clinical manifestation of neurocognitive disease (Grady 2012). Recently, to incorporate both factors associated with age-related cognitive decline and those thought to enhance function and reserve, a scaffold theory of compensatory activation has been proposed (Park 2013). The interventions that fall within the scope of this review are not expected to modify dementia pathology, but it is hypothesised that the increase in mentally stimulating activity that these interventions induce will have an impact on the development of clinical dementia (Bennett 2014).

Although the evidence base is very limited, human trials of cognitive training suggest positive neuroplastic changes, including reduced $\beta$-amyloid burden (Landau 2012), as a result of the intervention. A number of diverse studies investigating neurophysiological changes using functional magnetic resonance imaging have identified increased prefrontal and parietal activity and hippocampal activation (Olesen 2004; Rosen 2011; Suo 2012a; Valenzuela 2003). Electroencephalography and magnetic resonance spectrometry studies of cognitive training support the concept of functional neuroplasticity post training, with results indicating positive changes in brain metabolism, taskdependent brain activation, and resting-state networks (Belleville 2012; Berry 2010; Förster 2011). However, the research is limited, and significant further investigation is required.

\section{Why it is important to do this review}

The prevalence and financial implications of dementia are such that small effects on cognitive decline, or on the incidence of dementia, may have a large impact on healthcare costs and the overall burden of dementia to society and to individuals 
with the disease. The potential for computerised cognitive-based interventions to be effective in improving cognitive health and function, along with their low implementation and administration costs and their high availability and accessibility, has led to the American Alzheimer's Association's recommending development and testing of cognitive training as a research priority (Alzheimer's Association 2014).

To date, cognitive training research has been controversial, with insufficient data on which to base clear clinical guidelines for intervention. Results from meta-analyses have been inconsistent; negative findings have been reported, and opposing views have been published (Lampit 2014a; Papp 2009). Clinical trials have been criticised for poor specification of interventions, poor methodological rigour, small sample sizes, failure to assign treatments randomly, lack of active control, limited outcome measures to determine transfer of benefit to non-trained functions, and lack of longitudinal design to determine persistence of benefit (Gates 2010; Green 2014; Kueider 2012; Papp 2009; Park 2013; Reijnders 2013; Walton 2014). Additionally, results reported in some previous reviews have been hard to interpret, as cognitively healthy and clinical populations have been combined, and diverse types of cognitive intervention have been analysed together (e.g. Martin 2011). Recent meta-analyses in cognitively healthy older adults with defined intervention eligibility criteria have shown positive effects on cognition (Kueider 2012; Lampit 2014a; Shao 2015). It is important to note that primary studies have identified that the benefits of CCT may depend upon a number of factors. Comparisons between single- and multipledomain training suggest that multiple-domain training was better, consistent with increased global reserve (Cheng 2012), and nascent evidence suggests that different cognitive domains may respond differently to training, and hence may require different interventions for different durations (Lampit 2014).

For individuals, fear of cognitive decline and dementia may be a powerful motivator to seek preventive interventions. The World Alzheimer Report 2014 has reported that cognitively stimulating activities, including reading, playing musical instruments, and playing cards and board games, may be beneficial for improving, maintaining, and preventing decline in cognitive functioning, although most of these activities have not been investigated in clinical trials. Technology and computerised 'brain training' games and cognitive training programmes are being investigated more actively (Alzheimer's Association 2014; Peretz 2011; Sixsmith 2013). However, the proliferation of computer-based commercial products purporting to improve cognitive function and reduce dementia risk has frequently outpaced thorough research into product benefits (Gates 2014; Lampit 2015). The value of the brain training industry has reportedly risen from \$295 million in 2009 to $\$ 2$ billion to $\$ 8$ billion in 2015 (www.sharpbrains.com). In this context, it is important to assist clinicians and consumers to make informed choices that are based on evidence, take account of alternative cognitively stimulating activities, and protect against strong advertising claims.

A review is therefore warranted to investigate the efficacy of computerised cognitive interventions and to evaluate potential sources of bias and heterogeneity in the literature. If sufficient trials are identified, then it is important to examine intervention characteristics and other factors that may affect outcomes, along with examining transfer and persistence of benefit. Information about adverse effects is also important, although behavioural interventions such as CCT are often perceived to be at 'low risk' for adverse effects (Gates 2014). The findings of this review should be useful for older adults, public health decision-making bodies, health practitioners, and researchers, providing them with a comprehensive synthesis of information about the current state of the evidence and identifying research gaps and unanswered questions in the field.

\section{O B J E C T IVES}

To evaluate the effects of computerised cognitive training interventions lasting at least 12 weeks on cognitive function in cognitively healthy people in late life.

\section{MET HOD S}

\section{Criteria for considering studies for this review \\ Types of studies}

We included randomised controlled trials (RCTs) and quasiRCTs, published or unpublished, reported in any language. Full reports and other types of reports, such as conference abstracts, were eligible for inclusion. We included studies involving both randomised and non-randomised trial arms, but we considered only results from the former. We included cross-over studies, but we extracted and analysed data from the first treatment period only.

\section{Types of participants}

We included studies of cognitively healthy people in late life. 'Late life' was defined as over 65 years of age, in line with the World Health Organization (WHO) definition (who.int/healthinfo/survey/ ageingdefnolder/en/). At least $80 \%$ of the study population had to be in this age range. We covered healthy participants in midlife (40 to 65 years) in a separate review (Gates 2016a). If the age range of participants in a trial did not coincide with our categories, then we used the median and range, or the mean and standard deviation (SD), to place studies into the most appropriate review.

For a study to be included, its authors should have attempted to exclude those who were not cognitively healthy or who had dementia. We accepted and recorded the trial authors' own definitions of 'cognitively healthy'. It was acceptable, for this purpose, for authors to have used a cut-off score on a cognitive test as an exclusion criterion. We accepted any cut-offs used in the studies, and we examined this as a possible source of heterogeneity.

We excluded all studies in which more than $20 \%$ of participants were reported to have subjective memory complaints, or to have received a diagnosis of any cognitive, neurological, psychiatric, or medical condition.

We contacted study authors if we needed further clarification to determine health status. If we received no response, clinical experts in our review group classified the trials, or listed them as 'Studies awaiting classification'.

\section{Types of interventions}

We included studies of cognitive training interventions using interactive computerised technology of 12 or more weeks duration 
compared with active or inactive control interventions. The rationale for this threshold is described in the Introduction section.

Experimental interventions had to adhere to the following criteria: any form of interactive computerised cognitive intervention, including computer exercises, computer games, mobile devices, gaming console, and virtual reality, that involves repeated practice on standardised exercises of specified cognitive domains for the purpose of enhancing cognitive function.

By 'active control', we mean all those control conditions that involve unguided computer- and/or screen-based tasks that are not a planned intervention. These tasks can involve watching educational videos or playing computer games, with no particular training component. By 'inactive control', we refer to control groups in which no intervention is applied that may be expected to have an effect on cognition.

There was no minimum duration of follow-up. However, all included trials had to report outcomes at a minimum of one time point - 12 or more weeks after randomisation. Trials in cognitively healthy people with a duration as short as 12 weeks typically investigate cognitive enhancement rather than maintenance of cognitive function. We included these trials to give a full picture of the data, although it is recognised that the relationship between short-term cognitive enhancement and maintenance of cognitive function over longer periods of time is unclear.

We excluded interventions that did not involve any form of computer delivery. We excluded studies in which the experimental intervention was combined with any other form of intervention, unless the added intervention was provided in a standardised manner to both experimental and control groups.

\section{Types of outcome measures}

\section{Primary outcomes}

- Global cognitive functioning: measured using validated tests, for example (but not limited to):

* Mini Mental State Examination (MMSE);

* Alzheimer's Disease Assessment Scale (ADAS-Cog);

* Repeatable Battery for the Assessment Neuropsychological Status (RBANS); and

* Cambridge Cognition Examination (CAMCOG).

The main time point of interest was 'end of trial', defined as the time point with the longest follow-up duration, as measured from randomisation (see also section Data collection and analysis). We also extracted and presented outcome data reported at other time points after randomisation, when available.

\section{Secondary outcomes}

Secondary outcomes are cognitive tests not included in the training programme, administered before and after training, that provide any validated measure of:

- specific cognitive functioning subdomain: episodic memory;

- specific cognitive functioning subdomain: speed of processing;

- specific cognitive functioning subdomain: executive function;

- specific cognitive functioning subdomain: attention/working memory;

- specific cognitive functioning subdomain: verbal fluency;
- quality of life/psychological well-being, either generic or healthspecific;

- daily function, such as measures of instrumental activities of daily living; and

- number of participants experiencing one or more serious adverse event(s).

If a trial provided data on more than one cognitive scale for a specific outcome, we applied a hierarchy of cognition-related outcomes (manuscript in preparation) and used data on the cognitive scale that was highest in this hierarchy. For example, if a trial reported results on both the Mini Mental State Examination and the Clinical Dementia Rating scale (CDR), we used outcome data from the MMSE in our quantitative analyses. The order of a scale in the hierarchy was determined by the frequency of its use in a large set of 79 trials evaluating vitamin and mineral supplementation, dietary interventions, and physical exercise interventions.

\section{Outcomes to be included in the 'Summary of findings' table}

We planned to address critical effectiveness outcomes in the 'Summary of findings' table for each review. We included all outcomes related to cognitive function on non-trained tasks and quality of life. We were able to include for the first comparison the following outcomes: (1) global cognitive functioning, (2) episodic memory, (3) speed of processing, (4) executive functioning, (5) working memory, (6) quality of life, and (7) adverse events. For the second comparison, we included the following outcomes: (1) episodic memory, (2) speed of processing, (3) executive functioning, (4) working memory, and (5) verbal fluency.

\section{Search methods for identification of studies}

\section{Electronic searches}

We searched ALOIS (www.medicine.ox.ac.uk/alois) - the specialised register of the Cochrane Dementia and Cognitive Improvement Group (CDCIG) - up to 31 March 2018.

ALOIS was maintained by the Information Specialist for the CDCIG and contains studies that fall within the areas of dementia prevention, dementia treatment and management, and cognitive enhancement in healthy elderly populations. These studies are identified through:

- monthly searches of several major healthcare databases: MEDLINE, Embase, Cumulative Index to Nursing and Allied Health Literature (CINAHL), PsycINFO, and Latin American Caribbean Health Sciences Literature (LILACS);

- monthly searches of several trial registers: University hospital Medical Information Network (UMIN) Clinical Trials Registry (Japan) (UMIN-CTR) (www.umin.ac.jp/ctr/ index.htm); World Health Organization (WHO) portal (which covers ClinicalTrials.gov (clinicaltrials.gov/); International Standard Randomized Controlled Trials Number (ISRCTN) (www.isrctn.com/); Chinese Clinical Trials Register (ChiCTR) (who.int/ictrp/network/chictr/en/); German Clinical Trials Register (GermanCTR) (who.int/ictrp/network/drks2/en/); Iranian Registry of Clinical Trials (IRCT) (who.int/ictrp/network/ irct2/en/); and The Netherlands National Trials Register (NTR) (who.int/ictrp/network/ntr/en/), plus others);

- quarterly searches of the Central Register of Controlled Trials of the Cochrane Library (CENTRAL); and

Computerised cognitive training for 12 or more weeks for maintaining cognitive function in cognitively healthy people in late life 
- six-monthly searches of several grey literature sources: Institute for Scientific Information (ISI) Web of Knowledge Conference Proceedings; Index to Theses; and Australasian Digital Theses.

To view a list of all sources searched for ALOIS, see About ALOIS on the ALOIS website (www.medicine.ox.ac.uk/alois).

Details of the search strategies run in healthcare bibliographic databases, used for retrieval of reports of dementia, cognitive improvement, and cognitive enhancement trials, can be viewed in the 'Methods used in reviews' section within the editorial information about the Cochrane Dementia and Cognitive Improvement Group.

We conducted additional searches in MEDLINE, Embase, PsycINFO, CINAHL, CENTRAL, ClinicalTrials.gov, and the WHO Portal/ICTRP (www.apps.who.int/trialsearch), to ensure that the searches were as comprehensive and as up-to-date as possible, in identifying published, unpublished, and ongoing trials. The search strategies used are shown in Appendix 1.

\section{Searching other resources}

We screened the reference lists of all included trials. In addition, we screened the reference lists of recent systematic reviews, health technology assessment reports, and subject-specific guidelines identified through www.guideline.gov. We restricted the search to those guidelines meeting National Guideline Clearinghouse (NGC) 2013 published inclusion criteria.

We contacted experts in the field and companies marketing included interventions to request additional randomised trial reports not identified by the search.

\section{Data collection and analysis}

We used this protocol alongside instructions for data extraction, quality assessment, and statistical analyses generated by the editorial board of $\mathrm{CDCIG}$, and based in part on a generic protocol approved by the Cochrane Musculoskeletal Group for another series of reviews (da Costa 2012; da Costa 2014; Reichenbach 2010; Rutjes 2009a; Rutjes 2009b; Rutjes 2010).

\section{Selection of studies}

If multiple reports described the same trial, we included all of them to allow extraction of complete trial details.

We used crowdsourcing to screen the search results. Details of this are available at www.medicine.ox.ac.uk/alois/content/ modifiable-risk-factors. In brief, teams of volunteers would perform a 'first assess' on the search results. The crowd was recruited through the network called Students For Best Evidence (www.students4bestevidence.net). The crowd provided an initial screen of search results using an online tool developed for the Cochrane Embase project but tailored for this programme of work. The crowd decided (based on reading of title and abstract) whether the citation is describing a randomised or quasi-randomised trial, irrespective of the citation topic. It is estimated that this approach removes $75 \%$ to $90 \%$ of results retrieved. We then screened the remaining results (titles and abstracts). Four independent review authors (NG, EM, SK, RV) assessed the full text of studies for eligibility, with any disagreements resolved by a fifth independent review author.
We recorded the selection process in sufficient detail to complete a PRISMA flow diagram and a Characteristics of excluded studies table (Moher 2009). We did not impose any language restrictions.

\section{Data extraction and management}

Five review authors (NG, MN, SK, RV, GM), working independently, extracted trial information using a standardised and piloted extraction method, while referring also to a guidance document and resolving discrepancies by discussion or by involvement of a fifth review author. When possible, we extracted the following information related to characteristics of participants, interventions, and study design.

\section{Participant characteristics}

- Sex

- Age (range, median, mean)

- Education (level and years of education)

- Baseline cognitive function

- Cognitive diagnostic status

- Duration of cognitive symptoms

- Ethnicity

- Apo-E genotype

- Vascular risk factors (hypertension, diabetes, hyperlipidaemia)

- Body mass index (BMI)

- Depression and stress

- Physical activity

- Work status

\section{Intervention characteristics}

- Type and description of computerised cognition-based intervention

- Type and description of the control condition

- Delivery mode (individualised, group sessions, supervised)

- Length of training sessions (in minutes)

- Frequency of sessions (per week)

- Duration of treatment programme

- Any concomitant treatments for which benefits can be isolated from the intervention

\section{Methodological characteristics}

- Trial design (individual or cluster-randomisation, parallel-group, factorial, or cross-over design)

- Number of participants

- Allocation to trial (randomisation, blind allocation)

- Outcome measures used

- Duration of follow-up (as measured from randomisation)

- Duration of follow-up (as measured from end of treatment)

- Source of financial support

- Publication status

If outcome data were available at multiple time points within a given trial, we extracted data at 12 weeks, as well as short-term (up to one year), medium-term (one to two years), and longterm results (more than two years). Within these time periods, we extracted the latest data reported by the study (e.g. if the study reported data at six months, nine months, and one year, we 
extracted only the one-year data and analysed these for the oneyear (short-term) time point). For dichotomous outcomes (such as number of participants experiencing one or more serious adverse events), we extracted from each trial the number of participants with each outcome, at each time point. For continuous outcomes, we extracted the number of participants for whom the outcome was measured, and we determined the mean and the SD of the change from baseline for each outcome at each time point. If changes from baseline data were not available, we extracted the mean value at each time point. When necessary and possible, we approximated means and measures of dispersion from figures in the reports. For cross-over trials, we extracted data on the first treatment period only. Whenever possible, we extracted intention-to-treat data (i.e. analysing all participants according to the group randomisation); if this information was not available, we extracted and reported data from available case analyses. If none of these data were available, we considered data from per-protocol analyses. We contacted trial authors if we could not obtain the necessary data from the trial report.

\section{Assessment of risk of bias in included studies}

After completion of a standardised training session (provided by $\mathrm{AR}$ ), one member of the review author team and one experienced review author provided by the editorial team independently assessed the risk of bias in each of the included trials, using Cochrane's 'Risk of bias' tool (Higgins 2011), and resolved disagreements by consensus. We assessed the risk of bias potentially introduced by suboptimal design choices with respect to sequence generation, concealment of allocation, blinding of participants and caregivers, blinded outcome assessment, selective outcome reporting, and incomplete outcome data, including the type of statistical analysis used (true intention-totreat vs other). Based on the aforementioned criteria, we rated studies as having 'low risk', 'unclear risk', or 'high risk' of bias for each domain, including a description of the reasoning for our rating. The general definitions used are provided in the Cochrane Handbook for Systematic Reviews of Interventions (Higgins 2011). We derived review-specific definitions in part from a previously published systematic review (Rutjes 2012), and we explained them in detail in Appendix 2.

\section{Measures of treatment effect}

The measure of treatment effect for continuous outcomes was effect size (standardised mean difference), defined as the betweengroup difference in mean values divided by the pooled SD. In case a single trial contributed to a comparison, or if all studies used the same instrument, we used the mean difference to describe and analyse results. We expressed the treatment effect for dichotomous outcomes as a risk ratio (RR) with a $95 \%$ confidence interval $(\mathrm{CI})$.

\section{Unit of analysis issues}

We identified no cluster-randomised or cross-over trials for inclusion.

\section{Dealing with missing data}

Missing data in individual trials may put study estimates of effects at high risk of bias and may lower the overall quality of evidence according to the Grading of Recommendations Assessment, Development, and Evaluation (GRADE) Working Group (www.gradeworkinggroup.org). We dealt with missing data in our
'Risk of bias' assessments and evaluated attrition bias in stratified analyses of the primary outcomes (Appendix 2). We analysed available information and did not contact study authors with requests to provide missing information, nor did we impute missing data ourselves.

\section{Assessment of heterogeneity}

We planned to examine heterogeneity in stratified analyses by trial, participant, and intervention. We also planned to visually inspect forest plots for the presence of heterogeneity and to calculate the variance estimate tau ${ }^{2}$ as a measure of between-trial heterogeneity (DerSimonian 1986). We prespecified $a \operatorname{tau}^{2}$ of 0.04 to represent low heterogeneity, 0.09 to represent moderate heterogeneity, and 0.16 to represent high heterogeneity between trials (Spiegelhalter 2004). In addition, we used the $I^{2}$ statistic and the corresponding $\mathrm{Chi}^{2}$ test to assist readers more familiar with these statistics (Higgins 2011). $I^{2}$ describes the percentage of variation across trials attributable to heterogeneity rather than to chance, with values of $25 \%, 50 \%$, and $75 \%$ interpreted as low, moderate, and high (respectively) between-trial heterogeneity. We preferred tau ${ }^{2}$ over $1^{2}$ in interpretation of between-trial heterogeneity, as interpretation of $\mathrm{I}^{2}$ can be largely affected by the precision of trials included in the meta-analysis (Rücker 2008). All P values are two-sided.

\section{Assessment of reporting biases}

We did not identify a sufficient number of trials to formally explore reporting biases and other biases related to small-study effects (see Differences between protocol and review).

\section{Data synthesis}

We reported summary and descriptive statistics (means and SDs) for participant and intervention characteristics.

Additionally, we used standard inverse-variance random-effects meta-analysis to combine outcome data across trials at end of trial (DerSimonian 1986), and, if possible, at least one additional time point (see Primary outcomes and Data collection and analysis for definitions of time points). We conducted statistical analyses in Review Manager 5 (RevMan 2014), as well as in STATA, release 13 (Statacorp, College Station, Texas, USA).

\section{GRADE and 'Summary of findings' table}

We used GRADE to describe the quality of the overall body of evidence for each outcome in the 'Summary of findings' table (Guyatt 2008; Higgins 2011). We defined 'quality' as the degree of confidence that we can place in the estimates of treatment benefits and harms. Four ratings were possible: high, moderate, low, and very low. Rating evidence as 'high quality' implies that we are confident in our estimate of the effect, and further research is very unlikely to change this. A rating of 'very low' quality implies that we are very uncertain about the obtained summary estimate of effect. The GRADE approach rates evidence from RCTs that do not have serious limitations as 'high quality'. However, several factors can lead to downgrading of evidence to 'moderate', 'low', or 'very low'. The degree of downgrading is determined by the seriousness of these factors: study limitations (risk of bias); inconsistency; indirectness of evidence; imprecision; and publication bias (Guyatt 2008; Higgins 2011). 


\section{Subgroup analysis and investigation of heterogeneity}

Due to the limited number of trials identified, we were unable to conduct protocol-defined subgroup and sensitivity analyses (see Differences between protocol and review).

\section{RESULTS}

\section{Description of studies}

See Characteristics of included studies, Characteristics of excluded studies, Characteristics of studies awaiting classification, and Characteristics of ongoing studies.

\section{Results of the search}

We conducted searches in January 2015, July 2015, February 2016, July 2016, and March 2018. In total, we retrieved 7727 records from the five searches. After de-duplication, 5832 remained. A crowd (through crowdsourcing) and the CDCIG Information Specialist assessed these at title and abstract levels. In total, 1090 results remained after this assessment. The review team then assessed these and five additional records identified though other sources. Of these, we assessed 325 full-text articles for eligibility and found that eight studies (reported in nine articles) were eligible for inclusion (Desjardins-Crépeau 2016; Klusmann 2010; Lampit 2014; Legault 2011; Leung 2015; Peretz 2011; Shatil 2013; van het Reve 2014). This process is depicted in Figure 1. 
Figure 1. Study flow diagram.

Records identified through
other sources
$(\mathbf{n = 5})$
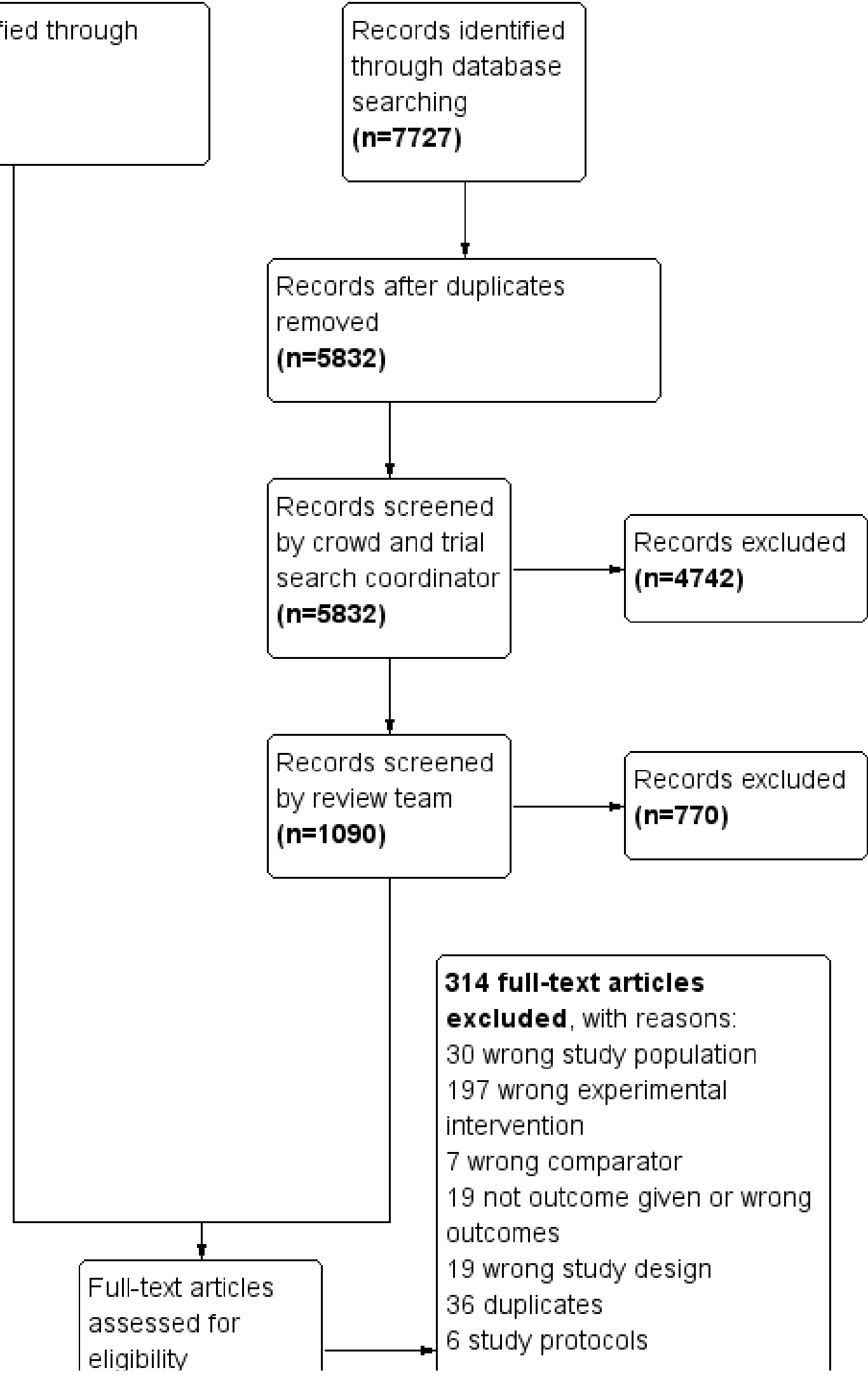

\section{4 full-text articles}

excluded, with reasons:

30 wrong study population

197 wrong experimental

intervention

7 wrong comparator

19 not outcome given or wrong outcomes

19 wrong study design

36 duplicates

6 study protocols 
Figure 1. (Continued)

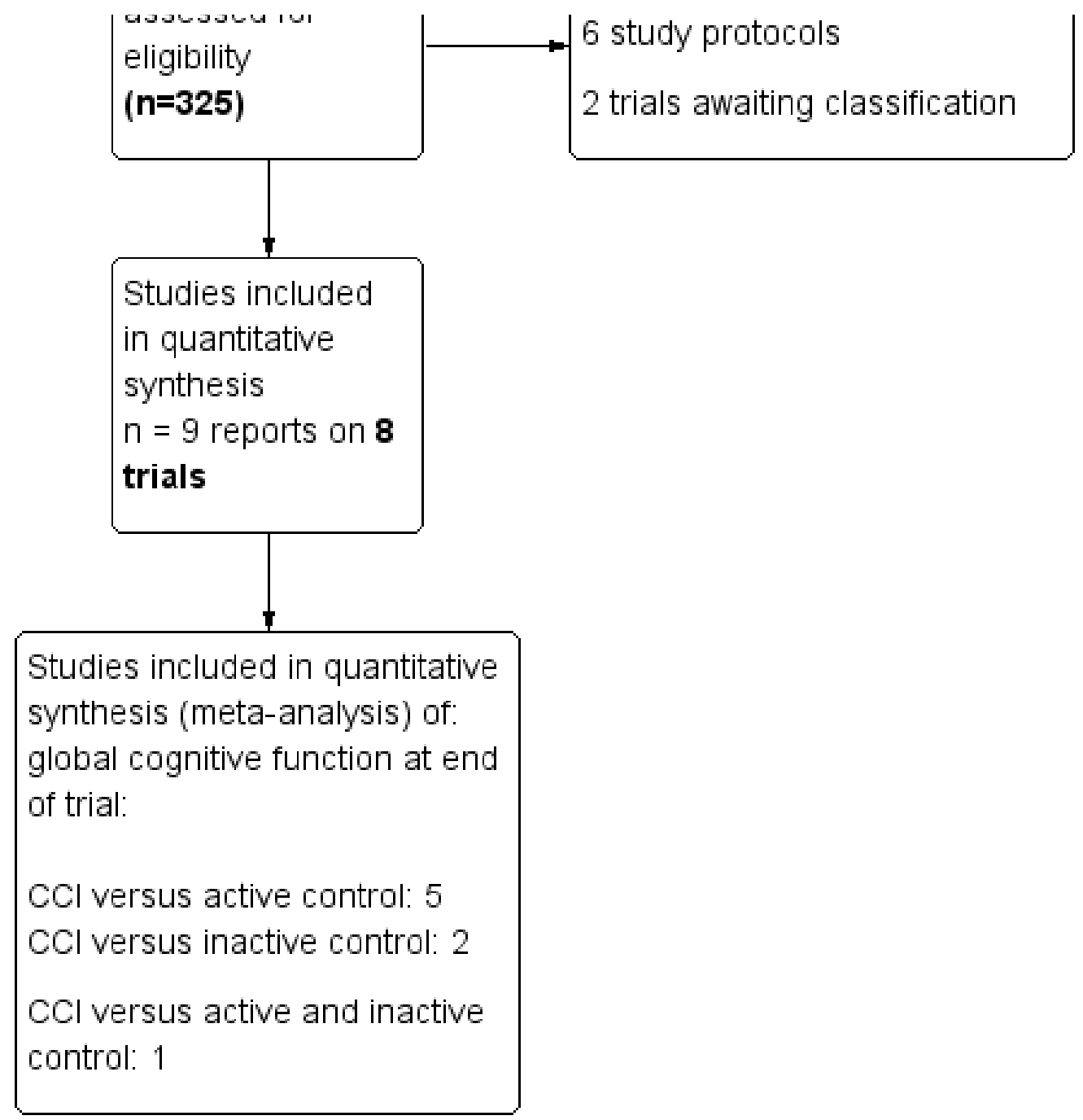

\section{Included studies}

We have provided details of the eight eligible studies in the Characteristics of included studies tables and have briefly summarised them below. Two additional studies meeting eligibility criteria are listed in the section Characteristics of studies awaiting classification.

\section{Design}

All studies used a randomised controlled design. Three used a factorial $2 \times 2$ design (Desjardins-Crépeau 2016; Legault 2011; Peretz 2011), and the remainder used separate interventions in a parallel-group design.

Durations of the included interventions were three months (12 or 13 weeks) (Desjardins-Crépeau 2016; Lampit 2014; Leung 2015; Peretz 2011; van het Reve 2014), four months (16 or 17 weeks) (Legault 2011; Shatil 2013), and six months (Klusmann 2010). All studies assessed outcomes at the end of the intervention period. Lampit 2014 also assessed outcomes 15 months after randomisation, which was 12 months after the end of the intervention.

\section{Sample size}

Desjardins-Crépeau 2016 included 136 participants in total and reported data on 42 participants in the experimental group and 34 in the control group. Klusmann 2010 included 92 participants in the experimental group and 76 in the control group. Lampit 2014 randomised 41 people to the experimental group and 39 to the control group. Legault 2011 randomised 18 participants to cognitive training, 19 to the combined intervention (cognitive training and exercise), and 18 to control. Leung 2015 included 109 participants in the experimental group and 100 in the control group. Peretz 2011 randomised 84 participants to the experimental group and 71 to the control group. Shatil 2013 randomised 42 to 48 participants in each of the four arms of the study (total 180 participants). Finally, van het Reve 2014 randomised 84 participants to the intervention group and 98 to the control group.

\section{Setting}

Desjardins-Crépeau 2016 did not provide information regarding the setting. Klusmann 2010 undertook this investigation in Germany but provided few details about the setting. Lampit 2014, Leung 2015, and Peretz 2011 were single-centre studies conducted in Australia, Hong Kong, and Israel, respectively. Legault 2011 and 
Shatil 2013 were single-centre studies conducted in the USA Fourteen centres from Switzerland and Germany participated in van het Reve 2014.

\section{Participants}

All participants were cognitively healthy with a minimum age of 65 years or older, other than those in Desjardins-Crépeau 2016, who were 60 years or older (the mean age in all groups in this study was $>70$ years; therefore we considered that inclusion in this review was warranted). Mean ages ranged from 67 to 82 years. Most studies except Legault 2011 reported a preponderance of women. None of the studies focused on high-risk groups for cognitive decline.

\section{Interventions}

\section{CCT versus active control}

Desjardins-Crépeau 2016 compared computerised dual task cognitive exercises versus an active control (lessons to introduce participants to computers and diverse software, e.g. Word, Excel) and to the internet (e.g. search engines, websites, online games). Researchers randomised participants in both groups to receive either aerobic and resistance exercises or stretching and toning exercises in a $2 \times 2$ factorial design. Lampit 2014 compared computerised COGPACK cognitive training exercises targeting five cognitive domains (memory, attention, response speed, executive functions, and language) versus an active control condition of watching educational videos and answering multiple choice questions. Similarly, Leung 2015 compared computerised cognitive training exercises versus an active control of watching educational videos (e.g. history, science) followed by questions. Peretz 2011 compared the CogniFit Personal Coach programme versus an active control of traditional computer games. Legault 2011 compared a computerised memory domain training programme in small groups monitored by skilled trainers versus an active control of weekly health lectures provided by an instructor and promotion of group interaction.

\section{CCT versus inactive control}

Klusmann 2010 compared a computer course that included multiple computer activities such as creative, co-ordinative, and memory tasks versus an inactive, no intervention control. van het Reve 2014 compared a strength-balance-cognitive programme - the CogniPlus computerised cognitive training programme - versus a strength-balance programme.

\section{CCT versus both active and inactive controls}

We included Shatil 2013 in our comparisons of computerised training versus both active and inactive controls. This study included four arms: (1) Cognifit, (2) Cognifit in combination with group-based supervised physical training, (3) supervised physical training, and (4) active control of book club reading. Therefore, we included Shatil 2013 in comparisons of computerised cognitive training (Cognifit) plus physical training versus physical training as inactive control, and computerised cognitive training (Cognifit) versus book club reading as active control.

\section{Outcomes}

In this section, we describe outcome measures that we included in meta-analyses in this review (see Types of outcome measures). We describe instruments that address outcomes of interest to this review but were not included in any meta-analyses in the Characteristics of included studies tables.

\section{Primary outcome}

\section{Global cognitive function}

Lampit 2014 measured global cognitive functioning using a composite score of memory, speed, and executive function after 3 and 15 months of follow-up. Peretz 2011 measured global cognitive functioning using an overall NexAde battery test composite score at three months.

\section{Secondary outcomes}

\section{Cognitive function subdomain: episodic memory}

Episodic memory was measured with the Rey Auditory Verbal Learning Test (RAVLT) by Desjardins-Crépeau 2016, the Rivermead Behavioural Memory Test (RBMT) by Klusmann 2010, the Logical Memory subtest of the Wechsler Memory Scale-III (WMS-III) by Legault 2011 and Leung 2015, and a memory recall test from the NexAde cognitive test battery by Peretz 2011.

\section{Cognitive function subdomain: speed of processing}

Shatil 2013 used the CogniFit neuropsychological evaluation subtest speed of visual information processing (SVP) to measure speed of processing. Desjardins-Crépeau 2016 and van het Reve 2014 used the Trail Making Test (TMT)-A, to measure speed of processing.

\section{Cognitive function subdomain: executive function}

Legault 2011 used TMT-B and -A, and van het Reve 2014 used TMT-B, to measure executive function. Klusmann 2010 assessed executive function with the Stroop test, Peretz 2011 used the Executive functions subtest of NexAde, and Desjardins-Crépeau 2016 used the Color-Word Interference Test (CWIT) of the Delis-Kaplan Executive Functions System (CWIT-switching).

\section{Cognitive function subdomain: working memory}

Working memory was measured with the Digit Span by Leung 2015, the NexAde Visuospatial working memory subtest by Peretz 2011, and the auditory working memory (AM) subtest of Cognifit by Shatil 2013.

\section{Cognitive function subdomain: verbal fluency}

Verbal fluency was measured via semantic verbal fluency by Klusmann 2010.

\section{Quality of life/psychological well-being}

None of the included studies reported on these outcomes.

\section{Daily functioning}

None of the included studies reported on this outcome.

\section{Number of participants experiencing one or more serious adverse events}

None of the studies reported on this outcome.

\section{Excluded studies}

We excluded 311 full-text articles that we had examined in full text. Of these, we excluded one because it focused on cognitively healthy people in midlife (Corbett 2015), another because the age of 
participants was given as ranging from 50 to 85 without means and standard deviations (Shah 2012), and eight because participants had mild cognitive impairment (Barnes 2013; Djabelkhir 2017; Fiatarone Singh 2014; Gooding 2016; Herrera 2012; Kwok 2013a; Optale 2010; Rozzini 2007). Nine of these trials are included in two other Cochrane reviews (Gates 2019a; Gates 2019b). We excluded 195 studies because they investigated an intervention shorter than 12 weeks, or because the intervention did not involve computerised cognitive training, and 18 studies because they used the wrong study design. We did not identify any ongoing trials in trial registers or conference proceedings. Reasons for study exclusion can be found in Characteristics of excluded studies.

\section{Risk of bias in included studies}

For graphical presentation of the risk of bias assessments, please see Figure 2 and Figure 3.

Figure 2. Risk of bias graph: review authors' judgements about each risk of bias item presented as percentages across all included studies.

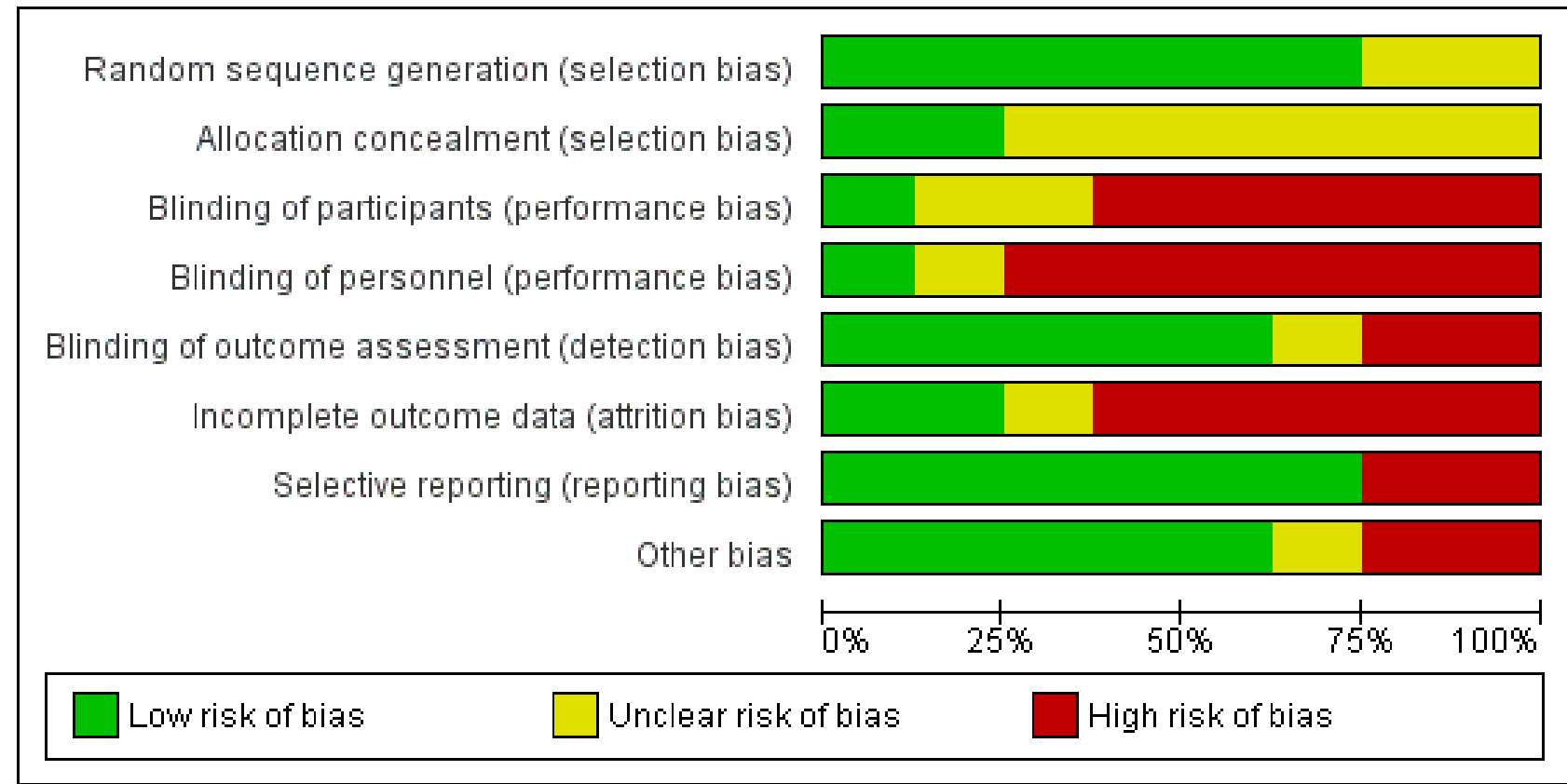


Figure 3. Risk of bias summary: review authors' judgements about each risk of bias item for each included study.

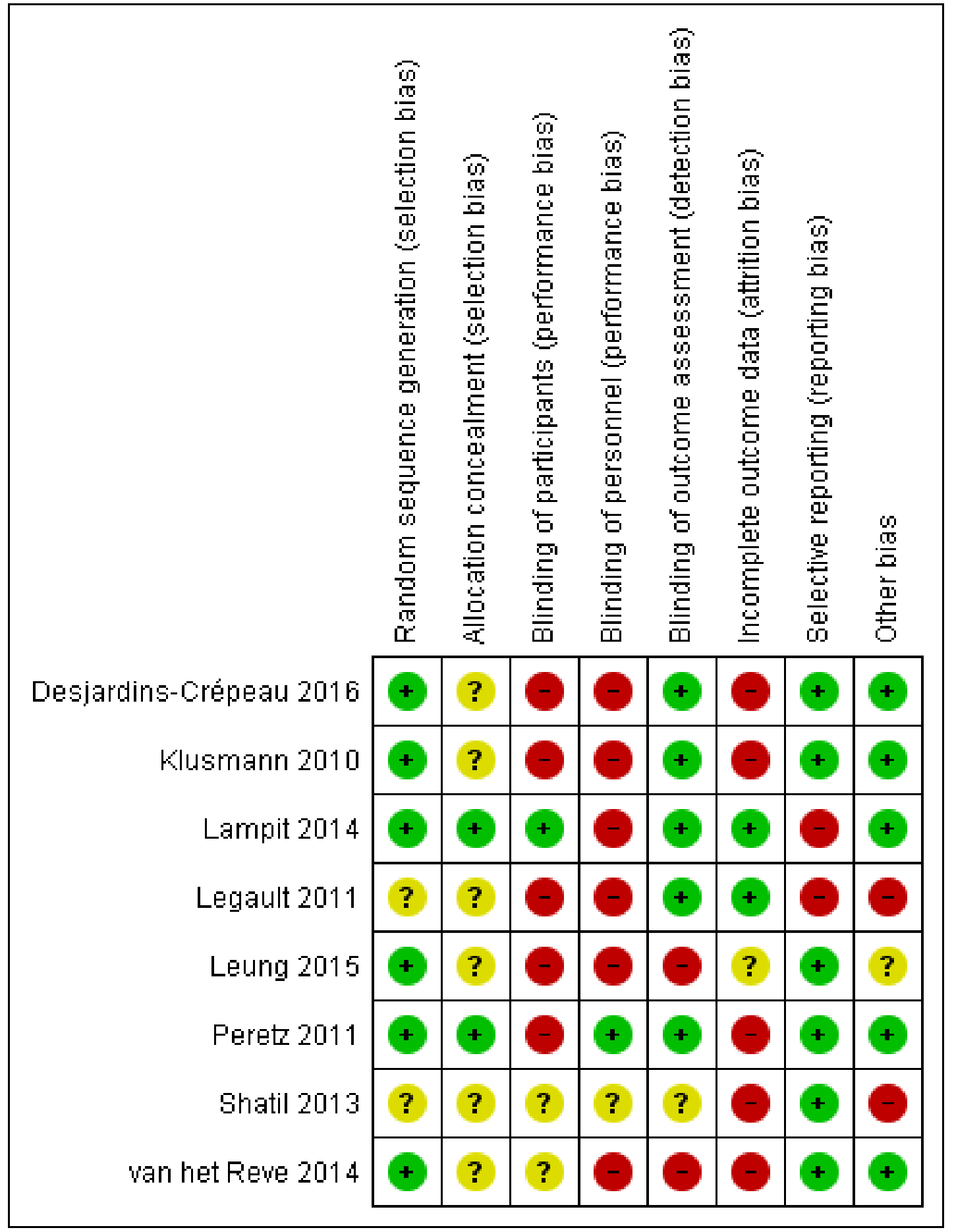

\section{Allocation}

We considered there to be low risk of selection bias for two studies, which reported adequate methods to generate random sequences and to conceal allocation (Lampit 2014; Peretz 2011). For three trials, we considered that there was an adequate method of random sequence generation but little or no information about allocation concealment; we therefore judged them to be at unclear risk (Klusmann 2010; Leung 2015; van het Reve 2014). In the remaining two trials, the risk of bias associated with both sequence generation and concealment of allocation was unclear (Legault 2011; Shatil 2013).

\section{Blinding}

We considered there to be unclear risk of performance and detection bias for one study, which lacked information on blinding of participants, personnel, and outcome assessors (Shatil 2013). We considered two studies to be at high risk of performance bias because patients and personnel were not blinded to the treatment

Computerised cognitive training for 12 or more weeks for maintaining cognitive function in cognitively healthy people in late life 18 (Review)

Copyright $\odot 2020$ The Cochrane Collaboration. Published by John Wiley \& Sons, Ltd. 
assigned, but at low risk of detection bias because blinding of outcome assessors was described (Klusmann 2010; Legault 2011). Lampit 2014 described adequate blinding of participants and outcome assessors, but not of personnel, so we considered it to be at high risk of performance bias and low risk of detection bias. We considered Leung 2015 to be at high risk of both performance and detection bias because patients, personnel, and outcome assessors were not blinded. Peretz 2011 described blinding of personnel and outcome assessors, but not of participants, so we considered it to be at high risk of performance bias and low risk of detection bias. van het Reve 2014 did not report any details regarding blinding of participants but had high risk of both performance and detection bias because neither personnel nor outcome assessors were blinded.

\section{Incomplete outcome data}

We considered two studies to be at low risk of attrition bias (Lampit 2014; Legault 2011), and we judged one study to be at unclear risk because of lack of information about how missing data were handled (Leung 2015). We considered Klusmann 2010, DesjardinsCrépeau 2016, and Shatil 2013 to be at high risk of attrition bias because on average, less than $90 \%$ of randomised participants were analysed. Peretz 2011 stated that researchers used an intention-totreat (ITT) analysis, but 18 participants in the experimental group and 16 in the control group did not complete the training and provided no data at baseline, follow-up, or both; we considered this to present high risk of attrition bias. We considered van het Reve 2014 to have high risk of attrition bias because only $82 \%$ and $78 \%$ of participants randomised to the two treatment groups were included in the statistical analyses.

\section{Selective reporting}

We considered five studies to be at low risk of reporting bias because all outcomes are described in the results section of the articles (Klusmann 2010; Leung 2015; Peretz 2011; Shatil 2013; van het Reve 2014). We considered two studies to be at high risk of reporting bias because we identified differences between the trial registry entry and the final article (Lampit 2014; Legault 2011).

\section{Other potential sources of bias}

We assessed Legault 2011 to be at high risk of bias for other reasons because the attendance rate in the combined CCT and physical activity group was statistically significantly better than in the physical activity only control group (Legault 2011). We assessed Shatil 2013 to be at high risk of bias for other reasons because Shatil works for the CogniFit company.

\section{Effects of interventions}

See: Summary of findings for the main comparison; Summary of findings 2

\section{Comparison: computerised cognitive training versus active control}

We refer to Summary of findings for the main comparison for an overview related to the comparison computerised cognitive training (CCT) versus active control. Unless otherwise stated, all outcomes were independent neuropsychological measures, not trained tasks, and any change would suggest transfer of training effects.

\section{Primary outcome}

Evidence on global cognitive function at end of trial was of low quality, downgraded for imprecision and risk of bias (Analysis 1.1; Figure 4). Therefore we are uncertain of this result. Negative values favour the CCT group. Two studies contributed to the analysis at the end of the intervention period (12 weeks) (Lampit 2014; Peretz 2011), yielding a standardised mean difference (SMD) of -0.31 (95\% confidence interval ( $\mathrm{Cl})-0.57$ to $-0.05 ; 2$ studies; 232 participants). One of these trials also assessed global cognitive function 12 months after completion of the intervention; this trial provided no clear evidence of a persistent effect (SMD $-0.21,95 \% \mathrm{Cl}$ -0.66 to $0.24 ; 77$ participants; 1 study; low-quality evidence). Results at all time points were imprecise. 
Figure 4. Forest plot of comparison: 1 Computerised cognition-based training versus active control, outcome: 1.1 Global cognitive function. Peretz 2011 published standard deviations as measure of spread for all outcomes. We deemed the published values for change from baseline values within groups to be more likely standard errors, and treated these as such.

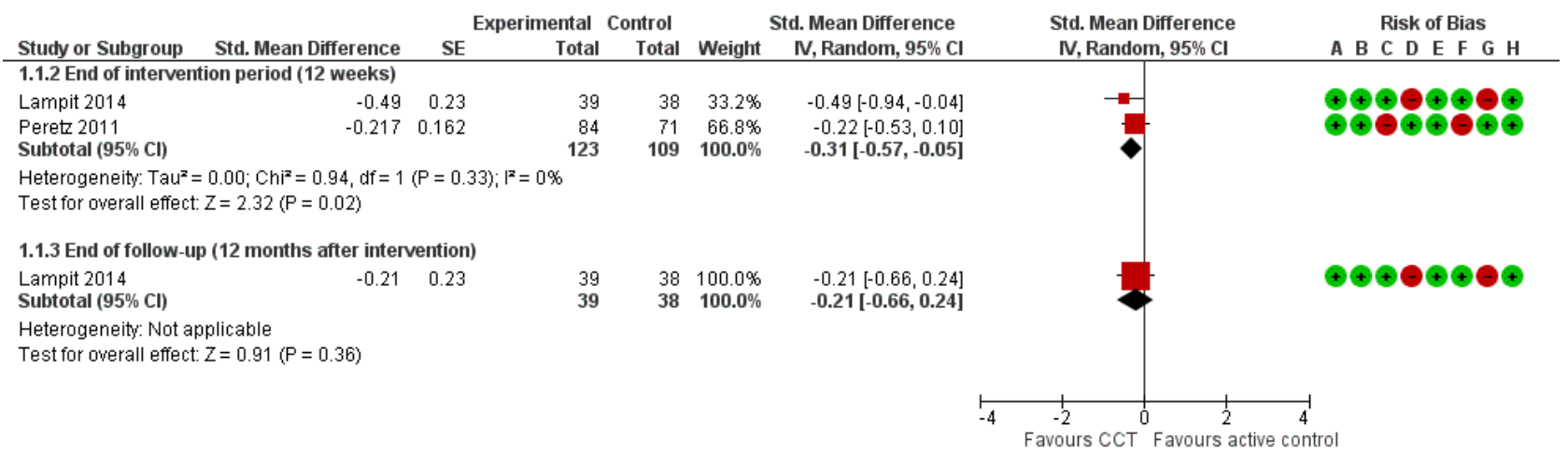

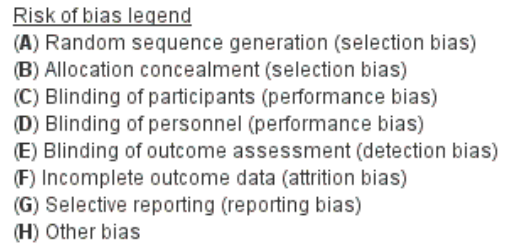

\section{Secondary outcomes}

Cognitive subdomain: episodic memory

Evidence on episodic memory at end of trial was of low quality, downgraded for imprecision and risk of bias (Analysis 1.2; Figure 5).
Therefore we are uncertain of this result. Negative values favour the CCT group. Four studies contributed to the analysis at the end of the intervention period (12 to 17 weeks) (Desjardins-Crépeau 2016; Legault 2011; Leung 2015; Peretz 2011), yielding an SMD of 0.06 ( $95 \% \mathrm{Cl}-0.14$ to $0.26 ; 4$ studies; 439 participants).

Figure 5. Forest plot of comparison: 1 Computerised cognition-based training versus active control, outcome: 1.2 Episodic memory.

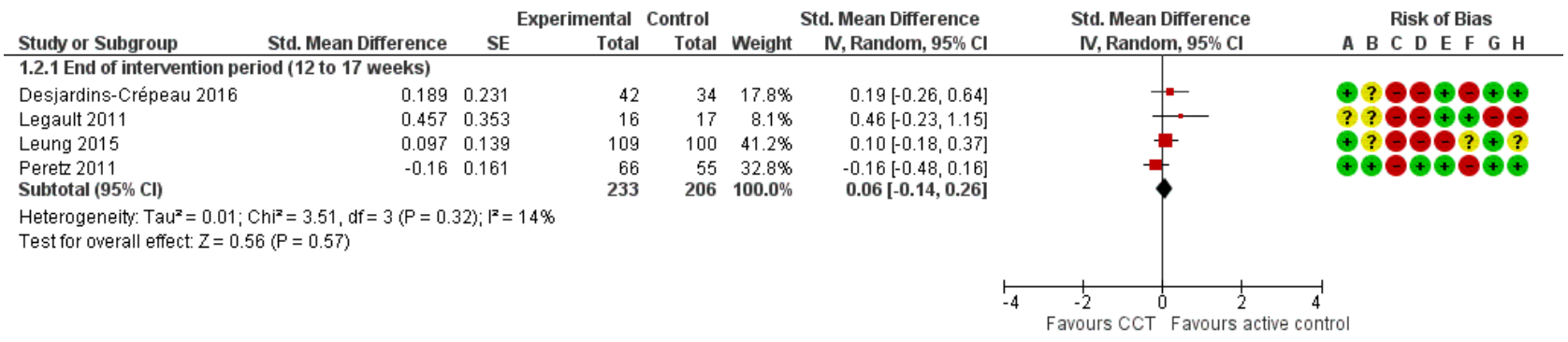

Risk of bias legend

(A) Random sequence generation (selection bias)

(B) Allocation concealment (selection bias)

(C) Blinding of participants (performance bias)

(D) Blinding of personnel (performance bias)

(E) Blinding of outcome assessment (detection bias)

(F) Incomplete outcome data (attrition bias)

(G) Selective reporting (reporting bias)

(H) Other bias

\section{Cognitive subdomain: speed of processing}

Two studies provided very low-quality evidence on speed of processing at the end of the intervention period (12 to 16 weeks) (Analysis 1.3) (Desjardins-Crépeau 2016; Shatil 2013). We downgraded the evidence for imprecision, inconsistency, and risk of bias. Therefore we are very uncertain of this result. Negative values favour the CCT group (SMD $-0.63,95 \% \mathrm{Cl}-1.14$ to $-0.12 ; 2$ studies; 138 participants).

\section{Cognitive subdomain: executive function}

Evidence on executive function at end of trial was of very low quality, downgraded for imprecision, inconsistency, and risk of bias (Analysis 1.4). Therefore we are very uncertain of this result. Negative values favour the CCT group. Included studies at the end of the intervention period (12 to 17 weeks) were Desjardins-Crépeau 2016, Legault 2011, and Peretz 2011. The SMD was -0.04 (95\% Cl -0.61 to 0.53 ; 3 studies; 230 participants). 


\section{Cognitive subdomain: working memory}

Evidence on working memory at the end of the intervention period (12 to 16 weeks) was of low quality (Analysis 1.5; Figure $6)$, downgraded for imprecision and risk of bias. Therefore we are uncertain of this result. Negative values favour the CCT group. Three studies contributed to the analysis (Leung 2015; Peretz 2011; Shatil 2013), yielding an SMD of -0.17 ( $95 \% \mathrm{Cl}-0.36$ to $0.02 ; 3$ studies; 392 participants).

Figure 6. Forest plot of comparison: 1 Computerised cognition-based training versus active control, outcome: 1.5 Working memory.

\begin{tabular}{|c|c|c|c|c|c|c|c|c|}
\hline Study or Subgroup & Std. Mean Difference & SE & $\begin{array}{r}\text { Experimental } \\
\text { Total }\end{array}$ & $\begin{array}{r}\text { Control } \\
\text { Total }\end{array}$ & Weight & $\begin{array}{l}\text { Std. Mean Difference } \\
\text { IV, Random, } 95 \% \mathrm{Cl}\end{array}$ & $\begin{array}{l}\text { Std. Mean Difference } \\
\text { IV, Random, } 95 \% \mathrm{Cl}\end{array}$ & \\
\hline \multicolumn{9}{|c|}{ 1.5.1 End of intervention period (12 to 16 weeks) } \\
\hline Leung 2015 & -0.201 & 0.139 & 109 & 100 & $49.0 \%$ & $-0.20[-0.47,0.07]$ & $\rightarrow$ & \\
\hline Peretz 2011 & -0.153 & 0.161 & 66 & 55 & $36.5 \%$ & $-0.15[-0.47,0.16]$ & $\rightarrow-$ & \\
\hline Shatil 2013 & -0.117 & 0.255 & 33 & 29 & $14.5 \%$ & $-0.12[-0.62,0.38]$ & $\vec{F}$ & \\
\hline Subtotal (95\% Cl) & & & 208 & 184 & $100.0 \%$ & $-0.17[-0.36,0.02]$ & & \\
\hline \multicolumn{9}{|c|}{$\begin{array}{l}\text { Heterogeneity: } \mathrm{Tau}^{2}=0.00 ; \mathrm{Chi}^{2}=0.10, \mathrm{df}=2(P=0.95) ;\left.\right|^{2}=0 \% \\
\text { Test for overall effect: } Z=1.76(P=0.08)\end{array}$} \\
\hline
\end{tabular}

\section{Comparison: computerised cognitive training versus inactive control}

We refer to Summary of findings 2 for an overview related to the comparison CCT versus inactive control. Unless otherwise stated, all outcomes were independent neuropsychological measures, not trained tasks, and any change would suggest transfer of training effects.

\section{Primary outcome}

No studies provided data on global cognitive function at end of trial.

\section{Secondary outcomes}

\section{Cognitive subdomain: episodic memory}

Evidence on episodic memory at end of trial was of low quality, downgraded for imprecision and risk of bias (Analysis 2.1; Figure 7). Negative values favour the CCT group. The analysis at the end of the intervention period (six months) included one study and yielded a mean difference (MD) of $-0.90(95 \% \mathrm{Cl}-1.73$ to $-0.07 ; 150$ participants) (Klusmann 2010).

Figure 7. Forest plot of comparison: 2 Computerised cognition-based training versus inactive control, outcome: 2.1 Episodic Memory.

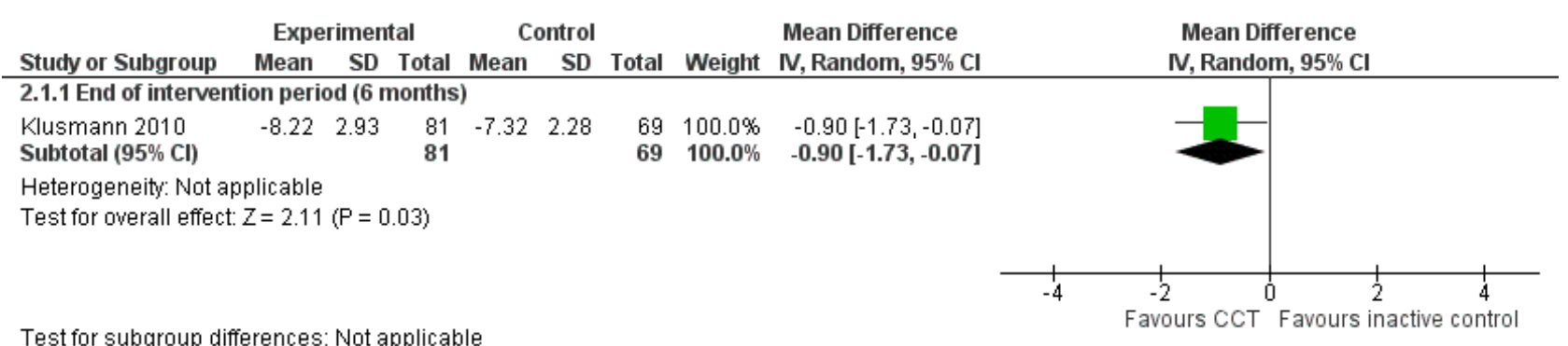

\section{Cognitive subdomain: speed of processing}

Two studies provided very low-quality evidence on speed of processing at the end of the intervention period (12 to 16 weeks) (Analysis 2.3) (Shatil 2013; van het Reve 2014). We downgraded the evidence for imprecision, inconsistency, and risk of bias. Therefore we are very uncertain of this result. Negative values favour CCT. The SMD was -0.28 ( $95 \% \mathrm{Cl}-0.82$ to $0.26 ; 2$ studies; 204 participants).

\section{Cognitive subdomain: executive function}

Evidence on executive function at the end of the intervention period (12 weeks to six months) was of low quality, downgraded for imprecision and risk of bias (Analysis 2.2; Figure 8). Negative values favour the CCT group. The analysis included two studies and yielded an SMD of $-0.08(95 \% \mathrm{Cl}-0.31$ to $0.15 ; 2$ studies; 292 participants) (Klusmann 2010; van het Reve 2014). Results at individual time points were as follows: at the end of the intervention at 12 weeks: SMD $-0.03(95 \% \mathrm{Cl}-0.35$ to $0.30 ; 1$ study; 144 participants); and at the end of the intervention at six months: SMD - 0.13 (95\% $\mathrm{Cl}-0.45$ to $0.20 ; 1$ study; 148 participants). 
Figure 8. Forest plot of comparison: 2 Computerised cognition-based training versus inactive control, outcome: 2.2 Executive function.

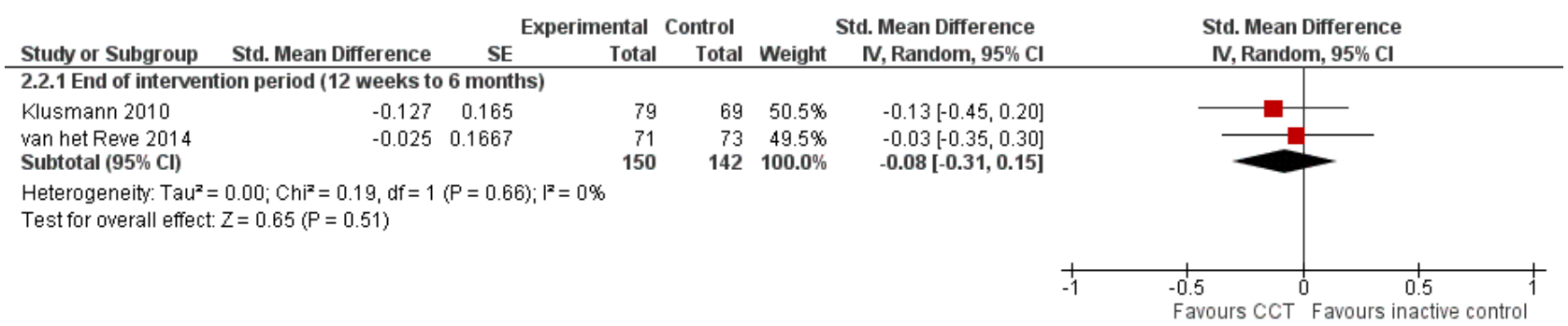

\section{Cognitive subdomain: working memory}

One study provided low-quality evidence on working memory (Analysis 2.4; Figure 9) (Shatil 2013). We downgraded the evidence because of imprecision and risk of bias. Negative values favour CCT.
At the end of the intervention period ( 16 weeks), the MD was -0.08 ( $95 \% \mathrm{Cl}-0.43$ to $0.27 ; 1$ study; 60 participants). This result means that, when compared with an inactive control, there may be little or no effect of CCT on working memory.

Figure 9. Forest plot of comparison: 2 Computerised cognition-based training versus inactive control, outcome: 2.4 Working memory.

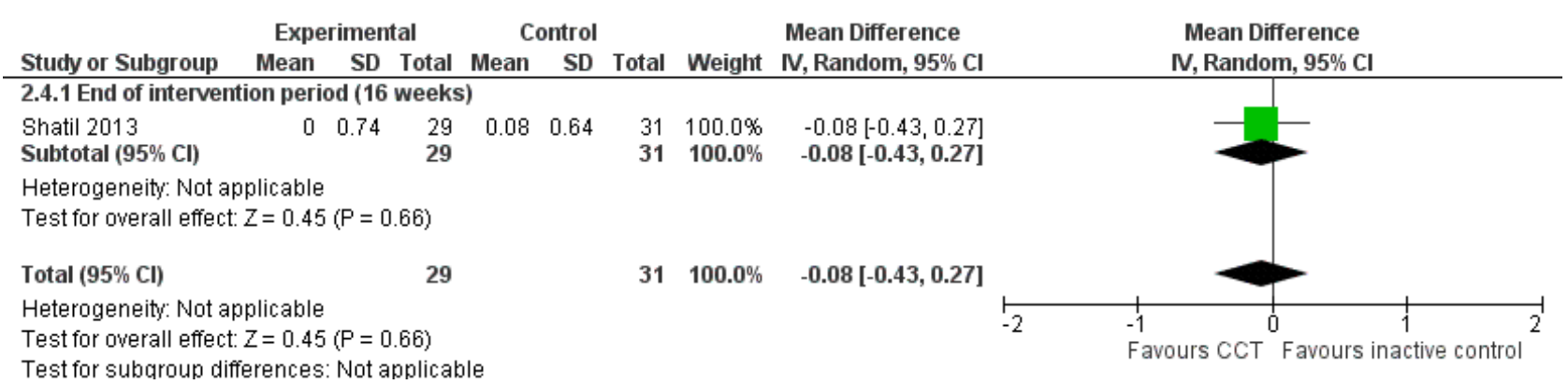

Cognitive subdomain: verbal fluency

One study provided low-quality evidence on verbal fluency at end of trial (Analysis 2.5; Figure 10) (Klusmann 2010). We downgraded the evidence for imprecision and risk of bias. Negative values favour

CCT. At the end of the intervention period (six months), the MD was -0.11 (95\% Cl -1.58 to $1.36 ; 1$ study; 150 participants). This result means that, when compared with an inactive control, there may be little or no effect of CCT on verbal fluency.

Figure 10. Forest plot of comparison: 2 Computerised cognition-based training versus inactive control, outcome: 2.5 Verbal fluency.

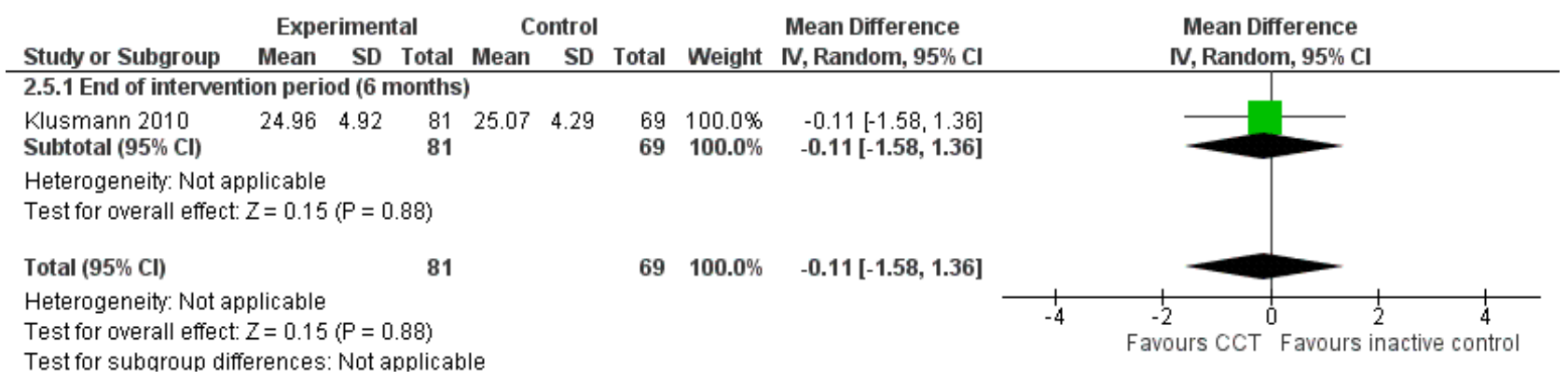

\section{Subgroup analyses and sensitivity analyses}

We could perform no subgroup analyses as too few studies contributed to the meta-analyses (see Differences between protocol and review).

\section{IS C U S S I O N}

\section{Summary of main results}

Computerised cognitive training (CCT) compared to active control interventions at end of trial

We found low-quality evidence suggesting that when compared with an active control, CCT may slightly improve global cognitive function at the end of 12 weeks of training, but not at 12 months 
after the end of training. CCT may have little or no effect on episodic memory and working memory. The quality of the evidence on speed of processing and executive function was very low, so we were unable to draw any conclusions about an effect of CCT on these outcomes.

\section{Computerised cognitive training (CCT) compared to inactive control at end of trial}

We found low-quality evidence suggesting that when compared with an inactive control, CCT may slightly improve episodic memory and may have little or no effect on executive function, working memory, or verbal fluency. The quality of the evidence on speed of processing was very low, so we were unable to draw any conclusions about an effect of CCT on this outcome.

\section{Overall completeness and applicability of evidence}

We made an a priori decision to operate a threshold around duration of exposure for inclusion in this review. As is evident from our PRISMA flow diagram, this threshold necessitated excluding a substantial proportion of the published literature. We did not deviate from our published protocol, but we recognise that our inclusion criteria may have led to the exclusion of potentially informative evidence.

Lack of long-term follow-up in the included studies meant that we found little evidence on the effect of CCT on maintenance of cognitive function over time. Ideally, follow-up should be long enough to allow age-related cognitive decline to occur.

We did not identify any trial that examined the outcomes quality of life, psychological well-being, daily functioning, and adverse events. These are all important outcomes for clinical decisionmaking and for potential consumers.

The extent to which CCT of duration shorter than 12 weeks can maintain or benefit cognitive function is not addressed by this review. For example, another review of computerised training in cognitively healthy elderly included 12 studies, nine of which provided training interventions of less than 12 weeks duration, and found that five short training programmes resulted in cognitive improvement across several cognitive domains (Shao 2015).

\section{Quality of the evidence}

We identified several limitations in the included studies, and we rated none as having low risk of bias. We considered only two studies to have low risk of selection bias (Lampit 2014; Peretz 2011), and we considered none to have low risk of performance bias. We judged that risk for, respectively, detection bias, attrition bias, and reporting bias was low in five studies (Desjardins-Crépeau 2016; Klusmann 2010; Lampit 2014; Legault 2011; Peretz 2011), three studies (Lampit 2014; Legault 2011; Shatil 2013), and six studies (Desjardins-Crépeau 2016; Klusmann 2010; Leung 2015; Peretz 2011; Shatil 2013; van het Reve 2014).

Overall, the quality of evidence was low or very low according to GRADE criteria, so we have low to very low confidence in the summary estimates of effects reported here. Identified issues with quality were mainly imprecision and risk of bias. Higher-quality evidence is required if we are to draw conclusions with greater certainty.

\section{Potential biases in the review process}

We used an exhaustive search strategy covering multiple data sources, considering full reports, abstracts, and other report types described in any language. We searched for unpublished and ongoing data, but we identified published data only. We did not detect publication bias, but this does not mean that we can rule out publication bias. We could not formally assess it in funnel plot evaluations because of the small number of studies identified.

Use of at least two independent review authors minimised bias at the review level. We followed Cochrane guidance and used a component approach to assess the methodological rigour of trials while applying GRADE to assess the quality of the overall body of evidence. We nevertheless are aware of some important limitations of this review. We had to choose a method to deal with the use of multiple instruments to measure a specific cognitive (sub)-domain within and across trials. We opted for use of a hierarchy that informed us which outcome data we should extract, so that for each cognitive outcome, data from a single validated instrument per trial contributed to analyses. The hierarchy of these outcomes can be consulted in the protocol of our review. As instruments differed across trials, we chose to use the standardised mean difference to combine outcome data across trials. An alternative strategy would have been to consider a single preferred instrument for each cognitive domain, using the mean difference to combine outcome data across trials. We preferred to use a hierarchy, so that we could include a larger number of trials. The disadvantage of our approach is that interpretation of effect size (standardised mean difference (SMD)) is less intuitive than results reported on a natural scale. As there is little consensus on the threshold for minimal clinically important differences, we refrained from translating estimates of the SMD back to the natural scale of, for example, the Mini Mental State Examination (MMSE). We may have introduced between-trial heterogeneity by combining SMDs derived from multiple instruments, but the small number of trials identified did not allow us to assess such impact. As we had no access to individual participant data, we chose not to combine results on multiple instruments within a trial before combining results across trials, as this would put the summary estimates at high risk of ecological fallacy.

\section{Agreements and disagreements with other studies or reviews}

Results from other meta-analyses and individual clinical trials vary. Other recent meta-analyses of computerised cognitive programmes with no minimum training duration showed improvement in executive function, global composite scores, memory, and processing speed compared to controls and in noncognitive outcomes including emotional well-being and everyday functioning (e.g. Gates 2011a; Gordon 2013; Kelly 2014a; Kueider 2012; Lampit 2014a; Rebok 2014; Shao 2015, Edwards 2018).

However, the overall evidence in cognitively healthy adults is mixed, and opposing professional views regarding the evidence base have been published (Lampit 2015; Ratner 2015). We identified a rather large number of reviews relative to the limited number of well-designed clinical trials. Diversity of interventions involving dose, duration, and intensity of cognitive training, along with methodological constraints such as lack of randomisation, small samples, and lack of blinding, may account for the disparate results 
(Gates 2010; Kueider 2012; Mowszowski 2010; Papp 2009; Shao 2015; Steiner 2010).

\section{AUTHORS' CONCLUSIONS}

\section{Implications for practice}

At the current time, there is a lack of high-quality evidence to show that computerised cognitive training (CCT) for 12 or more weeks helps to maintain cognitive function in healthy older adults. It is important to emphasise that our conclusions are applicable only to studies that delivered cognitive training over at least 12 weeks. There may be important and relevant evidence from studies with shorter intervention periods. Despite our intention to examine generalisation of effects to objective measures of everyday functioning, we are able to comment only on training effects on cognitive outcomes.

Clinicians and consumers may find the field confusing and may note contradictory messages about research evidence and divisive debates in the research community (e.g. Lampit 2015; Ratner 2015). Fear of developing dementia is common among older adults, and there is increasing demand for interventions to address age-related and non-pathological cognitive decline. This goes along with the development and commercialisation of brain training products targeting older consumers. Although we found no strong evidence in support of CCT in this review, it remains possible that longer interventions - or shorter, higher-dose interventions - could help to maintain cognitive function.

\section{Implications for research}

Studies of CCT in cognitively healthy adults could be improved by careful consideration given to study design, including choice and measurement of outcomes and time points of follow-up. Selection of outcomes ought to address the principal objective of CCT not only that training benefits the specific skills trained but also that those benefits transfer to improvement or maintenance of function on non-trained cognitive tasks, and generalise to noncognitive domains such as daily functioning (Kelly 2014a), although the topic of transfer is debated (Zelinski 2009). In this review, we found that measures of functional performance that may indicate generalisation were absent from the identified studies. Inclusion of outcomes that could demonstrate effects on quality of life, psychiatric symptoms, mood, and daily functioning should be encouraged in future studies.

To accurately measure change in cognitive function, and to identify transfer and generalisation, selected outcomes should be sensitive to subtle and possibly non-linear changes, should have high reliability, should have alternate forms or be psychometrically robust for repeated use, and should have low risk of floor and ceiling effects. This is particularly relevant for cognitively healthy adults, in whom ceiling effects may dominate (i.e. how do you improve on normal?). We advocate for establishment of an international multi-disciplinary panel to develop a standardised core outcome set for cognitive assessments in older individuals with and without cognitive decline, to improve outcome reporting and facilitate evidence synthesis. Ideally, studies should measure change immediately after an intervention ends and then should monitor function over time. Future research studies should move towards investigating different types of training exercises, differential effects of training on separate cognitive domains, and the impact of variability on the frequency, intensity, and duration of interventions. Furthermore, it would be helpful to assess effectiveness of training in realistic situations, including participants with health risk factors, comorbidities, and barriers to participation. Inactive controls are suitable for research examining possible neuroplastic mechanisms and brain reserve, and for inclusion in simple efficacy studies, and the clinical effectiveness and comparative studies described above will require an active control arm.

Improved reporting of study methods should be a priority because of the high proportion of unclear risks of bias, which could be improved through simple steps, such as adherence to CONSORT, improved data management to reduce the quantity of incomplete data, and development of methods to facilitate blinding of participants and personnel. Blinding of participants is especially important given the commercialisation of CCT, advertisements, and widespread community exposure, and an active control may partially address this potential bias.

The process of conducting this review has highlighted important methodological considerations for future updates and for other systematic reviews in this field. With hindsight, our 12 weeks duration inclusion criterion did not achieve what we hoped for. We had wanted to exclude studies in which exposure to training was modest and was unlikely to have meaningful, lasting effects. However, as is evident from comparisons of included and excluded studies, some excluded studies offered high-intensity training and hence an overall 'dose' of training that was higher than in many included studies. For future updates, various options are possible; it may be useful to consider dose of training and perhaps to perform meta-regression to look at the effects of dose on outcomes. Alternatively, length of follow-up may be a more useful inclusion criterion than duration of intervention. Although short-term effects are of scientific interest, for older people and for clinicians and policy makers, it is sustained benefits that matter most.

\section{ACKNOWLEDGEMENTS}

The review authors would like to thank the Group's Information Specialist, Anna Noel-Storr, for designing and running the electronic searches, and for co-ordinating the crowdsourced components of the review. This review is part of a programme grant by which 11 other reviews were produced via a protocol template (Abraham 2015; Al-Assaf 2015; Denton 2015; Forbes 2015; Forbes 2015a; Forbes 2015b; Gates 2019a; Gates 2019b; Harrison 2015; Siervo 2015; Tang 2015). All authors participating in this review also acted as authors in several other reviews. As a consequence, wording chosen in the methods section may be identical across reviews, and concepts discussed and reviews may be similar.

We also thank the following members of the Cochrane Crowd, who made significant contributions to screening the search results: Michael J. Arnatt, Soumyadeep Bhaumik, María Paz Campos Pérez, C Cartlidge, Daniel Casey, Mohamed Fawzy Abdelghafar, Cristi Francis, Pishoy Gouda, Dan Griffiths, Michael Haas, Shirley Hall, Jake Hartley, Michael Hull, Geanina Ilinoiu, Deborah Jackson, Sofia Jaramillo, Robert Kemp, Ivan Murrieta Alvarez, Shireen Rafeeq, Miriam Thiel, Jennifer Ware, and Hakan Yaman. 
R E F E R E N C E S

\section{References to studies included in this review}

Desjardins-Crépeau 2016 \{published data only\}

Desjardins-Crépeau L, Berryman N, Fraser SA, Vu TT, Kergoat MJ, Li KZ, et al. Effects of combined physical and cognitive training on fitness and neuropsychological outcomes in healthy older adults. Clinical Interventions in Aging 2016;11:1287-99.

\section{Klusmann 2010 \{published data only\}}

Klusmann V, Evers A, Schwarzer R, Schlattmann P, Reischies FM, Heuser I, et al. Complex mental and physical activity in older women and cognitive performance: a 6-month randomized controlled trial. Journals of Gerontology. Series A, Biological Sciences and Medical Sciences 2010;65(6):680-8.

\section{Lampit 2014 \{published data only\}}

Lampit A, Hallock H, Moss R, Kwok S, Rosser M, Lukjanenko M, et al. The timecourse of global cognitive gains from supervised computer-assisted cognitive training: a randomised, activecontrolled trial in elderly with multiple dementia risk factors. Journal of Prevention of Alzheimer's Disease 2014;1(1):33-9.

Lampit A, Hallock H, Suo C, Naismith SL, Valenzuela M. Cognitive training-induced short-term functional and longterm structural plastic change is related to gains in global cognition in healthy older adults: a pilot study. Frontiers in Aging Neuroscience 2015;7:14.

\section{Legault 2011 \{published data only\}}

Legault C, Jennings JM, Katula JA, Dagenbach D, Gaussoin SA, Sink KM, et al. Designing clinical trials for assessing the effects of cognitive training and physical activity interventions on cognitive outcomes: the Seniors Health and Activity Research Program Pilot (SHARP-P) study, a randomized controlled trial. BMC Geriatrics 2011;11:27.

\section{Leung 2015 \{published data only\}}

Leung NT, Tam HM, Chu LW, Kwok TC, Chan F, Lam LC, et al. Neural plastic effects of cognitive training on aging brain. Neural Plasticity 2015;2015:1-9.

\section{Peretz 2011 \{published data only\}}

Peretz C, Korczyn AD, Shatil E, Aharonson V, Birnboim S, Giladi N. Computer-based, personalized cognitive training versus classical computer games: a randomized double-blind prospective trial of cognitive stimulation. Neuroepidemiology 2011;36(2):91-9.

\section{Shatil 2013 \{published data only\}}

Shatil E. Does combined cognitive training and physical activity training enhance cognitive abilities more than either alone? A four-condition randomized controlled trial among healthy older adults. Frontiers in Aging Neuroscience 2013;5:8.

\section{van het Reve 2014 \{published data only\}}

van het Reve E, de Bruin ED. Strength-balance supplemented with computerized cognitive training to improve dual task gait and divided attention in older adults: a multicenter randomized-controlled trial. BMC Geriatrics 2014;14:134.

\section{References to studies excluded from this review}

\section{Adel 2013 \{published data only\}}

Adel D, Boulanouar K, Chauveau N, Delrieu J, Voisin T, Vellas B, et al. Structural MRI and FDG-PET modifications induced by one year multi domain intervention in elderly. Conference: 26th Annual Congress of the European Association of Nuclear Medicine, EANM 2013 Lyon France. 2013; Vol. Conference Start: 20131019 Conference End: 20131023:S208.

\section{Alves 2014 \{published data only\}}

Apóstolo JL, Cardoso DF, Rosa Al, Paúl C. The effect of cognitive stimulation on nursing home elders: a randomized controlled trial. Journal of Nursing Scholarship 2014;46(3):157-66.

\section{Alves 2014a \{published data only\}}

Alves J, Alves-Costa F, Magalhães R, Gonçalves OF, Sampaio A. Cognitive stimulation for Portuguese older adults with cognitive impairment: a randomized controlled trial of efficacy, comparative duration, feasibility, and experiential relevance. American Journal of Alzheimer's Disease and Other Dementias 2014;29(6):503-12.

\section{Anderson 2014 \{published data only\}}

Anderson S, White-Schwoch T, Choi HJ, Kraus N. Partial maintenance of auditory-based cognitive training benefits in older adults. Neuropsychologia 2014;62:286-96.

\section{Ann 2012 \{published data only\}}

Ann B, Eva E, Siv S, Elisabeth A. Effects of working memory training on functioning in daily life. Conference: 9th Annual Conference of the Special Interest Group in Neuropsychological Rehabilitation of the World Federation for NeuroRehabilitation, WFNR 2012 Bergen Norway. 2012; Vol. Conference Start: 20120702 Conference End: 20120703:182.

\section{Anon 2007 \{published data only\}}

Anon. Randomized prospective cognitive training study on elderly Japanese in Osaka. UMIN000001368 2007.

\section{Anon 2007a \{published data only\}}

NCT00544856. Effects of a complex cognitive training in mild cognitive impairment and mild Alzheimer's disease. clinicaltrials.gov 2007.

\section{Apostolo 2014 \{published data only\}}

Apóstolo JL, Cardoso DF, Rosa Al, Paúl C. The effect of cognitive stimulation on nursing home elders: a randomized controlled trial. Journal of Nursing Scholarship 2014;46(3):157-66.

\section{Baglio 2011 \{published data only\}}

Baglio F, Griffanti L, Preti MG, Lagana MM, Alberoni M, Critelli R, et al. Cognitive training in outpatients affected by mild cognitive impairment: a longitudinal study with fMRI. Conference: 6th Sindem Meeting: Italian Association for the Study of Dementia linked to the Italian Neurological Society, SIN Milan Italy. 2011; Vol. Conference Start: 20110317 Conference End: 20110319:S47-8. 
Ball 2002 \{published data only\}

Ball K, Berch DB, Helmers KF, Jobe JB, Leveck MD, Marsiske $\mathrm{M}$, et al. Effects of cognitive training interventions with older adults: a randomized controlled trial. JAMA 2002;288(18):2271-81.

\section{Ball 2002a \{published data only\}}

Ball K, Berch DB, Helmers KF, Jobe JB, Leveck MD, Marsiske $\mathrm{M}$, et al. Effects of cognitive training interventions with older adults: a randomized controlled trial. JAMA 2002;288(18):2271-81.

\section{Ball 2006 \{published data only\}}

Ball K, Unverzagt F, Rebok G, Morris J, Tennstedt SL, Marsiske M. ACTIVE: advanced cognitive training for independent and vital elderly. https://clinicaltrials.gov/ct2/show/NCT00298558 2006

Ball 2013 \{published data only\}

Ball KK, Ross LA, Roth DL, Edwards JD. Speed of processing training in the ACTIVE study: how much is needed and who benefits?. Journal of Aging and Health 2013;25(8):Suppl 65S-84S.

\section{Ballesteros 2014 \{published data only\}}

Ballesteros S, Prieto A, Mayas J, Toril P, Pita C, Ponce de León L, et al. Brain training with non-action video games enhances aspects of cognition in older adults: a randomized controlled trial. Frontiers in Aging Neuroscience 2014;6:277.

\section{Ballesteros 2014a \{published data only\}}

Ballesteros S, Prieto A, Mayas J, Toril P, Pita C, Ponce de León L, et al. Brain training with non-action video games enhances aspects of cognition in older adults: a randomized controlled trial. Frontiers in Aging Neuroscience 2014;6:277.

\section{Ballesteros 2015 \{published data only\}}

Ballesteros S, Mayas J, Prieto A, Toril P, Pita C, Laura Pde L, et al. A randomized controlled trial of brain training with non-action video games in older adults: results of the 3-month follow-up. Frontiers in Aging Neuroscience 2015;7:45.

\section{Ballesteros 2015a \{published data only\}}

Ballesteros S, Prieto A, Mayas J, Toril P, Pita C, Ponce de León L, et al. Corrigendum: brain training with non-action video games enhances aspects of cognition in older adults: a randomized controlled trial. Frontiers in Aging Neuroscience 2015;7:82.

\section{Ballesteros 2017 \{published data only\}}

Ballesteros S, Mayas J, Prieto A, Ruiz-Marquez E, Toril P, Reales JM. Effects of video game training on measures of selective attention and working memory in older adults: results from a randomized controlled trial. Frontiers in Aging Neuroscience 2017;9:354.

\section{Bamidis 2015 \{published data only\}}

Bamidis PD, Fissler P, Papageorgiou SG, Zilidou V, Konstantinidis EI, Billis AS, et al. Gains in cognition through combined cognitive and physical training: the role of training dosage and severity of neurocognitive disorder. Frontiers in Aging Neuroscience 2015;7:152.

\section{Baniqued 2014 \{published data only\}}

Baniqued PL, Kranz MB, Voss MW, Lee H, Cosman JD, Severson J, et al. Cognitive training with casual video games: points to consider. Frontiers in Psychology 2014;4:1010.

\section{Baniqued 2015 \{published data only\}}

Baniqued PL, Allen CM, Kranz MB, Johnson K, Sipolins A, Dickens $C$, et al. Working memory, reasoning, and task switching training: transfer effects, limitations, and great expectations?. PloS One 2015;10(11):e0142169.

\section{Barban 2012 \{published data only\}}

Barban F, Annicchiarico R, Perri R, Fadda L, Carlesimo GA, Pantelopoulos S, et al. Randomized clinical trial of a computerbased cognitive treatment for healthy elderly, clinical and preclinical Alzheimer's disease. the SOCIABLE project. Conference: 7th Congresso Sindem: Italian Association for the Study of Dementia Linked to the Italian Neurological Society, SIN Naples Italy. 2012; Vol. Conference Start: 20120322 Conference End: 20120324:101.

\section{Barban 2016 \{published data only\}}

Barban F, Annicchiarico R, Pantelopoulos S, Federici A, Perri R, Fadda L. Protecting cognition from aging and Alzheimer's disease: a computerized cognitive training combined with reminiscence therapy. International Journal of Geriatric Psychiatry 2016;31(4):340-8.

\section{Barbosa 2015 \{published data only\}}

Barbosa AR, Guimaraes AV. Effects of exergames on cognitive performance and functional fitness in older adults: a pilot study. Conference: 2015 Annual Scientific Meeting of the American Geriatrics Society National Harbor, MD, United States. 2015; Vol. Conference Start: 20150515 Conference End: 20150517:S176.

\section{Barcelos 2015 \{published data only\}}

Barcelos N, Shah N, Cohen K, Hogan MJ, Mulkerrin E, Arciero PJ, et al. Aerobic and cognitive exercise (ACE) pilot study for older adults: executive function improves with cognitive challenge while exergaming. Journal of the International Neuropsychological Society 2015;21(10):768-79.

\section{Barnes 2006 \{published data only\}}

Barnes DE, Yaffe K, Belfor N, Jagust WJ, DeCarli C, Reed BR, et al. Computer-based cognitive training for mild cognitive impairment: results from a pilot randomized controlled trial. Alzheimer Disease and Associated Disorders 2006;66(5):A249.

\section{Barnes 2009 \{published data only\}}

Barnes DE, Yaffe K, Belfor N, Jagust WJ, DeCarli C, Reed BR, et al. Computer-based cognitive training for mild cognitive impairment: results from a pilot randomized controlled trial. Alzheimer Disease and Associated Disorders 2009;23(3):205-10.

\section{Barnes 2013 \{published data only\}}

Barnes DE, Santos-Modesitt W, Poelke G, Kramer AF, Castro C, Middleton LE, et al. The mental activity and exercise (MAX) trial: a randomized controlled trial to enhance cognitive function in older adults. JAMA Internal Medicine 2013;173(9):797-804. 
Basak 2016 \{published data only\}

Basak C, O'Connell MA. To switch or not to switch: role of cognitive control in working memory training in older adults. Frontiers in Psychology 2016;7:230.

\section{Beck 2013 \{published data only\}}

Beck C, Fausett JK, Krukowski RA, Cornell CE, Prewitt TE, Lensing S, et al. A randomized trial of a community-based cognitive intervention for obese senior adults. Journal of Aging and Health 2013;25(1):97-118.

\section{Belchior 2007 \{published data only\}}

Belchior PD. Cognitive training with video games to improve driving skills and driving safety among older adults. University of Florida 2007;Thesis:209.

\section{Belchior 2008 \{published data only\}}

Belchior PC. Cognitive training with video games to improve driving skills and driving safety among older adults. Thesis 2008;68(9-B):5897.

\section{Belleville 2006 \{published data only\}}

Belleville S, Gilbert B, Fontaine F, Gagnon L, Ménard E, Gauthier S. Improvement of episodic memory in persons with mild cognitive impairment and healthy older adults: evidence from a cognitive intervention program. Dementia and Geriatric Cognitive Disorders 2006;22(5-6):486-99.

\section{Belleville 2014 \{published data only\}}

Belleville S, Mellah S, de Boysson C, Demonet JF, Bier B. The pattern and loci of training-induced brain changes in healthy older adults are predicted by the nature of the intervention. PLoS One 2014;9(8):e102710.

\section{Berry 2010 \{published data only\}}

Berry AS, Zanto TP, Clapp WC, Hardy JL, Delahunt PB, Mahncke HW, et al. The influence of perceptual training on working memory in older adults. PLoS One 2010;5(7):e11537.

\section{Bier 2015 \{published data only\}}

Bier N, Grenier S, Brodeur C, Gauthier S, Gilbert B, Hudon C, et al. Measuring the impact of cognitive and psychosocial interventions in persons with mild cognitive impairment with a randomized single-blind controlled trial: rationale and design of the MEMO plus study. International Psychogeriatrics 2015;27(3):511-25.

\section{Binder 2016 \{published data only\}}

Binder JC, Martin M, Zöllig J, Röcke C, Mérillat S, Eschen A. Multi-domain training enhances attentional control. Psychology and Aging 2016;31(4):390-408.

\section{Bittner 2013 \{published data only\}}

Bittner DM, Bittner V, Hausmann J, Reinhold D, Machts J, Westphal S, et al. Training intervention improves memory in mild cognitive impairment and healthy controls, but plasma BDNF acts differentially. Conference: International Conference "Aging and Cognition", IfADo 2013 Germany. 2013; Vol. Conference Start: 20130425 Conference End: 20130427 Sponsor: Brain Products - Solutions for
Neurophysiological Research, Dortmund Tourismus, DFG Deutsche Forschungsgemeinsch:49-50.

Borella 2010 \{published data only\}

Borella E, Carretti B, Riboldi F, De Beni R. Working memory training in older adults: evidence of transfer and maintenance effects. Psychology and Aging 2010;25(4):767-78.

Borella 2013 \{published data only\}

Borella E, Carretti B, Zanoni G, Zavagnin M, De Beni R. Working memory training in old age: an examination of transfer and maintenance effects. Archives of Clinical Neuropsychology 2013;28(4):331-47.

\section{Borella 2014 \{published data only\}}

Borella E, Carretti B, Cantarella A, Riboldi F, Zavagnin M, De Beni R. Benefits of training visuospatial working memory in young-old and old-old. Developmental Psychology 2014;50(3):714-27.

\section{Borella 2017 \{published data only\}}

Borella E, Carretti B, Sciore R, Capotosto E, Taconnat L, Cornoldi C, et al. Training working memory in older adults: is there an advantage of using strategies?. Psychology and Aging 2017;32(2):178-91.

\section{Boripuntakul 2012 \{published data only\}}

Boripuntakul S, Kothan S, Methapatara P, Munkhetvit P, Sungkarat $S$. Short-term effects of cognitive training program for individuals with amnestic mild cognitive impairment: a pilot study. Physical \& Occupational Therapy in Geriatrics 2012;30(2):138-49.

\section{Borness 2013 \{published data only\}}

Borness C, Proudfoot J, Crawford J, Valenzuela M. Putting brain training to the test in the workplace: a randomized, blinded, multisite, active-controlled trial. PLOS ONE 2013;8(3):e59982.

\section{Bottiroli 2009 \{published data only\}}

Bottiroli S, Cavallini E. Can computer familiarity regulate the benefits of computer-based memory training in normal aging? A study with an Italian sample of older adults. Neuropsychology, Development, and Cognition. Section B, Aging, Neuropsychology and Cognition 2009; Vol. 16, issue 4:401-18.

\section{Bottiroli 2009a \{published data only\}}

Bottiroli S, Cavallini E. Can computer familiarity regulate the benefits of computer-based memory training in normal aging? A study with an Italian sample of older adults. Neuropsychology, Development, and Cognition. Section B, Aging, Neuropsychology and Cognition 2009;16(4):401-18.

\section{Bozoki 2013 \{published data only\}}

Bozoki A, Radovanovic M, Winn B, Heeter C, Anthony JC. Effects of a computer-based cognitive exercise program on agerelated cognitive decline. Archives of Gerontology and Geriatrics 2013;57(1):1-7. 
Brehmer 2012 \{published data only\}

Brehmer Y, Westerberg H, Bäckman L. Working-memory training in younger and older adults: training gains, transfer, and maintenance. Frontiers in Human Neuroscience 2012;6:63.

\section{Brum 2013 \{published data only\}}

Brum P, Yassuda M, Forlenza O. Memory training in healthy elderly and seniors with mild cognitive impairment: benefits on cognitive parameters. Conference: Alzheimer's Association International Conference 2013 Boston, MA United States. 2013; Vol. Conference Start: 20130713 Conference End: 20130718:P493.

\section{Buitenweg 2017 \{published data only\}}

Buitenweg JI, van de Ven RM, Prinssen S, Murre JM, Ridderinkhof KR. Cognitive flexibility training: a large-scale multimodal adaptive active-control intervention study in healthy older adults. Frontiers in Human Neuroscience 2017;11:529.

\section{Buiza 2008 \{published data only\}}

Buiza C, Etxeberria I, Galdona N, González MF, Arriola E, López de Munain A, et al. A randomized, two-year study of the efficacy of cognitive intervention on elderly people: the Donostia longitudinal study. International Journal of Geriatric Psychiatry. 2008;23(1):85-94.

\section{Bureš 2016 \{published data only\}}

Bureš V, Čech P, Mikulecká J, Ponce D, Kuca K. The effect of cognitive training on the subjective perception of well-being in older adults. PeerJ 2016;4:e2785.

\section{Buschert 2011 \{published data only\}}

Buschert V, Giegling I, Merensky W, Jolk S, Teipel S, Hampel H, et al. Long-term effects of a multi-component cognitive intervention in amnestic mild cognitive impairment $(\mathrm{AMCl})$. Conference: Alzheimer's Association International Conference, AAIC 11 Paris France. 2011; Vol. Conference Start: 20110716 Conference End: 20110721:S513-4.

\section{Buschert 2011a \{published data only\}}

Buschert VC, Friese U, Teipel SJ, Schneider P, Merensky W, Rujescu D, et al. Effects of a newly developed cognitive intervention in amnestic mild cognitive impairment and mild Alzheimer's disease: a pilot study. Journal of Alzheimer's Disease 2011;25(4):679-94.

\section{Buschert 2012 \{published data only\}}

Buschert VC, Giegling I, Teipel SJ, Jolk S, Hampel H, Rujescu D, et al. Long-term observation of a multicomponent cognitive intervention in mild cognitive impairment. Journal of Clinical Psychiatry 2012;73(12):e1492-8.

\section{Buschert 2012a \{published data only\}}

Buschert VC, Giegling I, Teipel SJ, Jolk S, Hampel H, Rujescu D, et al. Long-term observation of a multicomponent cognitive intervention in mild cognitive impairment. Journal of Clinical Psychiatry 2012;73(12):e1492-8.

\section{Buschkuehl 2008 \{published data only\}}

Buschkuehl M, Jaeggi SM, Hutchison S, Perrig-Chiello P, Dapp C, Muller M, et al. Impact of working memory training on memory performance in old-old adults. Psychology and aging 2008;23(4):743-53. [PUBMED: 19140646]

\section{Calkins 2011 \{published data only\}}

Calkins AW, Deveney CM, Weitzman ML, Hearon BA, Siegle GJ, Otto MW. The effects of prior cognitive control task exposure on responses to emotional tasks in healthy participants. Behavioural and Cognitive Psychotherapy 2011;39(2):205-20.

\section{Cammarata 2011 \{published data only\}}

Cammarata S, Novello C, Pollero V, Colucci M. Cognitive rehabilitation in patients with mild cognitive impairment. Conference: 6th Sindem Meeting: Italian Association for the Study of Dementia linked to the Italian Neurological Society, SIN Milan Italy. 2011; Vol. Conference Start: 20110317 Conference End: 20110319:S50.

Cancela 2015 \{published data only\}

Cancela JM, Vila Suarez MH, Vasconcelos J, Lima A, Ayan C. Efficacy of brain gym training on the cognitive performance and fitness level of active older adults: a preliminary study. Journal of Aging and Physical Activity 2015;23(4):653-8.

\section{Candela 2015 \{published data only\}}

Candela F, Zucchetti G, Magistro D, Rabaglietti E. The effects of a physical activity program and a cognitive training program on the long-term memory and selective attention of older adults: a comparative study. Activities, Adaptation \& Aging 2015;39(1):77-91.

\section{Cantarella 2017 \{published data only\}}

Cantarella A, Borella E, Carretti B, Kliegel M, de Beni R. Benefits in tasks related to everyday life competencies after a working memory training in older adults. International Journal of Geriatric Psychiatry 2017;32(1):86-93.

Cao 2016 \{published data only\}

Cao W, Cao X, Hou C, Li T, Cheng Y, Jiang L, et al. Effects of cognitive training on resting-state functional connectivity of default mode, salience, and central executive networks. Frontiers in Aging Neuroscience 2016;8:70.

\section{Carretti 2013 \{published data only\}}

Carretti B, Borella E, Fostinelli S, Zavagnin M. Benefits of training working memory in amnestic mild cognitive impairment: specific and transfer effects. International Psychogeriatrics 2013; Vol. 25, issue 4:617-26.

\section{Casutt 2014 \{published data only\}}

Casutt G, Theill N, Martin M, Keller M, Jäncke L. The drivewise project: driving simulator training increases real driving performance in healthy older drivers. Frontiers in Aging Neuroscience 2014;6:85.

\section{Chapman 2015 \{published data only\}}

Chapman SB, Aslan S, Spence JS, Hart JJ Jr, Bartz EK, Didehbani $\mathrm{N}$, et al. Neural mechanisms of brain plasticity with 
complex cognitive training in healthy seniors. Cerebral Cortex 2015;25(2):396-405.

\section{Chapman 2016 \{published data only\}}

Chapman SB, Aslan S, Spence JS, Keebler MW, DeFina LF, Didehbani N, et al. Distinct brain and behavioral benefits from cognitive vs. physical training: a randomized trial in aging adults. Frontiers in Human Neuroscience 2016;10:338.

\section{Chapman 2017 \{published data only\}}

Chapman SB, Spence JS, Aslan S, Keebler MW. Enhancing innovation and underlying neural mechanisms via cognitive training in healthy older adults. Frontiers in Aging Neuroscience 2017;9:314.

\section{Cheng 2012 \{published data only\}}

Cheng Y, Wu W, Feng W, Wang J, Chen Y, Shen Y, et al. The effects of multi-domain versus single-domain cognitive training in nondemented older people: a randomized controlled trial.. BMC Medicine 2012;10:30.

\section{Cheng 2018 \{published data only\}}

Cheng CP, Chiu-Wa Lam L, Cheng ST. The effects of integrated attention training for older Chinese adults with subjective cognitive complaints: a randomized controlled study. Journal of Applied Gerontology 2018;37(10):1195-214.

\section{Cho 2002 \{published data only\}}

Cho BH, Ku J, Jang DP, Kim S, Lee YH, Kim IY, et al. The effect of virtual reality cognitive training for attention enhancement. Cyberpsychology and Behavior 2002;5(2):129-37.

\section{Cleverley 2012 \{published data only\}}

Cleverley M, Walker Z, Dannhauser T. Engaging patients at high risk of dementia in multimodal cognitive health promoting activities: the ThinkingFit study. Conference: Alzheimer's Association International Conference 2012 Vancouver, BC Canada. 2012; Vol. Conference Start: 20120714 Conference End: 20120719:P220-1.

\section{Cohen-Mansfield 2014 \{published data only\}}

Cohen-Mansfield J, Cohen R, Buettner L, Eyal N, Jakobovits H, Rebok $\mathrm{G}$, et al. Interventions for older persons reporting memory difficulties: a randomized controlled pilot study. International Journal of Geriatric Psychiatry 2015;30(5):478-86.

\section{Cohen-Mansfield 2014a \{published data only\}}

Cohen-Mansfield J, Cohen R, Buettner L, Eyal N, Jakobovits H, Rebok G, et al. Interventions for older persons reporting memory difficulties: a randomized controlled pilot study. International Journal of Geriatric Psychiatry 2014;30(5):478-86.

\section{Cohen-Mansfield 2015 \{published data only\}}

Cohen-Mansfield J, Cohen R, Buettner L, Eyal N, Jakobovits H, Rebok $\mathrm{G}$, et al. Interventions for older persons reporting memory difficulties: a randomized controlled pilot study. International Journal of Geriatric Psychiatry 2015;30(5):478-86.

\section{Cohen-Mansfield 2015a \{published data only\}}

Cohen-Mansfield J, Cohen R, Buettner L, Eyal N, Jakobovits H, Rebok $\mathrm{G}$, et al. Interventions for older persons reporting memory difficulties: a randomized controlled pilot study. International Journal of Geriatric Psychiatry 2015;30(5):478-86.

Combourieu 2014 \{published data only\}

Combourieu L, Perrot A, Bloch F, Seux ML, Kemoun G. Effect of three different trainings on executive function and gait speed in $\mathrm{MCl}$ old adults. Conference: 19th European Congress of Physical and Rehabilitation Medicine Marseille France. 2014; Vol. Conference Start: 20140526 Conference End: 20140531:e138.

Corbett 2015 \{published data only\}

Corbett A, Owen A, Hampshire A, Grahn J, Stenton R, Dajani S, et al. The effect of an online cognitive training package in healthy older adults: an online randomized controlled trial. Journal of the American Medical Directors Association 2015;16(11):990-7.

Costa 2015 \{published data only\}

Costa NB, Aramaki F, Cecato J, Stella B, Araujo I, Aprahamian I, et al. Benefits of a computer-based cognitive training program for elderly subjects with mild Alzheimer's disease. Conference: 17th IPA International Congress Berlin Germany. 2015; Vol. Conference Start: 20151013 Conference End: 20151016:S119.

Danassi 2015 \{published data only\}

Danassi E. SOCIABLE: a surface computing platform empowering effective cognitive training for healthy and cognitively impaired elderly. Advances in Experimental Medicine and Biology 2015;821:129-30.

\section{Dannhauser 2014 \{published data only\}}

Dannhauser TM, Cleverley M, Whitfield TJ, Fletcher BC, Stevens T, Walker Z. A complex multimodal activity intervention to reduce the risk of dementia in mild cognitive impairment - ThinkingFit: pilot and feasibility study for a randomized controlled trial. BMC Psychiatry 2014;14:129.

\section{de Almondes 2017 \{published data only\}}

de Almondes KM, Leonardo ME, Moreira AM. Effects of a cognitive training program and sleep hygiene for executive functions and sleep quality in healthy elderly. Dementia \& Neuropsychologia 2017;11(1):69-78.

\section{de Macedo 2015 \{published data only\}}

de Macedo LD, De Oliveira TC, Soares FC, Bento-Torres J, Bento-Torres NV, Anthony DC, et al. Beneficial effects of multisensory and cognitive stimulation in institutionalized elderly: 12-months follow-up. Clinical Interventions in Aging 2015;10:1351-9.

\section{De Vreesse 1996 \{published data only\}}

De Vreese LP, Neri M, Boiardi R, Ferrari P, Belloi L, Salvioli G. Memory training and drug therapy act differently on memory and metamemory functioning: evidence from a pilot study. Archives of Gerontology and Geriatrics 1996;22(Suppl 1):9-22.

\section{Diamond 2015 \{published data only\}}

Diamond K, Mowszowski L, Cockayne N, Norrie L, Paradise M, Hermens DF, et al. Randomized controlled trial of a healthy brain ageing cognitive training program: effects on memory, mood, and sleep. Journal of Alzheimer's Disease 2015;44(4):1181-91. 
Dittmann-Kohli 1991 \{published data only\}

Dittmann-Kohli F, Lachman ME, Kliegl R, Baltes PB. Effects of cognitive training and testing on intellectual efficacy beliefs in elderly adults. Journal of Gerontology 1991;46(4):P162-4.

\section{Djabelkhir 2017 \{published data only\}}

Djabelkhir L, Wu YH, Vidal JS, Cristancho-Lacroix V, Marlats F, Lenoir $\mathrm{H}$, et al. Computerized cognitive stimulation and engagement programs in older adults with mild cognitive impairment: comparing feasibility, acceptability, and cognitive and psychosocial effects. Clinical Interventions in Aging 2017;12:1967-75.

\section{Duncan 2009 \{published data only\}}

Duncan NL, Greenaway MC. The memory support system for mild cognitive impairment: emotional impacts of a cognitive rehabilitation program. Conference: 29th Annual Meeting of the National Academy of Neuropsychology New Orleans, LA United States. 2009; Vol. Conference Start: 20091111 Conference End: 20091114:438.

\section{Dwolatzky 2005 \{published data only\}}

Dwolatzky T. The effect of computerized cognitive training on neuropsychological measures of cognitive function in the elderly. NCT00146263 2005.

\section{Eckroth-Bucher 2009 \{published data only\}}

Eckroth-Bucher M, Siberski J. Preserving cognition through an integrated cognitive stimulation and training program. American Journal of Alzheimer's Disease and Other Dementias 2009;24(3):234-45.

\section{Edwards 2005 \{published data only\}}

Edwards JD, Wadley VG, Vance DE, Wood K, Roenker DL, Ball KK. The impact of speed of processing training on cognitive and everyday performance. Aging and Mental Health 2005;9(3):262-71.

\section{Edwards 2011 \{published data only\}}

Edwards JD. Cognitive speed of processing training transfers to improved functional performance. Conference: International Conference "Aging and Cognition" 2010 Dortmund Germany. 2011; Vol. Conference Start: 20101014 Conference End: 20101016:10.

\section{Edwards 2015 \{published data only\}}

Edwards JD, Valdés EG, Peronto C, Castora-Binkley M, Alwerdt J, Andel $R$, et al. The efficacy of insight cognitive training to improve useful field of view performance: a brief report. Journals of Gerontology. Series B, Psychological Sciences and Social Sciences 2015;70(3):417-22.

\section{Edwards 2015a \{published data only\}}

Edwards JD, Valdés EG, Peronto C, Castora-Binkley M, Alwerdt J, Andel $R$, et al. The efficacy of insight cognitive training to improve useful field of view performance: a brief report. Journals of Gerontology. Series B, Psychological Sciences and Social Sciences 2015;70(3):417-22.

\section{Efthymiou 2011 \{published data only\}}

Efthymiou A, Konstantinidis V, Tryfonopoulos E, Karpathiou N, Dimakopoulou E, Nikolaou C, et al. Non-pharmacological intervention: effectiveness of a multi-component rehabilitation program on cognitive functions of people with mild cognitive impairment. Conference: Alzheimer's Association International Conference, AAIC 11 Paris France. 2011; Vol. Conference Start: 20110716 Conference End: 20110721:S643.

\section{Engvig 2014 \{published data only\}}

Engvig A, Fjell AM, Westlye LT, Skaane NV, Dale AM, Holland D, et al. Effects of cognitive training on gray matter volumes in memory clinic patients with subjective memory impairment. Journal of Alzheimer's Disease 2014;41(3):779-91.

\section{Fabre 2002 \{published data only\}}

Fabre C, Chamari K, Mucci P, Massé-Biron J, Préfaut C. Improvement of cognitive function by mental and/or individualized aerobic training in healthy elderly subjects. International Journal of Sports Medicine. 2002;23(6):415-21.

\section{Faille 2007 \{published data only\}}

Faille L. Performance on a brain-plasticity-based memorytraining computer program for the elderly as influenced by cognitive functioning and gender. Thesis 2007;68(3-B):1922.

\section{Fairchild 2010 \{published data only\}}

Fairchild JK, Scogin FR. Training to enhance adult memory (TEAM): an investigation of the effectiveness of a memory training program with older adults. Aging and Mental Health 2010;14(3):364-73.

\section{Feng 2013 \{published data only\}}

Feng W, Li CB, Chen Y, Cheng Y, Wu WY. Integrative cognitive training for healthy elderly Chinese in community: a controlled study. Allied Academics 2013;24(2):223-9.

\section{Feng 2015 \{published data only\}}

Feng W, Yokoyama JS, Yu S, Chen Y, Cheng Y, Bonham LW, et al. APOE genotype affects cognitive training response in healthy Shanghai community-dwelling elderly individuals. Journal of Alzheimer's Disease 2015;47(4):1035-46.

\section{Feng 2017 \{published data only\}}

Feng H, Li G, Xu C, Ju C, Qiu X. Training rehabilitation as an effective treatment for patients with vascular cognitive impairment with no dementia. Rehabilitation Nursing 2017;42(5):290-7.

\section{Fiatarone Singh 2014 \{published data only\}}

Fiatarone Singh MA, Gates N, Saigal N, Wilson GC, Meiklejohn J, Brodaty $\mathrm{H}$, et al. The study of mental and resistance training (SMART) study - resistance training and/or cognitive training in mild cognitive impairment: a randomized, double-blind, double-sham controlled trial. Journal of the American Medical Directors Association 2014;15(12):873-80.

\section{Finn 2011 \{published data only\}}

Finn M, McDonald S. Computerised cognitive training for older persons with mild cognitive impairment: a pilot study 
using a randomised controlled trial design. Brain Impairment 2011;12(3):187-99.

\section{Finn 2015 \{published data only\}}

Finn M, McDonald S. Repetition-lag training to improve recollection memory in older people with amnestic mild cognitive impairment. A randomized controlled trial. Neuropsychology, Development, and Cognition. Section B, Aging, Neuropsychology and Cognition 2015;22(2):244-58.

\section{Finn 2015a $\{$ published data only\}}

Finn M, McDonald S. Repetition-lag training to improve recollection memory in older people with amnestic mild cognitive impairment. A randomized controlled trial. Neuropsychology, Development, and Cognition. Section B, Aging, Neuropsychology and Cognition 2015;22(2):244-58.

\section{Flak 2013 \{published data only\}}

Flak M, Hernes SS, Skranes J, Lohaugen GC. Memory aidcomputer based working memory training in elderly with mild cognitive impairment $(\mathrm{MCl})$. A randomized, controlled trial. Conference: 21st World Congress of Neurology Vienna Austria. 2013; Vol. Conference Start: 20130921 Conference End: 20130926:e322-3.

\section{Flak 2014 \{published data only\}}

Flak MM, Hernes SS, Chang L, Ernst T, Douet V, Skranes J, et al. The memory aid study: protocol for a randomized controlled clinical trial evaluating the effect of computer-based working memory training in elderly patients with mild cognitive impairment (MCl). Trials 2014;15:156.

\section{Flak 2014a \{published data only\}}

Flak MM, Hernes SS, Chang L, Ernst T, Douet V, Skranes J, et al. The memory aid study: protocol for a randomized controlled clinical trial evaluating the effect of computer-based working memory training in elderly patients with mild cognitive impairment (MCl). Trials 2014;15:156.

\section{Flak 2016 \{published data only\}}

Flak MM, Hernes SS, Chang L, Ernst T, Douet V, Skranes J, et al. Erratum to: 'The memory aid study: protocol for a randomized controlled clinical trial evaluating the effect of computer-based working memory training in elderly patients with mild cognitive impairment (MCl)'.[Erratum for Trials. 2014;15:156 Note: Chang, Linda; Ernst, Thomas; and Douet, Vanessa [Added]; PMID: 24886034]. Trials 2016;17:40.

\section{Foerster 2009 \{published data only\}}

Foerster S, Buschert VC, Buchholz HG, Teipel SJ, Zach C, Hampel $\mathrm{H}$, et al. Positive effects of a 6-month stage-specific cognitive intervention program on brain metabolism in subjects with amnestic mild cognitive impairment (AMCl) and mild Alzheimer's disease (AD). Conference: Alzheimer's Association International Conference on Alzheimer's Disease Vienna Austria. 2009; Vol. Conference Start: 20090711 Conference End: 20090716:38

\section{Forloni 2012 \{published data only\}}

Forloni G, Polito L, Davin A, Abbondanza S, Vaccaro R, Valle E. Cognitive stimulation and APOE genotype in non-demented elderly subjects: a randomized controlled study (RCT). Conference: 5th Conference Clinical Trials on Alzheimer's Disease Monte Carlo Monaco. 2012; Vol. Conference Start: 20121029 Conference End: 20121031:841-2.

\section{Forster 2011 \{published data only\}}

Forster S, Buschert VC, Teipel SJ, Friese U, Buchholz HG, Drzezga A, et al. Effects of a 6-month cognitive intervention on brain metabolism in patients with amnestic $\mathrm{MCl}$ and mild Alzheimer's disease. Journal of Alzheimer's Disease 2011;26(3):605-16.

\section{Fortman 2013 \{published data only\}}

Fortman J. Computer-based cognitive training for age-related cognitive decline and mild cognitive impairment. Thesis 2013;74(5-B(E)):1-69.

\section{Gagnon 2012 \{published data only\}}

Gagnon LG, Belleville S. Training of attentional control in mild cognitive impairment with executive deficits: results from a double-blind randomised controlled study. Neuropsychological Rehabilitation 2012;22(6):809-35.

\section{Gagnon 2012a \{published data only\}}

Gagnon L. Working memory in Alzheimer's disease and mild cognitive impairment $(\mathrm{MCl})$ : assessment and intervention. Thesis 2012;73(5-B):3262.

\section{Gaitan 2013 \{published data only\}}

Gaitán A, Garolera M, Cerulla N, Chico G, Rodriguez-Querol M, Canela-Soler J. Efficacy of an adjunctive computer-based cognitive training program in amnestic mild cognitive impairment and Alzheimer's disease. International Journal of Geriatric Psychiatry 2013;28(1):91-9.

\section{Gajewski 2012 \{published data only\}}

Gajewski PD, Falkenstein M. Training-induced improvement of response selection and error detection in aging assessed by task switching: effects of cognitive, physical, and relaxation training. Frontiers in Human Neuroscience 2012;6:130.

\section{Gajewski 2017 \{published data only\}}

Gajewski PD, Freude G, Falkenstein M. Cognitive training sustainably improves executive functioning in middle-aged industry workers assessed by task switching: a randomized controlled ERP study. Frontiers in Human Neuroscience 2017;11:81.

\section{Garcia-Campuzano 2013 \{published data only\}}

Garcia-Campuzano MT, Virues-Ortega J, Smith S, Moussavi Z. Effect of cognitive training targeting associative memory in the elderly: a small randomized trial and a longitudinal evaluation. Journal of the American Geriatrics Society 2013;61(12):2252-4.

\section{Gates 2011 \{published data only\}}

Gates NJ, Valenzuela M, Sachdev PS, Singh NA, Baune BT, Brodaty $\mathrm{H}$, et al. Study of mental activity and regular training (SMART) in at risk individuals: a randomised double blind, sham controlled, longitudinal trial. BMC Geriatrics 2011;11:19. 


\section{Gill 2016 \{published data only\}}

Gill DP, Gregory MA, Zou G, Liu-Ambrose T, Shigematsu R, Hachinski V, et al. The healthy mind, healthy mobility trial: a novel exercise program for older adults. Medicine and Science in Sports and Exercise 2016;48(2):297-306.

Gillette 2009 \{published data only\}

Gillette S. The multidomain Alzheimer preventive trial (MAPT): a new approach for the prevention of Alzheimer's disease. Conference: Alzheimer's Association International Conference on Alzheimer's Disease Vienna Austria. 2009; Vol. Conference Start: 20090711 Conference End: 20090716:145.

\section{Giovannini 2015 \{published data only\}}

Giovannini E, Borso E, Benso F, Carabelli E, Del Sette M, Ciarmiello A. FDG-PET in the evaluation of brain metabolic changes induced by cognitive stimulation in a $\mathrm{MCl}$ subjects. Conference: 28th Annual Congress of the European Association of Nuclear Medicine, EANM 2015 Hamburg Germany. 2015; Vol. Conference Start: 20151010 Conference End: 20151014:S552-3.

\section{Giuli 2016 \{published data only\}}

Giuli C, Papa R, Lattanzio F, Postacchini D. The effects of cognitive training for elderly: results from my mind project. Rejuvenation Research 2016;19(6):485-94

\section{Giuli 2017 \{published data only\}}

Giuli C, Fattoretti P, Gagliardi C, Mocchegiani E, Venarucci D, Balietti M, et al. My mind project: the effects of cognitive training for elderly - the study protocol of a prospective randomized intervention study. Aging Clinical and Experimental Research 2017;29(3):353-60.

Golino 2017 \{published data only\}

Golino MT, Flores Mendoza C, Golino HF. Effects of cognitive training on cognitive performance of healthy older adults. Spanish Journal of Psychology 2017;20:E39.

\section{Gooding 2016 \{published data only\}}

Gooding AL, Choi J, Fiszdon JM, Wilkins K, Kirwin PD, van Dyck $\mathrm{CH}$, et al. Comparing three methods of computerised cognitive training for older adults with subclinical cognitive decline. Neuropsychological Rehabilitation 2016;26(5-6):810-21.

\section{Haesner 2015 \{published data only\}}

Haesner M, O'Sullivan JL, Gövercin M, Steinhagen-Thiessen E. Requirements of older adults for a daily use of an internetbased cognitive training platform. Informatics for Health and Social Care 2015;40(2):139-53.

\section{Haesner 2015a \{published data only\}}

Haesner M, Steinert A, O'Sullivan JL, Weichenberger M. Evaluating an online cognitive training platform for older adults: user experience and implementation requirements. Journal of Gerontological Nursing 2015;41(8):22-31.

Haimov 2013 \{published data only\} Haimov I, Shatil E. Protocol_S1.doc.PLoS One 2013;8(4):e61390.

Haimov 2013a \{published data only\} Haimov I, Shatil E. Checklist_S1.pdf. PLoS One 2013;8(4):e61390.
Haimov 2013b \{published data only\}

Haimov I, Shatil E. Cognitive training improves sleep quality and cognitive function among older adults with insomnia. PLoS One 2013;8(4):e61390.

\section{Haimov 2013c \{published data only\}}

Haimov I, Shatil E. Cognitive training improves sleep quality and cognitive function among older adults with insomnia. PLoS One 2013;8(4):e61390.

\section{Haimov 2013d \{published data only\}}

Haimov I, Shatil E. Cognitive training improves sleep quality and cognitive function among older adults with insomnia. Conference: 5 th International World Association of Sleep Medicine Congress and the 22nd Annual Congress of the Spanish Sleep Society Valencia Spain. 2013; Vol. Conference Start: 20130928 Conference End: 20131002:e61390.

\section{Haimov 2014 \{published data only\}}

Haimov I, Shatil E. Cognitive training improves sleep quality and cognitive function among older adults with insomnia. Conference: 22nd Annual Meeting of the Israel Society for Neuroscience, ISFN and the 2nd Bi national Italy-Israel Neuroscience Meeting Eilat Israel. 2014; Vol. Conference Start: 20131214 Conference End: 20131217:S60.

\section{Haimov 2014a \{published data only\}}

Haimov I, Shatil E. Cognitive training improves sleep quality and cognitive function among older adults with insomnia. Conference: 22nd Congress of the European Sleep Research Society Tallinn Estonia. 2014; Vol. Conference Start: 20140916 Conference End: 20140920:137.

\section{Hardy 2015 \{published data only\}}

Hardy JL, Nelson RA, Thomason ME, Sternberg DA, Katovich K, Farzin $\mathrm{F}$, et al. Enhancing cognitive abilities with comprehensive training: a large, online, randomized, active-controlled trial. PLoS One 2015;10(9):e0134467.

\section{Hausmann 2012 \{published data only\}}

Hausmann J, MacHts J, Bittner V, Mueller N, Heinze HJ, Bittner D. No title provided. Conference: Alzheimer's Association International Conference 2012 Vancouver, BC Canada. 2012; Vol. Conference Start: 20120714 Conference End: 20120719:P393.

\section{Hayashi 2012 \{published data only\}}

Hayashi N, Morihara T, Kazui H, Kono A, Iwase M, Hamasaki T, et al. Cognitive training and occupational recreational therapy on elderly Japanese in Osaka: major outcome (ADAS) from prospective, randomized, open, blind-endpoint trial. Alzheimer's and Dementia 2012;7(4):S644.

\section{Hayslip B Jr 2016 \{published data only\}}

Hayslip B Jr, Paggi K, Caballero D. The impact of mental aerobics training on older adults. Journal of Applied Gerontology 2016;35(11):1130-53.

\section{Heinzel 2014 \{published data only\}}

Heinzel S, Schulte S, Onken J, Duong QL, Riemer TG, Heinz A, et al. Working memory training improvements and gains

Computerised cognitive training for 12 or more weeks for maintaining cognitive function in cognitively healthy people in late life 
in non-trained cognitive tasks in young and older adults. Neuropsychology, Development, and Cognition. Section B, Aging, Neuropsychology and Cognition 2014;21(2):146-73.

\section{Herrera 2012 \{published data only\}}

Herrera C, Chambon C, Michel BF, Paban V, Alescio-Lautier B. Positive effects of computer-based cognitive training in adults with mild cognitive impairment. Neuropsychologia 2012;50(8):1871-81.

\section{Hötting 2013 \{published data only\}}

Hötting K, Holzschneider K, Stenzel A, Wolbers T, Röder B. Effects of a cognitive training on spatial learning and associated functional brain activations. BMC Neuroscience 2013;14:73.

\section{Hudak 2013 \{published data only\}}

Hudak EM. The effects of cognitive stimulation and computerized memory training among older adults residing in independent-living facilities. Thesis 2013;74(1-B(E)):1-69.

\section{Hughes 2014 \{published data only\}}

Hughes TF, Flatt JD, Fu B, Butters MA, Chang CC, Ganguli M. Interactive video gaming compared with health education in older adults with mild cognitive impairment: a feasibility study. International journal of geriatric psychiatry 2014;29(9):890-8. [PUBMED: 24452845]

\section{Ignjatovic 2015 \{published data only\}}

Ignjatović VB, Kalabić S, Batić S, Žikić M. Improvement of cognitive efficiency through cognitive training in healthy subjects. Acta Clinica Croatica 2015;54(2):169-78.

\section{Irigaray 2012 \{published data only\}}

Irigaray Quarti T, Gomes Filho I, Schneider RH. Effects of an attention, memory and executive functions training on the cognition of healthy elderly people. Psicologia: Reflexão e Crítica 2012;25(1):188-202.

\section{Israel 1997 \{published data only\}}

Israël L, Myslinski M, Dubos G, Mélac M. [Combined therapies in family practice and hospitals. A controlled clinical study of a population of 162 patients with criteria of age-related memory disorders]. [French]. Presse Médicale 1997;26(25):1186-91.

\section{ISRCTN70130279 \{published data only\}}

ISRCTN70130279. Effects of the six-month training on cognitive, physical performance, and daily physical activity in older adults. isrctn.com.

\section{Jackson 2012 \{published data only\}}

Jackson JJ, Hill PL, Payne BR, Roberts BW, Stine-Morrow EA. Can an old dog learn (and want to experience) new tricks? Cognitive training increases openness to experience in older adults. Psychology and Aging 2012;27(2):286-92.

\section{Jansen 2012 \{published data only\}}

Jansen P, Dahmen-Zimmer K. Effects of cognitive, motor, and karate training on cognitive functioning and emotional wellbeing of elderly people. Frontiers in Psychology 2012;3:40.
Jean 2010 \{published data only\}

Jean L, Simard M, Wiederkehr S, Bergeron ME, Turgeon Y, Hudon C, et al. Efficacy of a cognitive training programme for mild cognitive impairment: results of a randomised controlled study. Neuropsychological Rehabilitation 2010;20(3):377-405.

\section{Jeong 2016 \{published data only\}}

Jeong JH, Na HR, Choi SH, Kim J, Na DL, Seo SW, et al. Groupand home-based cognitive intervention for patients with mild cognitive impairment: a randomized controlled trial. Psychotherapy and Psychosomatics 2016;85(4):198-207.

\section{Jobe 2001 \{published data only\}}

Jobe JB, Smith DM, Ball K, Tennstedt SL, Marsiske M, Willis SL, et al. ACTIVE: a cognitive intervention trial to promote independence in older adults. Controlled Clinical Trials 2001;22(4):453-79.

\section{Jones 2013 \{published data only\}}

Jones RN, Marsiske M, Ball K, Rebok G, Willis SL, Morris JN, et al. The ACTIVE cognitive training interventions and trajectories of performance among older adults. Journal of Aging and Health 2013;25(8 Suppl):186S-208S

\section{Kampanaros 2010 \{published data only\}}

Kampanaros D, Weber IL, Endler PC. Conventional and complementary interventions and cognitive performance in old age. Conference: 3rd European Congress for Integrative Medicine, ECIM 2010 Berlin Germany. 2010; Vol. Conference Start: 20101203 Conference End: 20101204:264.

\section{Kholin 2010 \{published data only\}}

Kholin V. Cognitive-emotional stimulation in mild cognitive impairment. Conference: 14th Congress of the European Federation of Neurological Societies, EFNS Geneva Switzerland. 2010; Vol. Conference Start: 20100925 Conference End: 20100928:362.

\section{Kim 2012 \{published data only\}}

Kim GH, Jeon S, Lee BH, Kim HS, Chin JH, Kim GY. Robot assisted cognitive training can change the brain in the elderly: a single blind, randomized controlled trial of clinical efficacy. Conference: 5th Conference Clinical Trials on Alzheimer's Disease Monte Carlo Monaco. 2012; Vol. Conference Start: 20121029 Conference End: 20121031:865-6.

\section{Kim 2013 \{published data only\}}

Kim HJ, Yang YS, Choi KH, Kim TY. The effect of computerbased cognitive training program on cognition. Dementia and Neurocognitive Disorders 2013;12(4):87-93.

Kim 2013a \{published data only\}

Kim GH, Jeon S, Im K, Seo SW, Cho H, Noh Y, et al. Structural brain changes after robot-assisted cognitive training in the elderly: a single-blind randomized controlled trial. Alzheimers and Dementia 2013;9(4):P476-7.

Kim 2015 \{published data only\}

Kim GH, Jeon S, Im K, Kwon H, Lee BH, Kim GY, et al. Structural brain changes after traditional and robot-assisted multi-domain 
cognitive training in community-dwelling healthy elderly. PLOS One 2015;10(4):e0123251.

\section{Kim 2015a \{published data only\}}

Kim KW, Choi Y, You H, Na DL, Yoh MS, Park JK, et al. Effects of a serious game training on cognitive functions in older adults. Journal of the American Geriatrics Society 2015;63(3):603-5.

\section{Kim 2015b \{published data only\}}

Kim GH, Jeon S, Im K, Kwon H, Lee BH, Kim GY, et al. Structural brain changes after traditional and robot-assisted multi-domain cognitive training in community-dwelling healthy elderly. PLOS One 2015;10(4):e0123251.

\section{Kivipelto 2014 \{published data only\}}

Kivipelto M, Ngandu T, Lehtisalo J, Hanninen T, Jula A, Laatikainen $\mathrm{T}$, et al. A multidomain two-year randomized controlled trial to prevent cognitive impairment - the FINGER study. Conference: 10th International Congress of the European Union Geriatric Medicine Society - Geriatric Medicine Crossing Borders, EUGMS 2014 Rotterdam Netherlands. 2014; Vol. Conference Start: 20140917 Conference End: 20140919:S69.

\section{Klusmann 2009 \{published data only\}}

Klusmann V, Evers A, Schwarzer R, Dimeo FC, Reischies FM, Heuser I. Complex mental and physical activity in older women maintains episodic memory and working memory: a 6-month randomized controlled trial. Conference: 64 th Annual Scientific Convention and Meeting of the Society of Biological Psychiatry Vancouver, BC, Canada. 2009; Vol. Conference Start: 20090514 Conference End: 20090516:106S.

\section{Klusmann 2010a \{published data only\}}

Klusmann V, Evers A, Schwarzer R, Schlattmann P, Reischies FM, Heuser I. Complex mental and physical activity in older women and cognitive performance: a 6-month randomized controlled trial. Journals of Gerontology. Series A, Biological Sciences and Medical Sciences 2010;65(6):680-8.

\section{Klusmann 2011 \{published data only\}}

Klusmann V, Evers A, Heuser I. Cognitive benefits from mental and physical activity in older women: results from the Berlin stays fit study. Conference: International Conference "Aging and Cognition" 2010 Dortmund Germany. 2011; Vol. Conference Start: 20101014 Conference End: 20101016:18.

\section{Kudelka 2014 \{published data only\}}

McDaniel MA, Binder EF, Bugg JM, Waldum ER, Dufault C, Meyer A, et al. Effects of cognitive training with and without aerobic exercise on cognitively demanding everyday activities. Psychology and Aging 2014;29(3):717-30.

\section{Kwak 2015 \{published data only\}}

Kwak KP, Lee S, Kim T, Bae N. Cognitive training programs for very old lone adults in a Korean rural community. Conference: Alzheimer's Association International Conference 2015 Washington, DC, United States. 2015; Vol. Conference Start: 20150718 Conference End: 20150723:P590.

\section{Kwak 2017 \{published data only\}}

Kwak K, Kim T. Cognitive stimulation intervention improves BDNF peripheral levels in older adults with non-amnestic mild cognitive impairment. Alzheimer's \& dementia. 2017; Vol. Alzheimer's Association International Conference, AAIC 2017. United Kingdom:P860-1.

\section{Kwok 2013 \{published data only\}}

Kwok T, Wong A, Chan G, Shiu YY, Lam KC, Young D, et al. Effectiveness of cognitive training for Chinese elderly in Hong Kong. Clinical Interventions in Aging 2013;8:213-9.

\section{Kwok 2013a \{published data only\}}

Kwok TC, Bai X, Li JC, Ho FK, Lee TM. Effectiveness of cognitive training in Chinese older people with subjective cognitive complaints: a randomized placebo-controlled trial. International Journal of Geriatric Psychiatry 2013;28(2):208-15.

\section{Lampit 2013 \{published data only\}}

Lampit A, Hallock H, Moss R, Kwok S, Rosser M, Lukjanenko M, et al. A dose-response relationship between computerized cognitive training and global cognition in older adults. Conference: 6th Conference Clinical Trials on Alzheimer's Disease San Diego, CA, United States. 2013; Vol. Conference Start: 20131114 Conference End: 20131116:803-4.

\section{Lavretsky 2016 \{published data only\}}

Lavretsky H. Changes in the functional brain connectivity and cognitive performance following yoga or memory training in older adults with subjective memory complaints. Conference: 71st Annual Scientific Convention and Meeting of the Society of Biological Psychiatry, SOBP 2016 Atlanta, GA, United States. 2016; Vol. Conference Start: 20160512 Conference End: 20160514:209S.

\section{Law 2014 \{published data only\}}

Law LL, Barnett F, Yau MK, Gray MA. Effects of functional tasks exercise on older adults with cognitive impairment at risk of Alzheimer's disease: a randomised controlled trial. Age and Ageing 2014;43(6):813-20.

\section{Law 2014a \{published data only\}}

Law LL, Barnett F, Yau MK, Gray MA. Effects of functional tasks exercise on older adults with cognitive impairment at risk of Alzheimer's disease: a randomised controlled trial. Age and Ageing 2014;43(6):813-20.

Lee 2013 \{published data only\}

Lee YM, Jang C, Bak IH, Yoon JS. Effects of computer-assisted cognitive rehabilitation training on the cognition and static balance of the elderly. Journal of Physical Therapy Science 2013;25(11):1475-7.

\section{Lee 2013a \{published data only\}}

Lee TS, Goh SJ, Quek SY, Phillips R, Guan C, Cheung YB, et al. A brain-computer interface based cognitive training system for healthy elderly: a randomized control pilot study for usability and preliminary efficacy. PLoS One 2013;8(11):e79419. 


\section{Lee 2013b \{published data only\}}

Lee TS, Goh SJ, Quek SY, Guan C, Cheung YB, Krishnan KR. Efficacy and usability of a brain computer interface system in improving cognition in the elderly. Conference: Alzheimer's Association International Conference 2013 Boston, MA, United States. 2013; Vol. Conference Start: 20130713 Conference End: 20130718:P296.

\section{Lee 2014 \{published data only\}}

Lee TS, Goh AS, Quek SY, Phillips R, Guan C, Cheung YB, et al. Pilot trials of EEG-based brain-computer interface $(\mathrm{BCl})$ training system for improving cognitive performance in older persons. Conference: NUHS Academic Psychiatry Conference 2014 Singapore Singapore. 2014; Vol. Conference Start: 20141031 Conference End: 20141101:S27.

\section{Lee 2015 \{published data only\}}

Lee TS, Quek SY, Goh SJ, Phillips R, Guan C, Cheung YB, et al. A pilot randomized controlled trial using EEG-based braincomputer interface training for a Chinese-speaking group of healthy elderly. Clinical Interventions in Aging 2015;10:217-27.

\section{León 2015 \{published data only\}}

León J, Ureña A, Bolaños MJ, Bilbao A, Oña A. A combination of physical and cognitive exercise improves reaction time in persons 61-84 years old. Journal of Aging and Physical Activity 2015;23(1):72-7.

\section{Li 2010 \{published data only\}}

Li KZ, Roudaia E, Lussier M, Bherer L, Leroux A, McKinley PA. Benefits of cognitive dual-task training on balance performance in healthy older adults. Journals of Gerontology. Series A, Biological Sciences and Medical Sciences 2010;65(12):1344-52.

\section{Linde 2014 \{published data only\}}

Linde K, Alfermann D. Single versus combined cognitive and physical activity effects on fluid cognitive abilities of healthy older adults: a 4-month randomized controlled trial with followup. Journal of Aging and Physical Activity 2014;22(3):302-13.

\section{Mace 2015 \{published data only\}}

Mace RA, Mansbach WE. The efficacy of a computer-assisted cognitive rehabilitation program for patients with mild cognitive deficits: a pilot study. Conference: Alzheimer's Association International Conference 2015 Washington, DC, United States. 2015; Vol. Conference Start: 20150718 Conference End: 20150723:P783.

\section{Mahncke 2006 \{published data only\}}

Mahncke HW, Connor BB, Appelman J, Ahsanuddin ON, Hardy JL, Wood RA, et al. Memory enhancement in healthy older adults using a brain plasticity-based training program: a randomized, controlled study. Proceedings of the National Academy of Sciences of the United States of America 2006;103(33):12523-8.

\section{Maillot 2012 \{published data only\}}

Maillot P, Perrot A, Hartley A. Effects of interactive physicalactivity video-game training on physical and cognitive function in older adults. Psychology and Aging 2012;27(3):589-600. [PUBMED: 22122605]

\section{Man 2012 \{published data only\}}

Man DW, Chung JC, Lee GY. Evaluation of a virtual reality-based memory training programme for Hong Kong Chinese older adults with questionable dementia: a pilot study. International Journal of Geriatric Psychiatry 2012;27(5):513-20.

Mann 2012 \{published data only\}

* Mann D, Szwanki VL, Mistry JJ. The effect of brain training on cognitive assessment: a pilot investigation. Conference: 10th Annual Conference on Brain Injury of the North American Brain Injury Society's, NABIS 2012 Miami, FL, United States. 2012; Vol. Conference Start: 20120912 Conference End: 20120915:E39-40.

\section{Margrett 2006 \{published data only\}}

Margrett JA, Willis SL. In-home cognitive training with older married couples: individual versus collaborative learning. Neuropsychology, Development, and Cognition. Section B, Aging, Neuropsychology and Cognition 2006;13(2):173-95.

\section{Mayas 2014 \{published data only\}}

Mayas J, Parmentier FB, Andrés P, Ballesteros S. Plasticity of attentional functions in older adults after non-action video game training: a randomized controlled trial. PLoS One 2014;9(3):e92269.

\section{McAvinue 2013 \{published data only\}}

McAvinue LP, Golemme M, Castorina M, Tatti E, Pigni FM, Salomone $S$, et al. An evaluation of a working memory training scheme in older adults. Frontiers in Aging Neuroscience 2013;5:20.

\section{McDaniel 2014 \{published data only\}}

McDaniel MA, Binder EF, Bugg JM, Waldum ER, Dufault C, Meyer A, et al. Effects of cognitive training with and without aerobic exercise on cognitively demanding everyday activities. Psychology and Aging 2014;29(3):717-30.

\section{McDougall 2012 \{published data only\}}

McDougall S, House B. Brain training in older adults: evidence of transfer to memory span performance and pseudo-Matthew effects. Neuropsychology, Development, and Cognition. Section B, Aging, Neuropsychology and Cognition 2012;19(1-2):195-221.

\section{Middleton 2012 \{published data only\}}

Middleton LE, Poelke G, Santos WM, Yaffe K, Barnes DE, Goodson W. Impact of a 12-week exercise intervention on non-cognitive outcomes in sedentary elders with cognitive complaints or mild cognitive impairment: findings from the max trial. Conference: Alzheimer's Association International Conference 2012, Vancouver, BC, Canada. 2012; Vol. Conference Start: 20120714 Conference End: 20120719:P146.

\section{Miller 2013 \{published data only\}}

Miller KJ, Dye RV, Kim J, Jennings JL, O'Toole E, Wong J, et al. Effect of a computerized brain exercise program on cognitive performance in older adults. American Journal of Geriatric Psychiatry 2013;21(7):655-63.

\section{Mohs 1998 \{published data only\}}

Mohs RC, Ashman TA, Jantzen K, Albert M, Brandt J, Gordon B, et al. A study of the efficacy of a comprehensive memory 
enhancement program in healthy elderly persons. Psychiatry Research 1998;77(3):183-95.

\section{Mombelli 2012 \{published data only\}}

Mombelli G, Riva M, Cerea E, Zanetti M, Rozzini L, Padovani A. Neuropsychological training (TNP) in $\mathrm{MCl}$ subjects: one year follow-up. Conference: SIN DEM, Napoli, 2012 Napoli, Italy. 2012; Vol. Conference Start: 20120803 Conference End: 20120803.

\section{Moon 2013 \{published data only\}}

Moon SK, Chung S, Han M-I. The effectiveness of self-efficacy based memory training program for the elderly with mild cognitive impairment. Conference: 16th International Congress of the International Psychogeriatric Association, IPA 2013, Seoul, South Korea. 2013; Vol. Conference Start: 20131001 Conference End: 20131004:S141-2.

\section{Mowszowski 2014 \{published data only\}}

Mowszowski L, Hermens DF, Diamond K, Norrie L, Cockayne N, Ward PB, et al. Cognitive training enhances pre-attentive neurophysiological responses in older adults 'at risk' of dementia. Journal of Alzheimer's Disease 2014;41(4):1095-108.

\section{Mowszowski 2014a \{published data only\}}

Mowszowski L, Hermens DF, Diamond K, Norrie L, Cockayne N, Ward PB, et al. Cognitive training enhances pre-attentive neurophysiological responses in older adults 'at risk' of dementia. Journal of Alzheimer's Disease 2014;41(4):1095-108.

\section{Mozolic 2010 \{published data only\}}

Mozolic JL, Hayasaka S, Laurienti PJ. A cognitive training intervention increases resting cerebral blood flow in healthy older adults. Frontiers in Human Neuroscience 2010;4:16.

\section{Mozolic 2011 \{published data only\}}

Mozolic JL, Long AB, Morgan AR, Rawley-Payne M, Laurienti PJ. A cognitive training intervention improves modality-specific attention in a randomized controlled trial of healthy older adults. Neurobiology of Aging 2011;32(4):655-68.

\section{Muller 2011 \{published data only\}}

Muller NG, Bittner V, Hausmann J, Bittner DM. The effect of a combined motor and cognitive training on cognitive function, structural and functional MRI and BDNF plasma levels in $\mathrm{MCI}$ patients. Conference: International Conference "Aging and Cognition" 2010, Dortmund, Germany. 2011; Vol. Conference Start: 20101014 Conference End: 20101016:22-3.

\section{Na 2013 \{published data only\}}

$\mathrm{Na}$ HR, Choi S, Jeong JH, Na D, Park SA, Kim EJ, et al. A multicenter, randomized trial to assess efficacy of home-based and group cognitive intervention programs in amnestic mild cognitive impairment. Conference: Alzheimer's Association International Conference 2013, Boston, MA, United States. 2013; Vol. Conference Start: 20130713 Conference End: 20130718:P495.

\section{Na 2014 \{published data only\}}

$\mathrm{Na}$ HR, Choi SH, Jeong JH, Kim JE, Na DL, Seo SW, et al. A multicenter, randomized trial to assess efficacy of home-based and group cognitive intervention programs for amnestic mild cognitive impairment. Conference: Alzheimer's Association International Conference 2014, Copenhagen, Denmark. 2014; Vol. Conference Start: 20140712 Conference End: 20140717:P916.

Naismith 2014 \{published data only\}

Mowszowski L, Hermens DF, Diamond K, Norrie L, Cockayne N, Ward PB, et al. Cognitive training enhances pre-attentive neurophysiological responses in older adults 'at risk' of dementia. Journal of Alzheimer's Disease 2014;41(4):1095-108.

Navarro 2006 \{published data only\}

Navarro JI, Menacho I, Alcalde C, Marchena E, Simon Velez R, Aguilar M. Comparative study of two cognitive training procedures for elderly people. [Spanish]. Geriátrika 2006;22(6):36-42.

\section{NCT02417558 2015 \{published data only\}}

NCT02417558. Study to evaluate the effectiveness of personalized brain network activation technology in a cognitive/physical computer-game blended training of elderly (Alterniity AR). clinicaltrials.gov 2015.

\section{NCT02462135 2014 \{published data only\}}

NCT02462135. The development and evaluation of the effectiveness of a virtual interactive memory training program for older adults with mild cognitive impairment: protocol of a randomized controlled study. clinicaltrials.gov 2014.

\section{NCT02480738 2012 \{published data only\}}

NCT02480738. Effectiveness of computerized cognitive training apparatus (CoCoTA) in the elderly with normal cognition, subjective cognitive impairment, mild cognitive impairment. clinicaltrials.gov 2012.

\section{NCT02512627 2015 \{published data only\}}

NCT02512627. Evolving methods to combine cognitive and physical training for individuals with mild cognitive impairment: an efficacy study. clinicaltrials.gov 2015.

NCT02747784 2016 \{published data only\}

NCT02747784. Randomized evaluation to assess cognitive training for the prevention of post-operative cognitive decline (REACT) - a pilot study. clinicaltrials.gov 2016.

\section{NCT02774083 2015 \{published data only\}}

NCT02774083. An evaluation of the feuerstein instrumental enrichment program for the cognitive enhancement of older people with mild cognitive impairment $(\mathrm{MCl})$ living in the community. clinicaltrials.gov 2015.

\section{NCT02785315 2016 \{published data only\}}

NCT02785315. Cognitive intervention for persons with amnestic mild cognitive impairment: the efficacy in enhancement of cognition and complex activities of daily living function. clinicaltrials.gov 2016. 


\section{NCT02808676 2016 \{published data only\}}

NCT02808676. Synchronizing exercises, remedies in galt and cognition (SYNERGIC): a randomized controlled double blind trial. clinicaltrials.gov 2016.

\section{Neely 2013 \{published data only\}}

Neely AS, Sehlstedt I, Ekman U, Eriksson J, Sandberg P, Qwillbard T, et al. Working memory updating training in older adults: is level of performance after training related to transfer?. Conference: International Conference "Aging and Cognition", IfADo, 2013, Germany. 2013; Vol. Conference Start: 20130425 Conference End: 20130427 Sponsor: Brain Products - Solutions for Neurophysiological Research, Dortmund Tourismus, DFG Deutsche Forschungsgemeinsch:69-70.

\section{Ng 2015 \{published data only\}}

Ng TP, Nyunt MSZ, Feng L, Niti M, Tan BY, Chan G, et al. Nutritional, physical, cognitive, and combination interventions and frailty reversal among older adults: a randomized controlled trial. American Journal of Medicine 2015;128(11):1225-36.

\section{Ngandu 2015 \{published data only\}}

Ngandu T, Lehtisalo J, Solomon A, Levälahti E, Ahtiluoto S, Antikainen R, et al. A 2 year multidomain intervention of diet, exercise, cognitive training, and vascular risk monitoring versus control to prevent cognitive decline in at-risk elderly people (FINGER): a randomised controlled trial. Lancet 2015;385(9984):2255-63.

\section{Ngandu 2015a \{published data only\}}

Ngandu T, Lehtisalo J, Solomon A, Levälahti E, Ahtiluoto S, Antikainen $\mathrm{R}$, et al. A 2 year multidomain intervention of diet, exercise, cognitive training, and vascular risk monitoring versus control to prevent cognitive decline in at-risk elderly people (FINGER): a randomised controlled trial. Lancet 2015;385(9984):2255-63.

\section{Nishiguchi 2015 \{published data only\}}

Nishiguchi S, Yamada M, Tanigawa T, Sekiyama K, Kawagoe T, Suzuki M, et al. A 12-week physical and cognitive exercise program can improve cognitive function and neural efficiency in community-dwelling older adults: a randomized controlled trial. Journal of the American Geriatrics Society 2015;63(7):1355-63.

\section{Nouchi 2012 \{published data only\}}

Nouchi R, Taki Y, Takeuchi H, Hashizume H, Akitsuki Y, Shigemune $Y$, et al. Brain training game improves executive functions and processing speed in the elderly: a randomized controlled trial. PLoS One 2012;7(1):e29676.

\section{Nouchi 2013 \{published data only\}}

Nouchi R, Taki Y, Takeuchi H, Hashizume H, Nozawa T, Kambara T, et al. Brain training game boosts executive functions, working memory and processing speed in the young adults: a randomized controlled trial. PLoS One 2013;8(2):e55518.

\section{Nozawa 2015 \{published data only\}}

Nozawa T, Taki Y, Kanno A, Akimoto Y, Ihara M, Yokoyama R, et al. Effects of different types of cognitive training on cognitive function, brain structure, and driving safety in senior daily drivers: a pilot study. Behavioural Neurology 2015;2015:525901.

O'Caoimh 2015 \{published data only\}

O'Caoimh R, Sato S, Wall J, Igras E, Foley MJ, Timmons S, et al. Potential for a "memory gym" intervention to delay conversion of mild cognitive impairment to dementia. Journal of the American Medical Directors Association 2015;16(11):998-9.

\section{Oei 2013 \{published data only\}}

Oei AC, Patterson MD. Enhancing cognition with video games: a multiple game training study. PLoS One 2013;8(3):e58546.

Oliveira 2013 \{published data only\}

Oliveira de Lima Queiroz L, Junqueira AX, Fontana AM, De Oliveira ER, Lima VC, Guarienti VC. Prevention of cognitive impairment through a cognitive stimulation and rehabilitation program mediated by computers and internet. Conference: 21st World Congress of Neurology, Vienna, Austria. 2013; Vol. Conference Start: 20130921 Conference End: 20130926:e537.

Optale 2010 \{published data only\}

Optale G, Urgesi C, Busato V, Marin S, Prion L, Priftis K, et al. Controlling memory impairment in elderly adults using virtual reality memory training: a randomized controlled pilot study. Neurorehabilitation and Neural Repair 2010;24(4):348-57.

Otsuka 2015 \{published data only\}

Otsuka T, Tanemura R, Noda K, Nagao T, Sakai H, Luo ZW. Development of computer-aided cognitive training program for elderly and its effectiveness through a 6 months group intervention study. Current Alzheimer Research 2015;12(6):553-62.

\section{Park 2009 \{published data only\}}

Park MH, Kwon DY, Seo WK, Lim KS, Song MS. The effects of cognitive training on community-dwelling elderly Koreans. Journal of Psychiatric and Mental Health Nursing 2009;16(10):904-9.

\section{Park 2014 \{published data only\}}

Park SH, Seo JH, Kim YH, Ko MH. Long-term effects of transcranial direct current stimulation combined with computer-assisted cognitive training in healthy older adults. Neuroreport 2014;25(2):122-6.

Payne 2012 \{published data only\}

Payne BR, Jackson JJ, Hill PL, Gao X, Roberts BW, StineMorrow EA. Memory self-efficacy predicts responsiveness to inductive reasoning training in older adults. Journals of Gerontology. Series B, Psychological Sciences and Social Sciences 2012;67(1):27-35.

\section{Payne 2017 \{published data only\}}

Payne BR, Stine-Morrow EA. The effects of home-based cognitive training on verbal working memory and language comprehension in older adulthood. Frontiers in Aging Neuroscience 2017:9:256. 


\section{Rahe 2015 \{published data only\}}

Rahe J, Petrelli A, Kaesberg S, Fink GR, Kessler J, Kalbe E. Effects of cognitive training with additional physical activity compared to pure cognitive training in healthy older adults. Clinical Interventions in Aging 2015;10:297-310.

\section{Rahe 2015a \{published data only\}}

Rahe J, Becker J, Fink GR, Kessler J, Kukolja J, Rahn A, et al. Cognitive training with and without additional physical activity in healthy older adults: cognitive effects, neurobiological mechanisms, and prediction of training success. Frontiers in Aging Neuroscience 2015;7:187.

\section{Rebok 2013 \{published data only\}}

Rebok GW, Langbaum JB, Jones RN, Gross AL, Parisi JM, Spira AP, et al. Memory training in the ACTIVE study: how much is needed and who benefits?. Journal of Aging and Health 2013;25(8 Suppl):21S-42S.

\section{Rebok 2014 \{published data only\}}

Rebok GW, Ball K, Guey LT, Jones RN, Kim HY, King JW, et al. Tenyear effects of the advanced cognitive training for independent and vital elderly cognitive training trial on cognition and everyday functioning in older adults. Journal of the American Geriatrics Society 2014;62(1):16-24.

\section{Redick 2013 \{published data only\}}

Redick TS, Shipstead Z, Harrison TL, Hicks KL, Fried DE, Hambrick DZ, et al. No evidence of intelligence improvement after working memory training: a randomized, placebocontrolled study. Journal of Experimental Psychology General 2013;142(2):359-79.

\section{Requena 2016 \{published data only\}}

Requena C, Turrero A, Ortiz T. Six-year training improves everyday memory in healthy older people. Randomized controlled trial. Frontiers in Aging Neuroscience 2016;8:135.

\section{Rizkalla 2015 \{published data only\}}

Rizkalla M. Cognitive training in the rural elderly: a randomized trial to evaluate the efficacy and accessibility of a new approach. Thesis 2015;75(11-B(E)):1-81.

\section{Rojas 2013 \{published data only\}}

Rojas GJ, Villar V, Turry M, Harris P, Serrano CM, Herrera JA, et al. Efficacy of a cognitive intervention program in patients with mild cognitive impairment. International Psychogeriatrics 2013;25(5):825-31.

\section{Rose 2015 \{published data only\}}

Rose NS, Rendell PG, Hering A, Kliegel M, Bidelman GM, Craik FI. Cognitive and neural plasticity in older adults' prospective memory following training with the Virtual Week computer game. Frontiers in Human Neuroscience 2015;9:592.

\section{Rosen 2011 \{published data only\}}

Rosen AC, Sugiura L, Kramer JH, Whitfield-Gabrieli S, Gabrieli JD. Cognitive training changes hippocampal function in mild cognitive impairment: a pilot study. Journal of Alzheimer's Disease 2011;26(Suppl 3):349-57.

\section{Rozzini 2007 \{published data only\}}

Rozzini L, Costardi D, Chilovi BV, Franzoni S, Trabucchi M, Padovani A. Efficacy of cognitive rehabilitation in patients with mild cognitive impairment treated with cholinesterase inhibitors. International Journal of Geriatric Psychiatry 2007;22(4):356-60.

\section{Ryu 2013 \{published data only\}}

Ryu SH, Kim S, Youn JH, Lee JY. Improvement cognitive functions in the elderly with mild cognitive impairment and subjective memory complaints. Conference: 16th International Congress of the International Psychogeriatric Association, IPA 2013, Seoul, South Korea. 2013; Vol. Conference Start: 20131001 Conference End: 20131004:S165.

\section{Sakka 2015 \{published data only\}}

Sakka P, Ntanasi E, Zoi P, Kalligerou F, Pantelopoulos S. Sociable: a comprehensive ICT cognitive training programme for healthy and cognitively impaired elderly. Neurology 2015;84(14):P6.188.

\section{Santos 2011 \{published data only\}}

Santos G, Ortega L, Yassuda M, Forlenza O, Nunes P. The effects of a multiprofessional cognitive and functional rehabilitation program for patients with Alzheimer's disease and mild cognitive impairment. Conference: Alzheimer's Association International Conference, AAIC 11, Paris, France. 2011; Vol. Conference Start: 20110716 Conference End: 20110721:S800.

\section{Schoene 2015 \{published data only\}}

Schoene D, Valenzuela T, Toson B, Delbaere K, Severino C, Garcia J, et al. Interactive cognitive-motor step training improves cognitive risk factors of falling in older adults - a randomized controlled trial. PLoS One 2015;10(12):e0145161.

\section{Schoene 2015a \{published data only\}}

Schoene D, Valenzuela T, Toson B, Delbaere K, Severino C, Garcia J, et al. Interactive cognitive-motor step training improves cognitive risk factors of falling in older adults - a randomized controlled trial. PLoS One 2015;10(12):e0145161.

\section{Schumacher 2013 \{published data only\}}

Schumacher V, Theill N, Martin M. Improving cognitive performance and motor-cognition adaptability of older adults using an integrative motor-cognitive training approach. Conference: International Conference "Aging and Cognition", IfADo, 2013, Germany. 2013; Vol. Conference Start: 20130425 Conference End: 20130427 Sponsor: Brain Products - Solutions for Neurophysiological Research, Dortmund Tourismus, DFG Deutsche Forschungsgemeinsch:68-9.

\section{Shah 2012 \{published data only\}}

Shah T, Verdile G, Sohrabi H, Martins R. Cross-training of auditory and visual brain training software program improves cognition and alters plasma BDNF levels in healthy older adults. Alzheimer's and Dementia. 2012:99.

Shah T, Verdile G, Sohrabi H, Martins R. Physical activity and cognitive stimulation improve cognition and alter levels of plasma beta-amyloid in healthy elderly. Alzheimer's and Dementia. 2012:151. 
Shatil 2014 \{published data only\}

Shatil E, Mikulecká J, Bellotti F, Bureš V. Novel television-based cognitive training improves working memory and executive function. PLoS One 2014;9(7):e101472.

\section{Shatil 2014a \{published data only\}}

Shatil E, Mikulecká J, Bellotti F, Bureš V. Novel television-based cognitive training improves working memory and executive function. PLoS One 2014;9(7):e101472.

\section{Sisco 2013 \{published data only\}}

Sisco SM, Marsiske M, Gross AL, Rebok GW. The influence of cognitive training on older adults' recall for short stories. Journal of Aging and Health 2013;25(8 Suppl):230S-48S.

\section{Slegers 2009 \{published data only\}}

Slegers K, van Boxtel M, Jolles J. Effects of computer training and internet usage on cognitive abilities in older adults: a randomized controlled study. Aging Clinical and Experimental Research 2009;21(1):43-54.

\section{Smith 2009 \{published data only\}}

Smith GE, Housen P, Yaffe K, Ruff R, Kennison RF, Mahncke HW, et al. A cognitive training program based on principles of brain plasticity: results from the improvement in memory with plasticity-based adaptive cognitive training (IMPACT) study. Journal of the American Geriatrics Society 2009;57(4):594-603.

\section{Smith-Ray 2014 \{published data only\}}

Smith-Ray RL, Makowski-Woidan B, Hughes SL. A randomized trial to measure the impact of a community-based cognitive training intervention on balance and gait in cognitively intact Black older adults. Health Education and Behavior 2014;41(1 Suppl):62S-9S.

\section{Smith-Ray 2015 \{published data only\}}

Smith-Ray RL, Hughes SL, Prohaska TR, Little DM, Jurivich DA, Hedeker D. Impact of cognitive training on balance and gait in older adults. Journals of Gerontology. Series B, Psychological Sciences and Social Sciences 2015;70(3):357-66.

\section{Smith-Ray 2015a \{published data only\}}

Smith-Ray RL, Hughes SL, Prohaska TR, Little DM, Jurivich DA, Hedeker D. Impact of cognitive training on balance and gait in older adults. Journals of Gerontology. Series B, Psychological Sciences and Social Sciences 2015;70B(3):357-66.

\section{Solomon 2014 \{published data only\}}

Solomon A, Levalahti E, Soininen H, Tuomilehto J, Lindstrom J, Lehtisalo J, et al. A multidomain, two-year, randomized controlled trial to prevent cognitive impairment: the FINGER study. Conference: Alzheimer's Association International Conference 2014, Copenhagen, Denmark. 2014; Vol. Conference Start: 20140712 Conference End: 20140717:P137-8.

\section{Song 2009 \{published data only\}}

Park MH, Kwon DY, Seo WK, Lim KS, Song MS. The effects of cognitive training on community-dwelling elderly Koreans. Journal of Psychiatric and Mental Health Nursing 2009;16(10):904-9.

\section{Stepankova 2014 \{published data only\}}

Stepankova H, Lukavsky J, Buschkuehl M, Kopecek M, Ripova D, Jaeggi SM. The malleability of working memory and visuospatial skills: a randomized controlled study in older adults. Developmental Psychology 2014;50(4):1049-59.

\section{Stine-Morrow 2014 \{published data only\}}

Stine-Morrow EA, Payne BR, Roberts BW, Kramer AF, Morrow DG, Payne $L$, et al. Training versus engagement as paths to cognitive enrichment with aging. Psychology and Aging 2014;29(4):891-906.

\section{Strenziok 2013 \{published data only\}}

Strenziok M, Parasuraman R, Clarke E, Cisler DS, Thompson JC, Greenwood PM. Neurocognitive enhancement in older adults: comparison of three cognitive training tasks to test a hypothesis of training transfer in brain connectivity. Neuroimage 2013;85(3):1027-39.

\section{Strenziok 2014 \{published data only\}}

Strenziok M, Parasuraman R, Clarke E, Cisler DS, Thompson JC, Greenwood PM. Neurocognitive enhancement in older adults: comparison of three cognitive training tasks to test a hypothesis of training transfer in brain connectivity. Neuroimage 2014;85(3):1027-39.

\section{Sturz 2011 \{published data only\}}

Stürz K, Hartmann S, Eder-Pelzer B, Günther V. [Computer assisted cognitive training advances mood and psychological wellbeing - a comparison to paper pencil training relating to neuropsychological parameters, mood and cognitions] [German]. Neuropsychiatrie 2011;25(2):85-92.

\section{Sturz 2011a \{published data only\}}

Sturz K, Hartmann S, Eder-Pelzer B, Gunther V. [Computer assisted cognitive training advances mood and psychological wellbeing - a comparison to paper pencil training relating to neuropsychological parameters, mood and cognitions]. [German]. Neuropsychiatrie 2011;25(2):85-92.

\section{Sturz 2015 \{published data only\}}

Sturz K, Hartmann S, Kemmler G, Gunther V. Influence of a relaxation program, cognitive training and a combination of both intervention forms on neuropsychological and affective parameters in elderly care home residents. Conference: 23rd European Congress of Psychiatry, EPA 2015, Vienna, Austria. 2015; Vol. Conference Start: 20150328 Conference End: 20150331:1447.

\section{Styliadis 2015 \{published data only\}}

Styliadis C, Kartsidis P, Paraskevopoulos E, loannides AA, Bamidis PD. Neuroplastic effects of combined computerized physical and cognitive training in elderly individuals at risk for dementia: an eLORETA controlled study on resting states. Neural Plasticity 2015;2015:172192.

\section{Styliadis 2015a \{published data only\}}

Styliadis C, Kartsidis P, Paraskevopoulos E, loannides AA, Bamidis PD. Neuroplastic effects of combined computerized physical and cognitive training in elderly individuals at risk 
for dementia: an eLORETA controlled study on resting states. Neural Plasticity 2015;2015:172192.

\section{Suo 2012 \{published data only\}}

Suo C, Fiatarone Singh MA, Sachdev PS, Gates NJ, Valenzuela M. Resting state network adaptation in older adults with $\mathrm{MCl}$ in the SMART trial: unique effects of combined cognitive training and physical exercise. Conference: 3rd Biennial Conference on Resting State Brain Connectivity, Magdeburg, Germany. 2012; Vol. Conference Start: 20120905 Conference End: 20120907:A90-1.

\section{Szelag 2012 \{published data only\}}

Szelag E, Skolimowska J. Cognitive function in elderly can be ameliorated by training in temporal information processing. Restorative Neurology and Neuroscience 2012;30(5):419-34.

\section{Talib 2008 \{published data only\}}

Talib LL, Yassuda MS, Diniz BS, Forlenza OV, Gattaz WF. Cognitive training increases platelet PLA2 activity in healthy elderly subjects. Prostaglandins, Leukotrienes, and Essential Fatty Acids 2008;78(4-5):265-9.

\section{Tappen 2014 \{published data only\}}

Tappen RM, Hain D. The effect of in-home cognitive training on functional performance of individuals with mild cognitive impairment and early-stage Alzheimer's disease. Research in Gerontological Nursing 2014;7(1):14-24.

\section{Tennstedt 2013 \{published data only\}}

Tennstedt SL, Unverzagt FW. The ACTIVE study: study overview and major findings. Journal of Aging and Health 2013;25(8):3S-20S.

\section{Tesky 2012 \{published data only\}}

Tesky V, Pantel J. Cognitively stimulating leisure activities: a new approach for patients with mild cognitive impairment (MCl). Conference: Alzheimer's Association International Conference 2012, Vancouver, BC, Canada. 2012; Vol. Conference Start: 20120714 Conference End: 20120719:P571.

\section{Tsai 2008 \{published data only\}}

Tsai AY, Yang MJ, Lan CF, Chen CS. Evaluation of effect of cognitive intervention programs for the community-dwelling elderly with subjective memory complaints. International Journal of Geriatric Psychiatry 2008;23(11):1172-4.

\section{Tsolaki 2013 \{published data only\}}

Tsolaki M, Poptsi E, Kounti F, Christina A, Evaggelia B, Aikaterini S, et al. Longitudinal cognitive training in people with mild cognitive impairment. Conference: Alzheimer's Association International Conference 2013, Boston, MA, United States. 2013; Vol. Conference Start: 20130713 Conference End: 20130718:P491-2.

\section{Tucker-Drob 2009 \{published data only\}}

Tucker-Drob EM, Johnson KE, Jones RN. The cognitive reserve hypothesis: a longitudinal examination of age-associated declines in reasoning and processing speed. Developmental Psychology 2009;45(2):431-46.

\section{Vance 2007 \{published data only\}}

Vance D, Dawson J, Wadley V, Edwards J, Roenker D, Rizzo M, et al. The accelerate study: the longitudinal effect of speed of processing training on cognitive performance of older adults. Rehabilitation Psychology 2007;52(1):89-96.

\section{van den Berg 2016 \{published data only\}}

van den Berg M, Sherrington C, Killington M, Smith S, Bongers B, Hassett $L$, et al. Video and computer-based interactive exercises are safe and improve task-specific balance in geriatric and neurological rehabilitation: a randomised trial. Journal of Physiotherapy 2016;62(1):20-8.

\section{van der Ploeg 2016 \{published data only\}}

van der Ploeg ES, Hoorweg A, van der Lee J. User friendliness of computer-based cognitive training for psychogeriatric patients with mild to moderate cognitive impairments [Gebruiksvriendelijkheid van computerondersteunde cognitieve training bij psychogeriatrische patiënten met lichte tot matige cognitieve functiestoornissen]. Tijdschrift voor Gerontologie en Geriatrie 2016;47(2):58-67.

\section{Vidovich 2009 \{published data only\}}

Vidovich MR, Lautenschlager NT, Flicker L, Clare L, Almeida OP. The PACE study: a randomised clinical trial of cognitive activity (CA) for older adults with mild cognitive impairment (MCI). Trials 2009;10:114.

\section{Vidovich 2015 \{published data only\}}

Vidovich MR, Lautenschlager NT, Flicker L, Clare L, McCaul K, Almeida OP. The PACE study: a randomized clinical trial of cognitive activity strategy training for older people with mild cognitive impairment. American Journal of Geriatric Psychiatry 2015;23(4):360-72.

\section{Vidovich 2015a \{published data only\}}

Vidovich MR, Lautenschlager NT, Flicker L, Clare L, McCaul K, Almeida OP. The PACE study: a randomized clinical trial of cognitive activity strategy training for older people with mild cognitive impairment. American Journal of Geriatric Psychiatry 2015;23(4):360-72.

\section{von Bastian 2013 \{published data only\}}

von Bastian CC, Langer N, Jancke L, Oberauer K. Effects of working memory training in young and old adults. Memory \& Cognition 2013;41(4):611-24.

\section{Wadley 2007 \{published data only\}}

Wadley VG, Crowe M, Marsiske M, Cook SE, Unverzagt FW, Rosenberg AL, et al. Changes in everyday function in individuals with psychometrically defined mild cognitive impairment in the Advanced Cognitive Training for Independent and Vital Elderly Study. Journal of the American Geriatrics Society 2007;55(8):1192-8.

\section{Walton 2015 \{published data only\}}

Walton CC, Kavanagh A, Downey LA, Lomas J, Camfield DA, Stough C. Online cognitive training in healthy older adults: a preliminary study on the effects of single versus multi-domain training. Translational Neuroscience 2015;6(1):13-9. 
Wang 2013 \{published data only\}

Wang JR, Hsieh S. Neurofeedback training improves attention and working memory performance. Clinical Neurophysiology 2013;124(12):2406-20.

\section{Weicker 2013 \{published data only\}}

Weicker J, Hudl N, Marichal E, Muller K, Lepsien J, Trapp S, et al. Training of working memory in healthy elderly subjects - a randomized controlled trial. Conference: Joint Meeting of the FESN/GNP 2013, Berlin, Germany. 2013; Vol. Conference Start: 20130912 Conference End: 20130914:371.

Wild-Wall 2012 \{published data only\} Wild-Wall N, Falkenstein M, Gajewski PD. Neural correlates of changes in a visual search task due to cognitive training in seniors. Neural Plasticity 2012;2012:529057.

\section{Williams 2014 \{published data only\}}

Williams K, Herman R, Bontempo D. Reasoning exercises in assisted living: a cluster randomized trial to improve reasoning and everyday problem solving. Clinical Interventions in Aging 2014;9:981-96

\section{Willis 1986 \{published data only\}}

Willis SL, Schaie KW. Training the elderly on the ability factors of spatial orientation and inductive reasoning. Psychology and Aging 1986;1(3):239-47.

\section{Willis 2006 \{published data only\}}

Willis SL, Tennstedt SL, Marsiske M, Ball K, Elias J, Koepke KM, Morris JN, et al. Long-term effects of cognitive training on everyday functional outcomes in older adults. JAMA 2006;296(23):2805-14.

\section{Willis 2006a \{published data only\}}

Willis SL, Tennstedt SL, Marsiske M, Ball K, Elias J, Koepke KM, et al. Long-term effects of cognitive training on everyday functional outcomes in older adults. JAMA 2006;296(23):2805-14.

\section{Willis 2007 \{published data only\}}

Willis SL, Tennstedt SL, Marsiske M, Ball K, Elias J, Koepke KM, et al. Long-term effects of cognitive training on everyday functional outcomes in older adults. American Journal of Health Prevention 2007;21(5):469-70.

\section{Willis 2013 \{published data only\}}

Willis SL, Caskie GI. Reasoning training in the ACTIVE study: how much is needed and who benefits?. Journal of Aging and Health 2013;25(8 Suppl):43S-64S.

\section{Wojtynska 2011 \{published data only\}}

Wojtynska R, Wlazlo A, Trypka E, Zimny A, Frydecka D. The evaluation of the effectiveness of the program of the cognitive rehabilitation of patients with $\mathrm{MCl}$ and early dementia of Alzheimer's type. European Psychiatry 2011;26(1):504.

\section{Wolinsky 2006 \{published data only\}}

Wolinsky FD, Unverzagt FW, Smith DM, Jones R, Wright E, Tennstedt SL. The effects of the ACTIVE cognitive training trial on clinically relevant declines in health-related quality of life.
Journals of Gerontology. Series B, Psychological Sciences and Social Sciences 2006;61B(5):S281-7.

Wolinsky 2006a \{published data only\}

Wolinsky FD, Unverzagt FW, Smith DM, Jones R, Stoddard A, Tennstedt SL. The ACTIVE cognitive training trial and healthrelated quality of life: protection that lasts for 5 years. Journals of Gerontology. Series A, Biological Sciences and Medical Sciences 2006;61(12):1324-9.

\section{Wolinsky 2010 \{published data only\}}

Wolinsky FD, Vander Weg MW, Martin R, Unverzagt FW, Willis SL, Marsiske M, et al. Does cognitive training improve internal locus of control among older adults?. Journals of Gerontology. Series B, Psychological Sciences and Social Sciences 2010;65(5):591-8.

\section{Wolinsky 2010a \{published data only\}}

Wolinsky FD, Mahncke H, Vander Weg MW, Martin R, Unverzagt FW, Ball KK, et al. Speed of processing training protects self-rated health in older adults: enduring effects observed in the multi-site ACTIVE randomized controlled trial. International Psychogeriatrics 2010; Vol. 22, issue 3:470-8.

Wolinsky 2013 \{published data only\}

Wolinsky FD, Vander Weg MW, Howren MB, Jones MP, Dotson MM. A randomized controlled trial of cognitive training using a visual speed of processing intervention in middle aged and older adults. PLoS One 2013;8(5):e61624.

\section{Wolinsky 2015 \{published data only\}}

Wolinsky FD, Vander Weg MW, Howren MB, Jones MP, Dotson MM. The effect of cognitive speed of processing training on the development of additional IADL difficulties and the reduction of depressive symptoms: results from the IHAMS randomized controlled trial. Journal of Aging and Health 2015;27(2):334-54.

\section{Yam 2014 \{published data only\}}

Yam A, Gross AL, Prindle JJ, Marsiske M. Ten-year longitudinal trajectories of older adults' basic and everyday cognitive abilities. Neuropsychology 2014;28(6):819-28.

\section{Yassuda 2015 \{published data only\}}

Yassuda MS, Camargo MC, Brum PS, Bento T, Silva L, Spindola L. Working memory training: effects on cognition and psychological wellbeing of seniors without dementia and depression. Conference: Alzheimer's Association International Conference 2015, Washington, DC, United States. 2015; Vol. Conference Start: 20150718 Conference End: 20150723:P462.

\section{Yip 2012 \{published data only\}}

Yip CB. An intelligent rehabilitation system for cognitive rehabilitation. Thesis 2012;73(3-B):1524.

Yoonmi 2012 \{published data only\}

Lee Y, Lee CR, Hwang B. Effects of computer-aided cognitive rehabilitation training and balance exercise on cognitive and visual perception ability of the elderly. Journal of Physical Therapy Science 2012;24(9):885-7.

Computerised cognitive training for $\mathbf{1 2}$ or more weeks for maintaining cognitive function in cognitively healthy people in late life 
Youn 2011 \{published data only\}

Youn JH, Lee JY, Kim S, Ryu SH. Multistrategic memory training with the metamemory concept in healthy older adults.

Psychiatry Investigation 2011;8(4):354-61.

\section{Zelinski 2011 \{published data only\}}

Zelinski EM, Dalton SE, Smith GE. Consumer-based brain fitness programs. Enhancing Cognitive Fitness in Adults: A Guide to the Use and Development of Community-Based Programs. Philadelphia, PA: Springer, 2011:45-66.

\section{Zelinski 2011a \{published data only\}}

Zelinski EM, Spina LM, Yaffe K, Ruff R, Kennison RF, Mahncke HW, et al. Improvement in memory with plasticitybased adaptive cognitive training: results of the 3-month followup. Journal of the American Geriatrics Society 2011;59(2):258-65.

\section{Zhuang 2013 \{published data only\}}

Zhuang JP, Fang R, Feng X, Xu XH, Liu LH, Bai QK, et al. The impact of human-computer interaction-based comprehensive training on the cognitive functions of cognitive impairment in elderly individuals in a nursing home. Journal of Alzheimer's Disease 2013;36(2):245-51.

\section{Zimmermann 2014 \{published data only\}}

Zimmermann N, Netto TM, Amodeo MT, Ska B, Fonseca RP. Working memory training and poetry-based stimulation programs: are there differences in cognitive outcome in healthy older adults?. NeuroRehabilitation 2014;35(1):159-70.

\section{References to studies awaiting assessment}

Boot 2013 \{published data only\}

Boot WR, Champion M, Blakely DP, Wright T, Souders DJ, Charness N. Video games as a means to reduce age-related cognitive decline: attitudes, compliance, and effectiveness. Front Psychol 2013;4:31.

\section{Stern 2011 \{published data only\}}

Stern Y, Blumen HM, Rich LW, Richards A, Herzberg G, Gopher D. Space Fortress game training and executive control in older adults: a pilot intervention. Neuropsychology, Development, and Cognition. Section B, Aging, Neuropsychology and Cognition 2011;18(6):653-77. [PUBMED: 21988726]

\section{Additional references}

\section{Abraham 2015}

Abraham RP, Denton DA, Al-Assaf AS, Rutjes AW, ChongLY, Malik MA, et al. Vitamin and mineral supplementation for prevention of dementia or delaying cognitive decline in people with mild cognitive impairment. Cochrane Database of Systematic Reviews 2015, Issue 10. [DOI: 10.1002/14651858.CD011905]

\section{Acevedo 2007}

Acevedo A, Loewenstein DA. Nonpharmacological cognitive interventions in aging and dementia. Journal of Geriatric Psychiatry and Neurology 2007;20(4):239-49.

\section{Aisen 2011}

Aisen PS, Andrieu S, Sampaio C, Carrillo M, Khachaturian ZS, Dubois $\mathrm{B}$, et al. Report of the task force on designing clinical trials in early (predementia) AD. Neurology 2011;76(3):280-6.

\section{Al-Assaf 2015}

Al-Assaf AS, Denton DA, Abraham RP, Rutjes AW, Chong LY, Anderson JL, et al. Vitamin and mineral supplementation for maintaining cognitive function in cognitively healthy people in late life. Cochrane Database of Systematic Reviews 2015, Issue 10. [DOI: 10.1002/14651858.CD011906]

\section{Alves 2013}

Alves J, Magalhaes R, Machado A, Gonçalves O, Sampaio A, Petrosyan A. Non-pharmacological cognitive interventions for aging and dementia: current perspectives. World Journal of Clinical Cases 2013;1(8):233-41.

\section{Alzheimer's Association 2014}

Fargo KN, Aisen P, Albert M, Au R, Corrada MM, DeKosky S, et al. 2014 Report on the Milestones for the US National Plan to Address Alzheimer's Disease. Alzheimer's and Dementia 2014;10(5 Suppl):S430-52.

\section{Amoyal 2012}

Amoyal N, Fallon E. Physical exercise and cognitive training clinical interventions used in slowing degeneration associated with mild cognitive impairment. A review of the literature. Topics in Geriatric Rehabilitation 2012;28(3):208-16.

\section{Baher-Fuchs 2013}

Baher-Fuchs A, Clare l, Woods B. Cognitive training and cognitive rehabilitation for mild to moderate Alzheimer's disease and vascular dementia. Cochrane Database of Systematic Reviews 2013, Issue 6. [DOI: 10.1002/14651858.CD003260.pub2]

\section{Barnes 2011}

Barnes DE, Yaffe K. The projected effect of risk factor reduction on Alzheimer's disease prevalence. The Lancet Neurology 2011;10(9):819-28.

\section{Belleville 2012}

Belleville S, Bherer L. Biomarkers of cognitive training effects in aging. Current Translational Geriatrics and Experiemental Gerontology Reports 2012;1(2):104-10.

\section{Bennett 2014}

Bennett DA, Arnold SE, Valenzeual MJ, Brayne C, Schneider JA. Cognitive and social lifestyle: links with neuropathology and cognition in late life. Acta Neuropathologica 2014;127(1):137-50.

\section{Beydoun 2014}

Beydoun MA, Beydoun HA, Gamaldo AA, Teel A, Zonderman AB, Wang Y. Epidemiologic studies of modifiable factors associated with cognition and dementia: systematic review and metaanalysis. BMC Public Health 2014;14(1):643. 


\section{Brookmeyer 1998}

Brookmeyer R, Johnson E, Ziegler-Graham K, Arrighi HM. Forecasting the global burden of Alzheimer's disease. Alzheimer's and Dementia 1998;3(3):186-91.

\section{Brown 2004}

Brown J, Bowling A, Fly T. Models of QoL: a taxonomy, overview and systematic review of the literature. Conference: European Forum on Population Ageing Research/European Group on Quality of Life Extending quality of life in old age (EQUAL). 2004; Vol. Conference Start: 20061206 Conference End: 20061206.

\section{Clare 2004}

Clare L, Woods RT. Cognitive training and cognitive rehabilitation for people with early-stage Alzheimer's disease: a review. Neuropsychological Rehabilitation 2004;14(4):385-401.

\section{da Costa 2012}

da Costa BR, Nuesch E, Reichenbach S, Juni P, Rutjes AW. Doxycycline for osteoarthritis of the knee or hip. Cochrane Database of Systematic Reviews 2012, Issue 11. [DOI: 10.1002/14651858.CD007323.pub3]

\section{da Costa 2014}

da Costa BR, Nüesch E, Kasteler R, Husni E, Welch V, Rutjes AW, et al. Oral or transdermal opioids for osteoarthritis of the knee or hip. Cochrane Database of Systematic Reviews 2014, Issue 9. [DOI: 10.1002/14651858.CD003115.pub4]

\section{Deary 2009}

Deary IJ, Corley J, Gow AJ, Harris SE, Houlihan LM, Marioni RE, et al. Age associated cognitive decline. BMJ 2009;92:135-52.

\section{Denton 2015}

Denton DA, Abraham RP, Al-Assaf AS, Rutjes AW, Chong LY, Anderson JL, et al. Vitamin and mineral supplementation for maintaining cognitive function in cognitively healthy people in mid life. Cochrane Database of Systematic Reviews 2015, Issue 10. [DOI: 10.1002/14651858.CD011904]

\section{Depp 2012}

Depp CA, Harmell A, Vahia IV. Successful cognitive aging. Current Topics in Behavioral Neurosciences 2012;10:35-50.

\section{DerSimonian 1986}

DerSimonian R, Laird N. Meta-analysis in clinical trials. Controlled Clinical Trials 1986;7(3):177-88.

\section{Dresler 2013}

Dresler M, Sandberg A, Ohla K, Bublitz C, Trenado C, Mroczko-Wąsowicz A, et al. Non-pharmacological cognitive enhancement. Neuropharmacology 2013;64:529-43.

\section{Edwards 2018}

Edwards JD, Fausto BA, Tetlow AM, Corona RT, Valdés EG. Systematic review and meta-analyses of useful field of view cognitive training. Neuroscience and biobehavioral reviews 2018;84:72-91.

\section{Forbes 2015}

Forbes SC, Forbes D, Forbes S, Blake CM, Chong LY, Thiessen EJ, et al. Exercise interventions for preventing dementia or delaying cognitive decline in people with mild cognitive impairment. Cochrane Database of Systematic Reviews 2015, Issue 5. [DOI: 10.1002/14651858.CD011706]

\section{Forbes 2015a}

Forbes SC, Forbes D, Forbes S, Blake CM, Chong LY, Thiessen EJ, et al. Exercise interventions for maintaining cognitive function in cognitively healthy people in mid life. Cochrane Database of Systematic Reviews 2015, Issue 5. [DOI: 10.1002/14651858.CD011705]

\section{Forbes 2015b}

Forbes SC, Forbes D, Forbes S, Blake CM, Chong LY, Thiessen EJ, et al. Exercise interventions for maintaining cognitive function in cognitively healthy people in late life. Cochrane Database of Systematic Reviews 2015, Issue 5. [DOI: 10.1002/14651858.CD011704]

\section{Förster 2011}

Förster S, Buschert VC, Teipel SJ, Friese U, Buchholz HG, Drzezga $A$, et al. Effects of a 6-month cognitive intervention on brain metabolism in patients with amnestic $\mathrm{MCl}$ and mild Alzheimers Disease. Journal of Alzheimer's Disease 2011;26(Suppl 3):337-48.

\section{Gates 2010}

Gates NJ, Valenzuela MJ. Cognitive exercise and its role in cognitive function in older adults. Current Psychiatry Reports 2010;12(1):20-7.

\section{Gates 2011a}

Gates NJ, Sachdev PS, Fiatarone Singh MA, Valenzuela M. Cognitive and memory training in adults at risk of dementia: a systematic review. BMC Geriatrics 2011;11:55.

\section{Gates 2014}

Gates NJ, Sachdev P. Is cognitive training an effective treatment for preclinical and early Alzheimer's disease?. Journal of Alzheimer's Disease 2014;4(Suppl 4):S551-9.

\section{Gates 2016a}

Gates NJ, Karim S, Rutjes AW, Ware J, Chong LY, March E, et al. Computerised cognition-based interventions for maintaining cognitive function in cognitively healthy people in midlife. Cochrane Database of Systematic Reviews 2016, Issue 7. [DOI: 10.1002/14651858.CD012278]

\section{Gates 2019a}

Gates NJ, Rutjes AWS, Di Nisio M, Karim S, Chong L, March E, Vernooij RWM. Computerised cognitive training for maintaining cognitive function in cognitively healthy people in midlife. Cochrane Database of Systematic Reviews [under submission], Issue [under submission].

\section{Gates 2019b}

Gates NJ, Vernooij RWM, Di Nisio M, Karim S, March E, Rutjes AWS. Computerised cognitive training for preventing dementia in people with mild cognitive impairment. Cochrane 
Database of Systematic Reviews [under submission], Issue [under submission].

\section{Geda 2012}

Geda YE, Silber TC, Roberts RO, Knopman DS, Christianson TJ, Pankratz VS, et al. Computer activities, physical exercise, aging, and mild cognitive impairment: a population-based study. Mayo Clinic Proceedings 2012;87(5):437-42.

\section{Gordon 2013}

Gordon E, Palmer DM, Liu H, Rekshan W, DeVarney S. Online cognitive brain training associated with measurable improvements in cognition and emotional wellbeing. Technology and Innovation 2013;15:53-62.

\section{Grady 2012}

Grady C. The cognitive neuroscience of ageing. Nature Reviews. Neurosciences 2012;13(7):491-505.

\section{Green 2014}

Green CS, Strobach T, Schubert T. On methodological standards in training and transfer experiments. Psychological Research 2014;78(6):756-72.

\section{Guyatt 2008}

Guyatt GH, Oxman AD, Vist GE, Kunz R, Falck-Ytter Y, AlonsoCoello $P$, et al. GRADE: an emerging consensus on rating quality of evidence and strength of recommendations. BMJ 2008;336(7650):924-6.

\section{Harrison 2015}

Harrison SL, Birdi R, Smart CO, Brittain K, Rutjes AW, Siervo M, et al. Dietary interventions for maintaining cognitive function in cognitively healthy people in mid life. Cochrane Database of Systematic Reviews 2015, Issue 10. [DOI: 10.1002/14651858.CD011911]

\section{Hendrie 2006}

Hendrie HC, Albert MS, Butters MA, Gao S, Knopman DS, Launer LJ, et al. The NIH cognitive and emotional health project. Report of the critical evaluation study committee. Alzheimer's and Dementia 2006;2(1):12-32.

\section{Higgins 2011}

Higgins JPT, Green S (editors). Cochrane Handbook for Systematic Reviews of Interventions Version 5.1.0 (updated March 2011). The Cochrane Collaboration, 2011. Available from www.cochrane-handbook.org.

\section{Hoyer 2006}

Hoyer WJ, Verhaeghen P. Memory aging. In: Birren JE, Schaie KW editor(s). Handbook of the Psychology of Aging. 6th Edition. Amsterdam: Academic Press, 2006:209-32.

\section{Karp 2006}

Karp A, Paillard-Borg S, Wang HX, Silverstein M, Winblad B, Fratiglioni L. Mental, physical and social components in leisure activities equally contribute to decrease dementia risk. Dementia and Geriatric Cognitive Disorders 2006;21(2):65-73.

\section{Kelly 2014}

Kelly ME, Loughney D, Lawlor BA, Robertson IH, Walsh C, Brennan S. The impact of exercise on the cognitive functioning of healthy older adults: a systematic review and meta-analysis. Ageing and Research Reviews 2014;16:12-31.

\section{Kelly 2014a}

Kelly E, Loughrey D, Lawlor BA, Robertson IH, et al. The impact of cognitive training and mental stimulation on the cognitive functioning of healthy older adults. Aging Research Reviews 2014;15:28-33.

\section{Kueider 2012}

Kueider AM, Parisi JM, Gross AL, Rebok GW. Computerized cognitive training with older adults: a systematic review. PLOS ONE 2012;7(7):e40588.

\section{Lampit 2014a}

Lampit A, Hallock H, Valenzuela M. Computerized cognitive training in cognitively healthy older adults: a systematic review and meta-analysis of effect modifiers. PLoS Medicine 2014;11(11):e1001756

\section{Lampit 2015}

Lampit A, Hallock H, Suo C, Naismith S, Valenzuela M. Cognitive training-induced short-term functional and long-term structural plastic change is related to gains in global cognition in healthy older adults: a pilot study. Frontiers in Aging Neuroscience 2015;7:14.

\section{Landau 2012}

Landau SM, Marks SM, Mormino EC, Rabinovici GD, Oh H, $\mathrm{O}$ 'Neil JP, et al. Association of lifetime cognitive engagement and low B-amyloid deposition. Archives of Neurology 2012;69(5):623-9.

\section{Leifer 2003}

Leifer BP. Early diagnosis of Alzheimer's disease: clinical and economic benefits. Journal of the American Geriatrics Society 2003;51(5 Suppl):S281-8.

\section{Lustig 2009}

Lustig C, Shah P, Seidle R, Reuter-Lorenz P. Aging, training, and the brain and future directions. Neuropsychology Review 2009;19(4):504-22.

\section{Marioni 2012}

Marioni RE, Valenzuela MJ, van den Hout A, Brayne C, Matthews FE, MRC Cognitive Function and Ageing Study. Active cognitive lifestyle is associated with positive health transitions and compression of morbidity from age sixty-five. PLOS ONE 2012;7(12):e50940.

\section{Marioni 2014}

Marioni RE, Proust-Lima C, Amieva H, Brayne C, Matthews FE, Dartigues JF, et al. Cognitive lifestyle jointly predicts longitudinal cognitive decline and mortality risk. European Journal of Epidemiology 2014;29(3):211-9. 


\section{Marquine 2012}

Marquine MJ, Segawa E, Wilson RS, Bennett DA, Barnes LL. Association between cognitive activity and cognitive function in older Hispanics. Journal of the International Neuropsychological Society 2012;18(6):1041-51.

\section{Martin 2011}

Martin M, Clare L, Altgassen AM, Cameron MH, Zehnder F. Cognition-based interventions for healthy older people and people with mild cognitive impairment. Cochrane Database of Systematic Reviews 2011, Issue 1. [DOI: 10.1002/14651858.CD006220.pub2]

\section{Moher 2009}

Moher D, Liberati A, Tetzlaff J, Altman DG, The PRISMA Group. Preferred reporting items for systematic reviews and metaanalyses: the PRISMA statement. BMJ 2009;339:2535.

\section{Mowszowski 2010}

Mowszowski L, Batchelor J, Naismith SL. Early intervention for cognitive decline: can cognitive training be used as a selective prevention technique?. International Psychogeriatrics 2010;22(4):537-48.

\section{Norton 2014}

Norton S, Matthews FE, Barnes DE, Yaffe K, Brayne C. Potential for primary prevention of Alzheimer's disease: an analysis of population-based data. The Lancet Neurology 2014;13(8):788-94

\section{Olesen 2004}

Olesen PJ, Westerberg H, Klingberg T. Increased prefrontal and parietal activity after training of working memory. Nature Neurosciences 2004;7(1):75-9.

\section{Papp 2009}

Papp KV, Walsh SJ, Snyder PJ. Immediate and delayed effects of cognitive interventions in healthy elderly: a review of current literature and future directions. Alzheimer's and Dementia 2009;5(1):50-60.

\section{Park 2007}

Park DC, Gutchess AH, Meade ML, Stine-Morrow EA. Improving cognitive function in older adults. Journals of Gerontology. Series B, Psychological Sciences and Social Sciences 2007;62:45-52.

\section{Park 2013}

Park DC, Bishof GN. The ageing mind: neuroplasticity in response to cognitive training. Dialogues in Clinical Neuroscience 2013;15(1):109-19.

\section{Petersen 2018}

Petersen RC, Lopez O, Armstrong MS, Getchius TSD, Ganguli M. Practice guideline update summary: mild cognitive impairment. Neurology 2018;90(3):126-35

\section{Prince 2013}

Prince M, Bryce R, Albanese E, Wimo A, Ribeiro W, Ferri CP. The global prevalence of dementia: a systematic review and metaanalysis. Alzheimer's and Dementia 2013;9(1):63-75.

\section{Ratner 2015}

Ratner E, Atkinson D. Why cognitive training and brain games will not prevent or forestall dementia. Journal of the American Geriatrics Society 2015;63(12):2612-4.

\section{Reichenbach 2010}

Reichenbach S, Rutjes AW, Nuesch E, Trelle S, Juni P. Joint lavage for osteoarthritis of the knee. Cochrane Database of Systematic Reviews 2010, Issue 5. [DOI: 10.1002/14651858.CD007320.pub2]

\section{Reijnders 2013}

Reijnders J, van Heugten, van Boxtel M. Comparative interventions in healthy adults and those with mild cognitive impairment: a systematic review. Ageing Research Reviews 2013;12(1):263-75

\section{RevMan 2014 [Computer program]}

The Nordic Cochrane Centre, The Cochrane Collaboration. Review Manager (RevMan). Version 5.3. Copenhagen: The Nordic Cochrane Centre, The Cochrane Collaboration, 2014.

\section{Rutjes 2009a}

Rutjes AW, Nüesch E, Sterchi R, Kalichman L, Hendriks E, Osiri M, et al. Transcutaneous electrostimulation for osteoarthritis of the knee. Cochrane Database of Systematic Reviews 2009, Issue 4. [DOI: 10.1002/14651858.CD002823.pub2]

\section{Rutjes 2009b}

Rutjes AW, Nuesch E, Reichenbach S, Juni P. SAdenosylmethionine for osteoarthritis of the knee or hip. Cochrane Database of Systematic Reviews 2009, Issue 4. [DOI: 10.1002/14651858.CD007321.pub2]

\section{Rutjes 2010}

Rutjes AW, Nuesch E, Sterchi R, Juni P. Therapeutic ultrasound for osteoarthritis of the knee or hip. Cochrane Database of Systematic Reviews 2010, Issue 1. [DOI: 10.1002/14651858.CD003132.pub2]

\section{Rutjes 2012}

Rutjes AW, Juni P, da Costa BR, Trelle S, Nuesch E, Reichenbach S. Viscosupplementation for osteoarthritis of the knee: a systematic review and meta-analysis. Annals of Internal Medicine 2012;157(3):180-91.

\section{Rücker 2008}

Rücker G, Schwarzer G, Carpenter JR, Schumacher M. Undue reliance on 12 in assessing heterogeneity may mislead. $B M C$ Medical Research Methodology 2008;8:79.

\section{Salthouse 2003}

Salthouse TA. Memory aging from 18 to 80 . Alzheimer Disease and Associated Disorders 2003;17(3):162-7.

\section{Salthouse 2011}

Salthouse T. Neuroanatomical substrates of age-related cognitive decline. Psychological Bulletin 2011;137(5):753-84.

Computerised cognitive training for $\mathbf{1 2}$ or more weeks for maintaining cognitive function in cognitively healthy people in late life 


\section{Shao 2015}

Shao Y, Mang J, Li P, Wang J, Deng T, Xu Z. Computer-based cognitive programs for improvement of memory, processing speed and executive function during age-related cognitive decline: a meta-analysis. PLoS One 2015;10(6):e0130831.

\section{Siervo 2015}

Siervo M, Lara J, Munro A, Tang EY, Rutjes AW, Stephan B. Dietary interventions for maintaining cognitive function in cognitively healthy people in late life. Cochrane Database of Systematic Reviews 2015, Issue 10. [DOI: 10.1002/14651858.CD011910]

\section{Sixsmith 2013}

Sixsmith A, Carrillo M, Phillips D, Lansley P, Woolrych R. International initiatives in technology and aging. In: Sixsmith A, Gutman GM editor(s). Technologies for Active Aging (International Perspectives on Aging). Vol. 9, New York: Springer, 2013:201-22.

\section{Spiegelhalter 2004}

Spiegelhalter DJ, Abrams KR, Myles JP. Bayesian Approaches to Clinical Trials and Health-Care Evaluation. Chichester: Wiley, 2004.

\section{Steiner 2010}

Steiner JR. Minding the aging brain: technology-enabled cognitive training for healthy elders. Current Neurology and Neuroscience Reports 2010;10:374-80.

\section{Stern 2012}

Stern Y. Cognitive reserve in ageing and Alzheimer's disease. The Lancet Neurology 2012;11(11):1006-12.

\section{Suo 2012a}

Suo C, Valenzuela MJ. Neuroimaging outcomes of brain training trials. In: Bright P editor(s). Neuroimaging Cognitive and Clinical Neuroscience. INTECH Open Access Publisher, 2012.

\section{Tang 2015}

Tang EY, Harrison SL, Albanese E, Gorman TJ, RutjesAW, Siervo M, et al. Dietary interventions for prevention of dementia in people with mild cognitive impairment. Cochrane Database of Systematic Reviews 2015, Issue 10. [DOI: 10.1002/14651858.CD011909]

\section{Unverzagt 2012}

Unverzagt FW, Guey LT, Jones RN, Marsiske M, King JW, Wadley VG, et al. ACTIVE cognitive training and rates of incident dementia. Journal of the International Neuropsychological Society 2012;18(4):669-77.

\section{Valenzuela 2003}

Valenzuela MJ, Jones M, Wen W, Rae C, Graham S, Shnier R, et al. Memory training alters hippocampal neurochemistry in healthy elderly. Neuroreport 2003;14(10):1333-7.

\section{Valenzuela 2006a}

Valenzuela MJ, Sachdev P. Brain reserve and dementia: a systematic review. Psychological Medicine 2006;36(4):441-54.

\section{Valenzuela 2006b}

Valenzuela MJ, Sachdev P. Brain reserve and cognitive decline: a non parametric systematic review. Psychological Medicine 2006;36:1065-73.

\section{Valenzuela 2009}

Valenzuela M, Sachdev P. Can cognitive exercise prevent the onset of dementia? Systematic review of randomised clinical trials with longitudinal follow-up. American Journal of Geriatric Psychiatry 2009;17(3):179-87.

\section{Verghese 2003}

Verghese J, Lipton RB, Katz MJ, Hall CB, Derby CA, Kuslansky G, et al. Leisure activities and the risk of dementia in the elderly. New England Journal of Medicine 2003;348(25):2508-24.

\section{Walton 2014}

Walton C, Mowszowski L, Lewis SJ, Naismith SL. Stuck in the muck: time for change in the implementation of cognitive training research in ageing?. Frontiers in Aging Neuroscience 2014;6:43.

\section{WHO 2016}

World Health Organization. Ageing and life-course. www.who.int/ageing/en/ (accessed 1 April 2016).

\section{Wilson 2002}

Wilson RS, Mendes De Leon CF, Barnes LL, Schneider JA, Bienias JL, Evans DA, et al. Participation in cognitive stimulating activities and risk of incidence of Alzheimer's disease. JAMA 2002;287(6):742-8.

\section{Wilson 2012}

Wilson RS, Segawa E, Boyle PA, Bennett DA. Influence of late-life cognitive activity on cognitive health. Neurology 2012;78(15):1123-9.

\section{Wimo 2010}

Wimo A, Winblad B, Jönsson L. The worldwide societal costs of dementia: estimates for 2009. Alzheimer's \& Dementia 2010;6(2):98-103.

\section{Woods 2012}

Woods B, Aguirre E, Spector AE, Orrell M. Cognitive stimulation to improve cognitive functioning in people with dementia. Cochrane Database of Systematic Reviews 2012, Issue 2. [DOI: 10.1002/14651858.CD005562.pub2]

\section{World Alzheimer Report 2014}

The World Alzheimer Report 2014. Dementia and Risk Reduction: an analysis of protective and modifiable factors. London: Alzheimer's Disease International (ADI), 2014.

\section{Zehnder 2009}

Zehnder F, Martin M, Altgassen M, Clare L. Memory training effects in old age as markers of plasticity: a meta-analysis. Restorative Neurology and Neuroscience 2009;27(5):509-20.

\section{Zelinski 2009}

Zelinski EM. Far transfer in cognitive training of older adults. Restorative Neurology and Neuroscience 2009;27(5):455-71. 


\section{CHARACTERISTICS OF STUDIES}

Characteristics of included studies [ordered by study ID]

\section{Desjardins-Crépeau 2016}

- Design: $2 \times 2$ factorial RCT design
- Recruitment period: not reported
- No. of centres involved: not reported
- Unit of randomisation: individuals
- No. randomised: 136 participants
- Number of arms considered in this review: 4
- Maximum trial duration: 12 weeks.
- Funding by non-profit organisation: this study was supported by a Canadian Institutes of Health
Research (CIHR) grant (\#187596). One study author was supported by a doctoral fellowship from the
CIHR, and the other study author was supported by the Canada Research Chair Programme
- Funding by commercial organisation: none reported

Participants

- Patient flow: 136 participants were randomised, 91 completed the programme, and 76 were considered in the report. Each of 38 participants had aerobic and resistance (AR) and stretching and toning (ST) exercises. Of these, 22 in AR and 20 in ST received the computerised stimulation (experimental group), and 16 in AR and 18 in ST received computer lessons (control group), respectively

- Number of females: arm with AR: 13 of 22 (59\%) in experimental group, 8 of 16 (50\%) in control group; arm with ST: 17 of 20 (85\%) in experimental group, 15 of $18(83 \%)$ in control group

- Average age (SD): arm with AR: 72.7 (7.4) years in experimental group, 70.9 (7.4) years in control group; arm with ST: 73.2 (6.3) years in experimental group, 72.5 (7.0) years in control group

- Average (SD) education: arm with AR: 14.4 (2.8) years in experimental group, 15.9 (2.1) years in control group; arm with ST: 14.1 (4.3) years in experimental group, 14.1 (3.8) years in control group

- Baseline cognitive function: MMSE in arm with AR: 28.8 (1.3) in experimental group, 28.8 (1.0) in control group; MMSE in arm with ST: 29.4 (0.7) in experimental group, 28.5 (1.4) in control group

- Selection criteria on cognition: community-dwelling participants were recruited from the research centre's participant pool. A telephone-based screening interview was used to assess the eligibility of each candidate. Exclusion criteria were as follows: history of neurological disease or major surgery in the year preceding the study, auditory or visual impairments that were not corrected, smoking, severe mobility limitations, any other contraindication to perform physical activity, currently engaged in any type of structured physical activity, high score on geriatric depression scale, $<60$ years old

- Ethnicity: not reported

- APOE: number of participants positive for APOE not reported weeks; intervention provided in small group format under supervision of a neuropsychologist student

- Details of experimental intervention: each weekly session of dual task (DT) training took place in a room with 10 computer stations and was supervised by a student in neuropsychology. Participants were trained on a computerised visual DT analog. The task consisted of 2 visual discrimination tasks performed separately and concurrently. The first task was a number discrimination task $(3,5$, and 8$)$, and the second was a shape discrimination task (circle, square, and diamond). Participants had to respond to the number or shape presented on the screen with a key press on the appropriate button identified on the keyboard. The DT consisted of 4 different blocks, each containing different types of trials

- Type of concomitant treatment provided: arm with AR: included two 60-minute sessions/week for 12 weeks of physical exercise of cardiorespiratory fitness and lower body muscle strength; arm with ST included two 60-minute sessions/week for 12 weeks of series of exercises aimed at improving flexibility and general motor skills without a specific focus on increasing cardiorespiratory capacity or strength 
Desjardins-Crépeau 2016 (Continued)

- Session duration: 60 minutes in the experimental group

- Number of treatment sessions: 12 in the experimental group

- Treatment frequency: 1 session per week

- Maximum treatment duration in weeks: 12 in the experimental group

Type of control intervention: inactive; treatment duration of 12 weeks; intervention provided in group format, under supervision

- Details of control intervention: computer lessons (control) condition consisted of introductory exercises to computers and diverse software (e.g. Word, Excel), as well as an introduction to the Internet (search engines, websites, online games, etc.). These sessions took place in the same computer room as the DT training programme and were taught by a student in neuropsychology

- Type of concomitant treatment provided: arm with AR: included two 60-minute sessions/week for 12 weeks of physical exercise of cardiorespiratory fitness and lower body muscle strength; arm with ST included two 60-minute sessions/week for 12 weeks of series of exercises aimed at improving flexibility and general motor skills without a specific focus on increasing cardiorespiratory capacity or strength

- Session duration: 60 minutes in the control group

- Number of treatment sessions: 12 in the control group

- Treatment frequency: 1 session per week

- Maximum treatment duration in weeks: 12 in the control group

Outcomes

- Cognitive functioning outcomes considered

* Episodic memory measured with Rey Auditory Verbal Learning Test, delayed at 12 weeks, on a scale from 0 to 15, with higher values indicating benefit

* Executive function measured in seconds with the Color-Word Interference Test (CWIT-switching) of the Delis-Kaplan Executive Functions System is based on the Stroop procedure at 12 weeks on a scale from not reported to not reported with lower values indicating benefit

* Speed of processing measured with TMT-A at 12 weeks on a scale from not reported to not reported with lower values indicating benefit

- Physical functioning outcome considered: none reported

- Quality of life outcome considered: none reported

- Safety outcome considered: none reported

- Depression outcome considered: none reported

- Other outcome data on cognitive functioning, not considered in our meta-analyses

* Episodic memory measured with Rey Auditory Verbal Learning Test, total 5 trials and immediate recall at 12 weeks, on a scale from not reported to not reported with higher values indicating benefit

* Executive function measured in seconds with the Color-Word Interference Test (CWIT-inhibition) of the Delis-Kaplan Executive Functions System is based on the Stroop procedure, TMT part B at 12 weeks on a scale from not reported to not reported with lower values indicating benefit

* Executive function measured in seconds with BDT-DT index at 12 weeks on a scale from not reported to not reported with higher values indicating benefit

* Speed of processing as measured in seconds with the Color-Word Interference Test (CWIT-color naming and seconds) of the Delis-Kaplan Executive Functions System is based on the Stroop procedure and BDT-simple tasks at 12 weeks in seconds, with lower values indicating benefit

Notes

This study was supported by a Canadian Institutes of Health Research (CIHR) grant (\#187596). One

study author was supported by a doctoral fellowship from the CIHR, and another study author was sup-

ported by the Canada Research Chair Program. Study authors report no conflict of interest in the study

We combined data from ST and AR arms

\section{Risk of bias}


Desjardins-Crépeau 2016 (Continued)
Random sequence genera- Low risk
Judgement: adequate random sequence generation

tion (selection bias)

Quote(s): "the study was carried on in waves of 16-32 participants randomly assigned to one of the four training combinations using the website randomization.com"

$\begin{array}{ll}\begin{array}{l}\text { Allocation concealment } \\ \text { (selection bias) }\end{array} & \text { Judgement: method of allocation concealment not reported } \\ & \begin{array}{l}\text { Quote(s): "the study was carried on in waves of 16-32 participants randomly } \\ \text { assigned to one of the four training combinations using the website random- } \\ \text { ization.com" }\end{array}\end{array}$

\begin{tabular}{ll}
\hline $\begin{array}{l}\text { Blinding of participants } \\
\text { (performance bias) }\end{array}$ & High risk Judgement: blinding not feasible
\end{tabular}

\begin{tabular}{|c|c|c|}
\hline $\begin{array}{l}\text { Blinding of personnel (per- } \\
\text { formance bias) }\end{array}$ & High risk & Judgement: blinding not feasible \\
\hline $\begin{array}{l}\text { Blinding of outcome as- } \\
\text { sessment (detection bias) } \\
\text { All outcomes }\end{array}$ & Low risk & $\begin{array}{l}\text { Judgement: explicit reporting of blinded outcome assessment } \\
\text { Quote(s): "the evaluators at both pretest and posttest were blind to the group } \\
\text { membership of participants" }\end{array}$ \\
\hline $\begin{array}{l}\text { Incomplete outcome data } \\
\text { (attrition bias) } \\
\text { All outcomes }\end{array}$ & High risk & $\begin{array}{l}\text { Judgement: we judged high risk of bias, as on average less than } 90 \% \text { of ran- } \\
\text { domised participants were analysed } \\
\text { Quote(s): "among the } 125 \text { participants who were enrolled in the study, } 91 \text { par- } \\
\text { ticipants completed the program. Among those, three participants failed to } \\
\text { participate in the posttest evaluations and two participants had invalid data } \\
\text { due to illness at posttest examinations and were thus excluded from analyses" }\end{array}$ \\
\hline
\end{tabular}

\begin{tabular}{lll}
\hline $\begin{array}{l}\text { Selective reporting (re- } \\
\text { porting bias) }\end{array}$ & Low risk & $\begin{array}{l}\text { Judgement: all outcomes described in the methods section are adequately } \\
\text { addressed in the results section }\end{array}$ \\
\hline Other bias & Low risk & Judgement: no other sources of bias detected \\
\hline
\end{tabular}

\section{Klusmann 2010}

\begin{tabular}{|c|c|}
\hline Methods & $\begin{array}{l}\text { - Design: 3-arm RCT with parallel-group design } \\
\text { - Recruitment period: } 2006 \text { to } 2008 \\
\text { - No. of centres involved: not reported } \\
\text { - Unit of randomisation: individuals } \\
\text { - No. randomised: } 259 \\
\text { - Number of arms considered in this review: } 2 \\
\text { - Maximum trial duration: } 6 \text { months } \\
\text { - Funding by non-profit organisation: German Research Foundation (grant number 429) Doctoral Pro- } \\
\text { gramme "Neuropsychiatry and Neuropsychology of Aging" (years covered: } 2006 \text { too 2008) to I.H. and } \\
\text { - } \text { - Funding Gertrud and Hugo Adler Foundation (years covered: } 2006 \text { to 2008) } \\
\text { - Publication status: full-text report }\end{array}$ \\
\hline Participants & $\begin{array}{l}\text { - Patient flow: } 92 \text { randomised, } 92 \text { described at baseline in experimental group; } 76 \text { randomised, } 76 \text { de- } \\
\text { scribed at baseline in control group } \\
\text { - Number of females: } 92 \text { of } 92(100 \%) \text { in experimental group } 1 ; 76 \text { of } 76(100 \%) \text { in control group } \\
\text { - Average age (SD): } 74 \text { (4.4) years in experimental group } 1 ; 74 \text { (4.3) years in control group } \\
\text { - Average (SD) education: } 12 \text { (2.6) years in experimental group; } 12 \text { (2.8) years in control group }\end{array}$ \\
\hline
\end{tabular}

Computerised cognitive training for 12 or more weeks for maintaining cognitive function in cognitively healthy people in late life 
- Baseline cognitive function: baseline cognitive function measured with: selection criteria on cognition overall: participants were screened to rule out the presence of cognitive impairment or depression and were included if they made no more than 4 errors on the Mini Mental State Examination (MMSE; 20) and scored less than 6 points on the 15-item short-form Geriatric Depression Scale (GDSSf; 21). Baseline mean MMSE (SD) was 28.76 (0.97)

- Selection criteria on cognition in experimental group: participants were screened to rule out the presence of cognitive impairment or depression and were included if they made no more than 4 errors on the Mini Mental State Examination (MMSE; 20) and scored less than 6 points on the 15-item short-form Geriatric Depression Scale (GDS-Sf; 21). Baseline mean MMSE (SD): 28.84 (0.94)

- Selection criteria on cognition in control group: participants were screened to rule out the presence of cognitive impairment or depression and were included if they made no more than 4 errors on the Mini Mental State Examination (MMSE; 20) and scored less than 6 points on the 15-item short-form Geriatric Depression Scale (GDS-Sf; 21). Mean baseline MMSE (SD): 28.62 (1.08)

- Ethnicity: not reported

- APOE: number of participants positive for APOE not reported

Interventions

Type of experimental intervention: computerised CT individualised; treatment duration of 26 weeks; intervention provided as individual training, under supervision

- Details of experimental intervention: the computer course covered heterogeneous and multi-faceted tasks such as learning how to operate with common software and hardware, writing, playing, calculating, surfing on the Internet, emailing, drawing, image editing, and videotaping

- Session duration: 90 minutes in experimental group

- Number of treatment sessions: 75 in experimental group

- Treatment frequency: not reported in experimental group

- Maximum treatment duration in weeks: 26 in experimental group

Type of control intervention: inactive; duration of 26 weeks; without supervision

- Details of control intervention: usual daily life/care

- Type of concomitant treatment provided: none reported

- Session duration: not reported in control group

- Number of treatment sessions: not reported in control group

- Maximum treatment duration in weeks: 26 in control group

Outcomes

- Cognitive functioning outcomes considered

* Episodic memory measured with Rivermead Behavioural Memory Test (RBMT), delayed story recall at 6.5 months, on a scale from 0 to not reported with higher values indicating benefit*

* Executive functioning measured with Stroop test at 6.5 months, on a scale from not reported to not reported with higher values indicating benefit

* Verbal fluency measured with semantic verbal fluency at 6.5 months, on a scale from 0 to not reported with higher values indicating benefit

- Physical functioning outcome considered: none reported

- Quality of life outcome considered: none reported

- Safety outcome considered: none reported

- Depression outcome considered: none reported

- Other outcome data on cognitive functioning, not considered in our meta-analyses

* Episodic memory measured with Rivermead Behavioural Memory Test (RBMT), immediate story recall at 6.5 months, on a scale from 0 to not reported with higher values indicating benefit*

* Episodic memory measured with Free and Cued Selective Reminding Test (FCSRT), short delay at 6.5 months, on a scale from 0 to 48 with higher values indicating benefit

* Episodic memory measured with Free and Cued Selective Reminding Test (FCSRT), long delay at 6.5 months, on a scale from 0 to 16 with higher values indicating benefit

* Executive function measured with Trail Making Test (TMT)-B/A at 6.5 months, on a scale from not reported to not reported with lower values indicating benefit 
Klusmann 2010 (Continued)

*Our hierarchy did not indicate a preference for the delayed subscale over the immediate subscale. Whenever both immediate and delayed subscales were available, the delayed subscale was included in the meta-analyses.

Notes

Baseline characteristics were reported for the randomised population, whereas outcome data are presented only for those with pretest and post-test evaluations

\title{
Risk of bias
}

\begin{tabular}{lll}
\hline Bias & Authors' judgement & Support for judgement \\
\hline $\begin{array}{ll}\text { Random sequence genera- } \\
\text { tion (selection bias) }\end{array}$ & Low risk & Judgement: adequate random sequence generation \\
& & $\begin{array}{l}\text { Quote(s): "the randomization sequence for each of the seven study cohorts } \\
\text { was generated using Research Randomizer (www.randomizer.org) by VK" }\end{array}$
\end{tabular}

Allocation concealment Unclear risk (selection bias)

\begin{abstract}
Judgement: envelopes were not reported to be opaque. Although preparation of envelopes was done centrally by an independent research assistant, we are unsure if the nurse who was in charge of handing over the envelopes could foresee the codes kept in the envelopes

Quote(s): "a study assistant prepared seven sets of 34 numbered envelopes containing the accordant randomization results ( 12 for the intervention groups each and 10 for the control group)"; "the sealed envelopes, all prepared before starting the examination of the first cohort and kept locked in a safe deposit box, were given on a daily basis to the study nurse in consecutive order. Envelopes were opened after the main part of the clinical baseline evaluation to have the participants of the exercise group undergo the additional stress ECG. If study candidates withdrew from the study or were excluded because of lacking eligibility criteria at a later point in time, the study assistant prepared additional envelopes containing the corresponding assignments of those who dropped out in the sequence of deposit"
\end{abstract}

Judgement: patients were not blinded to the treatment assigned

Quote(s): "before participants were informed about their group assignment, at a second 2.5-hour appointment"; "finally, we used a single-, not a double-, blind design. However, to design a "placebo" control group would be methodologically challenging and, furthermore, to keep participants fully blinded would raise ethical questions"

Judgement: blinding not feasible

Blinding of personnel (per- High risk formance bias)

Blinding of outcome as- Low risk sessment (detection bias)

All outcomes

Judgement: explicit reporting of blinded outcome assessment. Therapists were also outcome assessors

Quote(s): "participants and neuropsychological assessors were blinded to group allocation up to the completed baseline examination of the whole cohort (double blind); participants were then informed by mail. Assessors were kept blind at post-test by explicitly instructing the participants not to discuss any of the information regarding randomization and intervention with the research staff conducting the testing"

Incomplete outcome data High risk (attrition bias)

All outcomes
Judgement: we judged high risk of bias, as on average less than $90 \%$ of randomised participants were analysed

Quote(s): "259 participants to be randomized (91 for the exercise, 92 for the computer, and 76 for the control condition), of whom 12 participants ( 5 of the exercise and 7 of the computer condition) refused to participate after being informed about their group assignment and withdrew consent before treatment 
started. Thus, 247 (95.4\% of randomized participants; ie, 86 for the exercise, 85 for the computer, and 76 for the control condition) women were allocated to the corresponding groups, of whom 230 (93.1\% of baseline, $88.8 \%$ of randomized) returned for follow-up"; "three women of the computer group were excluded from analyses of pre-post change in one cognitive test each, due to incorrect test data assessment"

Selective reporting (re- Low risk Judgement: all outcomes described in the methods section are adequately porting bias) addressed in the results section

Other bias Low risk Judgement: no other sources of bias were detected

Lampit 2014

- Design: 2-arm RCT with parallel-group design
- Recruitment period: 2011 to 2012
- No. of centres involved: 1
- Unit of randomisation: individuals
- No. randomised: 80
- Maximum trial duration: 15 months
- Funding by non-profit organisation: this study was funded by the Dementia Collaborative Research
Centres (DCRC) - Assessment and Better Care (ID PDCRC-CB50), in which HB is the director, as well
as the Dreikurs Bequest. MV is a National Health and Medical Research Council of Australia Career
Development Fellow (ID 1004156)

- Funding by commercial organisation: none reported

- Publication status: full-text report

Participants

- Patient flow: 41 randomised, 39 described at baseline in experimental group; 39 randomised, 38 described at baseline in control group

- Number of females: 29 of $39(74 \%)$ in experimental group 1; 24 of $38(63 \%)$ in control group

- Average age (SD): 72 (7.1) years in experimental group 1; 72 (5.3) years in control group

- Education: experimental group 1: low education ( $\leq 10$ years), 11/39 (28.2); control: low education ( $\leq$ 10 years), $11 / 38$ (29\%)

- Baseline cognitive function: MMSE scores ranged from 24 to 30 (mean MMSE 28, SD 1.6). All participants had at least 1 established dementia risk factor, the most prevalent being subjective memory complaints (68.9\% in women; $70.1 \%$ in men)

- Selection criteria on cognition: intervention group: MMSE (SD): 28.2 (1.4). All participants had at least 1 established dementia risk factor, the most prevalent being subjective memory complaints (69\%), hypertension (31\%), hypercholesterolaemia (36\%). Control group: MMSE (SD): 27.8 (1.8). All participants had at least 1 established dementia risk factor, the most prevalent being subjective memory complaints (71\%), hypertension (53\%), hypercholesterolaemia (37\%)

- Ethnicity: not reported.

- APOE: number of participants positive for APOE not reported

Interventions

Type of experimental intervention: computerised CT group; treatment duration of 12 weeks; intervention provided in group format, under supervision

- Details of experimental intervention: 24 exercises from the COGPACK package, version 8.1 (Marker Software), to cover the 5 cognitive domains: memory, attention, response speed, executive functions, and language

- Type of concomitant treatment provided: none reported

- Session duration: 30 to 45 minutes in experimental group

- Number of treatment sessions: 36 in experimental group 
- Treatment frequency: $3 /$ week in experimental group

- Maximum treatment duration in weeks: 12 in experimental group

Type of control intervention: other; treatment duration of 12 weeks; intervention provided in group format, under supervision

- Details of control intervention: this control intervention was developed for general sensorimotor stimulation, computer use, socialisation, motivation, simple learning and memory demands, and other non-specific effects inherent to supervised $\mathrm{CCl}$, and was used in a previous trial conducted by this group. Participants viewed 7 National Geographic videos per session on computer and answered multiple choice questions immediately after each presentation

- Type of concomitant treatment provided: none reported

- Session duration: 30 to 45 minutes in control group

- Number of treatment sessions: 36 in control group

- Treatment frequency: $3 /$ week in control group

- Maximum treatment duration in weeks: 12 in control group

- Cognitive functioning outcomes considered
$*$ Global cognitive functioning measured with composite score of memory, speed, and executive
function at 3 and 15 months, on a scale from not reported to not reported with higher values indi-
cating benefit
- Physical functioning outcome considered: none reported
- Quality of life outcome considered: none reported
- Safety outcome considered: none reported*
- Depression outcome considered: none reported
Other outcome data on cognitive functioning, not considered in our meta-analyses: none report-
*Study authors reported: "no adverse effects related to the intervention were recorded throughout the
study period". As this is about attributed AEs only, we did not consider the data
Timecourse Trial. ACTRN12611000702910. The funding panel had no role in study design, data collec-
tion, data analysis, interpretation of data, writing of the report, or the decision to submit the paper for
publication. There were also no systematic differences in protocol adherence in the CCI group (35.1
sessions, $97.5 \%)$ compared to the AC training group (34.7 sessions, $96.4 \%$; $P=0.581)$

\section{Risk of bias}

Bias Authors' judgement Support for judgement

Random sequence genera- Low risk tion (selection bias)

\section{Judgement: adequate random sequence generation}

Quote(s): "participants were randomised using a simple computer-generated randomisation sequence in a 1:1 ratio to either $\mathrm{CCl}$ or active control (AC) group"; from trial registration: "simple randomisation table created by a computer software"

Allocation concealment Low risk
(selection bias)

Judgement: allocation was done by the principal investigator, who does not seem to be involved with training or outcome assessment, and seems to be independent. Randomisation was organised centrally, and for this reason, we judged central randomisation

Quote(s): "randomisation was conducted by the principal investigator (MV) and was concealed from the rest of the research team until the first day of training"; from trial registration: "allocation involved contacting the holder of the allocation schedule who was "off-site" or at central administration site" 
Lampit 2014 (Continued)

Blinding of participants Low risk_ Judgement: an attempt was made to blind participants, as the 2 types of in(performance bias) terventions were distinguishable, but as participants were blinded to the study hypothesis, we deem it likely that blinding was successful

Quote(s): "participants were blinded to the study hypotheses. On-going participant blinding achieved by describing $\mathrm{CCl}$ as a "diversified set of cognitive exercises", and AC as comprehension and memory exercises"

Blinding of personnel (per- High risk Judgement: blinding of therapists not feasible
formance bias)

\begin{tabular}{|c|c|c|}
\hline $\begin{array}{l}\text { Blinding of outcome as- } \\
\text { sessment (detection bias) } \\
\text { All outcomes }\end{array}$ & Low risk & $\begin{array}{l}\text { Judgement: outcome assessors explicitly reported to be blinded } \\
\text { Quote(s): "assessors were blinded to group allocation" }\end{array}$ \\
\hline
\end{tabular}

Incomplete outcome data Low risk (attrition bias)

All outcomes

\begin{abstract}
Judgement: for the outcome global cognitive functioning: 39 out of 41 (95\%) randomised were analysed in experimental group, and 38 out of $39(97 \%)$ randomised were analysed in control group. Statistical analyses were reported to be done according to the intent-to-treat principle. In the experimental group, 15/41 participants were not evaluated 12 months post training. In the control group, 10/39 patients were not evaluated 12 months post training. Although study authors reported that this was an intention-to-treat (ITT) analysis, they deemed the fraction of missing data was too large. MMRM incorporates a model for missing data values and so avoids discrete imputation or omission of cases. All analyses are therefore ITT. Twelve participants withdrew during the intervention period ( 8 in the $\mathrm{CCl}$ group, 4 in the $\mathrm{AC}$ group; 2 -sided $\mathrm{Chi}^{2} \mathrm{P}=$ 0.347 ), and 10 additional participants (5 in each group) were lost to longitudinal follow-up (see Figure 1). No baseline sociodemographic or clinical differences were noted between dropouts and those who completed the intervention
\end{abstract}

Judgement: all outcomes described in the methods section are adequately addressed in the results section, but on the trial registration site, an additional primary outcome is listed that is described as post-hoc testing in the full publication. In addition, 2 instruments were dropped due to lack of feasibility

Quote(s): "trial registration: first primary outcome (out of 2) - scores in (1) a computer-based adaptation of WAIS 4 Matrix Reasoning test; (2) Controlled Oral Word Association Test (COWAT); (3) Boston Naming Test (short versions); and (4) a computerised adaptation of the Recognition Memory Test and full text: These 4 tests were included in the more expansive post hoc Global Cognitive Score and full text: one test was initially planned but not implemented because of poor usability with our participants (Mindstreams Visual-Spatial Orientation test), and another test (Cogscreen) could not be implemented because of technical issues. These changes were documented in the trial registry"

Other bias Low risk Judgement: no other sources of bias were detected

\section{Legault 2011}

$\begin{array}{ll}\text { - Dethods } & \text { - Recruitment period: } 2008 \text { to } 2009 \\ \text { - No. of centres involved: } 1 \\ \text { - Unit of randomisation: individuals } \\ \text { - No. randomised: } 73 \\ \text { - Number of arms considered in this review: } 4\end{array}$

Computerised cognitive training for 12 or more weeks for maintaining cognitive function in cognitively healthy people in late life (Review)

Copyright $\odot 2020$ The Cochrane Collaboration. Published by John Wiley \& Sons, Ltd. 
Legault 2011 (Continued)

- Maximum trial duration: 4 months

- Funding by non-profit organisation: Department of Health and Human Services, National Institutes of Health (1R01AG029285 - 01A1), and the General Clinical Research Center of Wake Forest University Baptist Medical Center (M01-RR07122)

- Funding by commercial organisation: none reported

- Publication status: full-text report

Participants

Interventions
- Patient flow: 18 randomised, 18 described at baseline in experimental group; 18 randomised, 18 described at baseline in control group

- Number of females: 8 of $18(44 \%)$ in experimental group $1 ; 7$ of $18(38 \%)$ in control group 1

- Average age (SD): 76 (5.2) years in experimental group 1; 75 (4.8) years in control group 1

- Education: experimental group 1: high school or less: 4 (22\%), more than high school: 14 (78\%); control group 1: high school or less: 5 (28\%), more than high school: 13 (72\%)

- Baseline cognitive function: experimental group 1: selection criteria on cognition overall: community-dwelling persons, aged 70 to 85 years, who were at risk for cognitive decline but who did not have mild cognitive impairment

- Selection criteria on cognition in experimental group: community-dwelling persons, aged 70 to 85 years, who were at risk for cognitive decline but who did not have mild cognitive impairment. Control group: community-dwelling persons, aged 70 to 85 years, who were at risk for cognitive decline but who did not have mild cognitive impairment

- Ethnicity: experimental group: 17 white, 0 Indian, 0 Asian, 1 black, 0 other, 0 unclear; control group: 17 white, 0 Indian, 0 Asian, 1 black, 0 other, 0 unclear

- Genetic marker: experimental group: present: 2 (17\%), absent: 10 (83\%); control group: present: 3 (25\%), absent: 9 (75\%)

Type of experimental intervention: computerised CT group; treatment duration of 17.2 weeks; intervention provided in small group format under supervision

- Details of experimental intervention: sessions were centre-based, conducted via computer, carried out with small groups of no more than 6 individuals, and monitored by skilled trainers. For each session, participants studied a list of 30 words, followed by a recognition test consisting of 30 studied words and 30 new words with each new word repeated once, and were asked to respond "yes" to study words and "no" to new items both times they occurred

- Type of concomitant treatment provided: none in comparison 1; physical activity in comparison 2

- Session duration: 10 to 12 minutes in experimental group

- Number of treatment sessions: 24 in experimental group

- Treatment frequency: training consisted of 4 consecutive 10- to 12 -minute sessions per day, administered 2 times per week for 2 months, which then tapered to 1 time per week for 2 additional months in experimental group

- Maximum treatment duration in weeks: 17.2 in experimental group

Type of control intervention: inactive; treatment duration of 17.2 weeks; intervention provided in group format, under supervision

- Details of control intervention: Healthy Aging Education control intervention consisted of weekly lectures based on health education and was based on a programme developed originally at Stanford and adapted for the Lifestyle interventions and Independence for Elders pilot trial. Topics such as medications, foot care, travelling, and nutrition were covered

- Type of concomitant treatment provided: none in comparison 1; physical activity in comparison 2

- Session duration: not reported in control group

- Number of treatment sessions: not reported in control group

- Treatment frequency: 1 /week in control group

- Maximum treatment duration in weeks: 17.2 in control group 
Legault 2011 (Continued)

Outcomes
- Cognitive functioning outcomes considered for both comparisons

* Episodic memory measured with Logical Memory task from the Wechsler Memory Scale-III (LM2), Recall Total Score at 4 months, on a scale from 0 to not reported with higher values indicating benefit

* Executive functioning measured with Trails B Time-Trails A Time at 4 months, on a scale from 0 to not reported with lower values indicating benefit

- Physical functioning outcome considered: none reported

- Quality of life outcome considered: none reported

- Safety outcome considered: none reported

- Depression outcome considered: none reported

- Other outcome data on cognitive functioning, not considered in our meta-analyses

* Episodic memory measured with Logical Memory task from the Wechsler Memory Scale-III (LM1) Supplemental Score, 1st Recall at 4 months, on a scale from 0 to not reported with higher values indicating benefit

* Episodic memory measured with Hopkins Verbal Learning Test (HVLT), immediate recall at 4 months, on a scale from 0 to not reported with higher values indicating benefit

* Episodic memory measured with Hopkins Verbal Learning Test (HVLT), delayed recall at 4 months, on a scale from 0 to not reported with higher values indicating benefit

* Executive functioning measured with Flanker Task, Incongruent-Congruent RTs at 4 months, on a scale from 0 to not reported with higher values indicating benefit

* Executive functioning measured with Task Switching, Switch-Non-switch RTs at 4 months, on a scale from 0 to not reported with higher values indicating benefit

* Executive functioning measured with Self-Ordered Pointing Task, \% correct at 4 months, on a scale from 0 to not reported with higher values indicating benefit

* Executive functioning measured with 1-Back, \% Hits-False Alarms at 4 months, on a scale from 0 to not reported with higher values indicating benefit

* Executive functioning measured with 2-Back, \% Hits-False Alarms at 4 months, on a scale from 0 to not reported with higher values indicating benefit of participants in the pooled experimental group and 50\% in the pooled control group received standardised physical activity. Pooling was justified, as no interaction effect of physical activity was observed. Study authors stated: "Depending on the choice of outcome, two-armed full-scale trials may require fewer than 1000 participants (continuous outcome) or 2000 participants (categorical outcome)". One SAE occurred, but the trial authors did not report in which trial arm

\section{Risk of bias}

\begin{tabular}{lll}
\hline Bias & Authors' judgement & Support for judgement \\
\hline $\begin{array}{l}\text { Random sequence genera- } \\
\text { tion (selection bias) }\end{array}$ & Unclear risk & $\begin{array}{l}\text { Judgement: method of random sequence generation not reported } \\
\text { Quote(s): "following this, they were randomly assigned with equal probability } \\
\text { among the four experimental conditions" }\end{array}$ \\
\hline $\begin{array}{l}\text { Allocation concealment } \\
\text { (selection bias) }\end{array}$ & Unclear risk & $\begin{array}{l}\text { Judgement: method of allocation concealment not reported } \\
\text { Quote(s): "following this, they were randomly assigned with equal probability } \\
\text { among the four experimental conditions" }\end{array}$ \\
\hline
\end{tabular}

Blinding of participants High risk Judgement: blinding not feasible

(performance bias)

Blinding of personnel (per- High risk formance bias)

Judgement: blinding not feasible 
Legault 2011 (Continued)

Blinding of outcome as- Low risk Judgement: study described as "single-blinded", and at clinicaltrials.gov, it is sessment (detection bias) explicitly described that outcome assessors were blinded

All outcomes

Quote(s): "clinicaltrials.gov - Masking: Single Blind (Outcomes Assessor)"

Incomplete outcome data Low risk (attrition bias)

All outcomes
Judgement: for the outcome executive functioning: statistical analyses were reported to be done according to the intent-to-treat principle. Study authors described the analysis as being done according to the ITT principle, but we wonder if they referred only to the principle that the participant was analysed in the group to which he/she was randomised, regardless of cross-over. We are unsure if the 2 participants with missing data in the experimental group and the 1 in the control group were included in the analyses. We treated them as not analysed in our meta-analyses, in accordance with how the trial authors depicted their data in the tables
Selective reporting (re- High risk
porting bias)
Judgement: all outcomes indicated in the methods section are adequately addressed in the results section, but at least 2 instruments (perceived cognitive functioning problems and quality of life) mentioned in NCT00688155 are not mentioned in the full publication

Other bias

High risk

\begin{abstract}
Judgement: comparison 1: no other potential sources of bias detected; comparison 2: attendance rate in the combined $\mathrm{CCl}$ and physical activity group was statistically significantly better than in the physical activity only control group. The direction of bias would likely inflate $\mathrm{CCl}$ effects; we thus judged high risk of bias for comparison 2 .
\end{abstract}

Quote(s): "intervention attendance rates were higher in the CT and PACT groups: CT: $96 \%$, PA: $76 \%$, PACT: $90 \%(P=0.004) "$

Leung 2015

\begin{tabular}{|c|c|}
\hline Methods & $\begin{array}{l}\text { - Design: 2-arm RCT with parallel-group design } \\
\text { - Recruitment period: not reported } \\
\text { - No. of centres involved: } 1 \\
\text { - Unit of randomisation: individuals } \\
\text { - No. randomised: not reported } \\
\text { - Number of arms considered in this review: } 2 \\
\text { - Maximum trial duration: } 3 \text { months } \\
\text { - Funding by non-profit organisation: this work was supported by Health and Health Services Re- } \\
\text { - Search Fund (No. } 09100911 \text { ) } \\
\text { - Punding by commercial organisation: none reported }\end{array}$ \\
\hline Participants & $\begin{array}{l}\text { - Patient flow: unclear number randomised; } 109 \text { described at baseline in experimental group; } 100 \text { de- } \\
\text { scribed at baseline in control group } \\
\text { - Number of females: } 87 \text { of } 109 \text { (80\%) in experimental group } 1 ; 77 \text { of } 100 \text { ( } 77 \%) \text { in control group } 1 \\
\text { - Average age (SD): } 70 \text { (6.2) years in experimental group } 1 ; 70 \text { (6.6) years in control group } 1 \\
\text { - Average (SD) education: } 8.71 \text { (3.84) years in experimental group; } 9.49 \text { (4.44) years in control group } \\
\text { - Baseline cognitive function: selection criteria on cognition in experimental group: right-handed } \\
\text { community-dwelling Chinese older adults at risk of cognitive decline, as indicated by their Montre- } \\
\text { al Cognitive Assessment (MoCA) scores falling into the range of } 19 \text { to } 26 \text {. MoCA, Hong Kong version, } \\
\text { mean total score } 23.6 \text { (SD 1.88). Selection criteria on cognition in control group: right-handed com- } \\
\text { munity-dwelling Chinese older adults at risk of cognitive decline, as indicated by their MoCA scores } \\
\text { falling into the range of } 19 \text { to } 26 \text {. MoCA, Hong Kong version, mean total score } 23.8 \text { (SD 1.97) }\end{array}$ \\
\hline
\end{tabular}

Computerised cognitive training for 12 or more weeks for maintaining cognitive function in cognitively healthy people in late life 
Leung 2015 (Continued)

- Ethnicity: experimental group: white, Indian 109; Asian, Black, other unclear. Control group: white, Indian 100; Asian, Black, other unclear

- APOE: number of participants positive for APOE not reported

Interventions Type of experimental intervention: computerised CT group; treatment duration 13 weeks; intervention provided in group format, under supervision

- Details of experimental intervention: for both CT and AC groups, each participant was assigned a laptop, a headset, and a mouse, all of which were used for performing cognitive exercises. They used the same laptop for their entire training

- Type of concomitant treatment provided: none reported

- Session duration: 60 minutes in experimental group

- Number of treatment sessions: 39 in experimental group

- Treatment frequency: $3 /$ week in experimental group

- Maximum treatment duration in weeks: 13 in experimental group

Type of control intervention: other; treatment duration 13 weeks; intervention provided in group format, under supervision

- Details of control intervention: participants in active control group "..were shown educational programs covering diverse topics (e.g., history, science, health information, and local social issues) on a group basis. Immediately after watching the video, they were instructed to answer several questions that were related to the video content"

- Type of concomitant treatment provided: none reported

- Session duration: 60 minutes in control group

- Number of treatment sessions: 39 in control group

- Treatment frequency: $3 /$ week in control group

- Maximum treatment duration in weeks: 13 in control group
- Cognitive functioning outcomes considered

* Episodic memory measured with WMS-III Logical Memory Delayed recall at 3.25 months, on a scale from not reported to not reported with higher values indicating benefit*

* Working memory measured with Digit Span, total at 3.25 months, on a scale from not reported to not reported with higher values indicating benefit

- Physical functioning outcome considered: none reported

- Quality of life outcome considered: none reported

- Safety outcome considered: none reported

- Depression outcome considered: none reported

- Other outcome data on cognitive functioning, not considered in our meta-analyses

* Episodic memory measured with WMS-III Logical Memory Immediate recall at 3.25 months, on a scale from not reported to not reported with higher values indicating benefit*

* Episodic memory measured with WMS-III Family Pictures Delayed recall at 3.25 months, on a scale from not reported to not reported with higher values indicating benefit

* Episodic memory measured with WMS-III Family Pictures Immediate recall at 3.25 months, on a scale from not reported to not reported with higher values indicating benefit

* Working memory measured with Digit Vigilance Test at 3.25 months, on a scale from not reported to not reported with higher values indicating benefit

* Working memory measured with Visual Spatial Span, total at 3.25 months, on a scale from not reported to not reported with higher values indicating benefit

Notes

Risk of bias

Authors' judgement Support for judgement

Computerised cognitive training for 12 or more weeks for maintaining cognitive function in cognitively healthy people in late life 
Leung 2015 (Continued)

Random sequence genera- Low risk tion (selection bias)
Judgement: adequate random sequence generation

Quote(s): "the 209 participants were randomly assigned to the CT and AC groups by an experimenter blind to the cognitive status of the participants using computer-generated random sequences of numbers"

$\begin{array}{ll}\begin{array}{l}\text { Allocation concealment } \\ \text { (selection bias) }\end{array} & \text { Judgement: the method of concealment is unclear as it is not understandable } \\ & \text { why participants had to be "rearranged", and we suspect that participants } \\ & \text { were not allocated consecutively, while it remains unclear if allocation of a } \\ \text { participant could be foreseen by the researcher }\end{array}$

Quote(s): "specifically, each participant ID was paired with a random number, and the order of the participants was rearranged based on the value of the assigned number (from smallest to largest)"

\begin{tabular}{ll}
\hline $\begin{array}{l}\text { Blinding of participants } \\
\text { (performance bias) }\end{array}$ & High risk Judgement: patients were not blinded to treatment
\end{tabular}

\section{Blinding of personnel (per- High risk} formance bias)

\section{Judgement: research assistants could not be blinded, and they both super-} vised training and performed post-training assessments

Quote(s): "a research assistant was present in each training session to keep track of their attendance and address any questions pertaining to the task instruction raised by the participants. These research assistants were also responsible for conducting the post-training assessments"

$\begin{array}{lll}\begin{array}{l}\text { Blinding of outcome as- } \\ \text { sessment (detection bias) }\end{array} & \text { High risk } & \begin{array}{l}\text { Judgement: therapists, who could not be blinded, supervised training and } \\ \text { perform post-training assessments }\end{array}\end{array}$

All outcomes

Quote(s): "a research assistant was present in each training session to keep track of their attendance and address any questions pertaining to the task instruction raised by the participants. These research assistants were also responsible for conducting the post-training assessments"

Incomplete outcome data Unclear risk
(attrition bias)

All outcomes

\begin{abstract}
Judgement: reporting is inconclusive. Although according to the flow diagram it seems that 109 were randomised to experimental and 100 to control, we wonder if this merely reflects the number randomised who completed the follow-up assessment. There is no mention of intent-to-treat analyses, missing data, dropouts, or withdrawals, so that we judged risk as unclear
\end{abstract}

Quote(s): "our final sample consisted of 209 older adults (...) who successfully completed the pre- and post-training assessment, of which 109 older adults were randomly assigned to the CT group (...) and 100 older adults were in the AC group".

\begin{tabular}{|c|c|c|}
\hline $\begin{array}{l}\text { Selective reporting (re- } \\
\text { porting bias) }\end{array}$ & Low risk & $\begin{array}{l}\text { Judgement: all outcomes described in the methods section are adequately } \\
\text { addressed in the results section }\end{array}$ \\
\hline Other bias & Unclear risk & $\begin{array}{l}\text { Judgment: the selection process is not clear because study authors do not in- } \\
\text { dicate the number of participants actually screened, those excluded, and rea- } \\
\text { sons for exclusion. It is not clear whether inclusion was consecutive, and study } \\
\text { authors mention that baseline characteristics were "matched". With the latter, } \\
\text { we assume they meant "comparable" }\end{array}$ \\
\hline
\end{tabular}

Quote(s): "participants from the CT and AC groups were matched for their demographic characteristics" 
Peretz 2011

\begin{tabular}{ll}
\hline Methods & Design: 2 -arm RCT with factorial design \\
- Recruitment period: not reported \\
- Unit of randomisation: individuals \\
- No. randomised: 155 \\
- Number of arms considered in this review: 2 \\
- Maximum trial duration: 3 months \\
- Funding by non-profit organisation: none reported \\
- Funding by commercial organisation: NexSig Cognifit \\
- Publication status: full-text report \\
- Patient flow: 84 randomised, 84 described at baseline in experimental group; 71 randomized, 71 de- \\
- Scribed at baseline in control group \\
- Averager of females: 56 of 84 (67\%) in experimental group $1 ; 40$ of 71 (56\%) in control group 1 \\
- Average (SD) education: 14.6 (2.8) years in experimental group; 15.1 (3.6) years in control group \\
- Baseline cognitive function: MMSE 29.0 (SD 1.2) \\
- Selection criteria on cognition overall: healthy \\
- Ethnicity: not reported \\
- APOE: number of participants positive for APOE not reported
\end{tabular}

Interventions

Type of experimental intervention: computerised $\mathrm{CT}$, individualised; treatment duration of 12 weeks; intervention provided as individual training, without supervision

- Details of experimental intervention: the personalised cognitive training programme selected for this study was the CogniFit Personal Coach. This programme's training regimen is based on the results of a baseline cognitive evaluation called the Neuropsychological Examination-CogniFit Personal Coach

- Session duration: 20 to 30 minutes in experimental group

- Number of treatment sessions: 36 in experimental group

- Treatment frequency: $3 /$ week in experimental group

- Maximum treatment duration in weeks: 12 in experimental group

Type of control intervention: active computer; treatment duration of 12 weeks; intervention provided as individual training, without supervision

- Details of control intervention: "twelve classic computer games that significantly engage cognitive processing were selected to create the computer games program. This program shared several features with the personalized cognitive training program, including the baseline cognitive evaluation, a total of 24 sessions comprising 3 different tasks, and a similar graphic design (Appendix 2). However, it did not have the adaptive training features of the personalized cognitive training program"

- Session duration: 25 minutes in control group

- Number of treatment sessions: 36 in control group

- Treatment frequency: $3 /$ week in control group

- Maximum treatment duration in weeks: 12 in control group

Outcomes

- Cognitive functioning outcomes considered

* Global cognitive functioning measured with Overall score: NexAde battery at 3 months, on a scale from not reported to not reported with higher values indicating benefit

* Episodic memory measured with Memory recall at 3 months, on a scale from not reported to not reported with higher values indicating benefit

* Executive functioning measured with Executive functions at 3 months, on a scale from not reported to not reported with higher values indicating benefit

* Working memory measured with Visuospatial working memory at 3 months, on a scale from not reported to not reported with higher values indicating benefit 
Peretz 2011 (Continued)

- Physical functioning outcome considered: none reported

- Quality of life outcome considered: none reported

- Safety outcome considered: none reported

- Depression outcome considered: none reported

- Other outcome data on cognitive functioning, not considered in our meta-analyses

* Episodic memory measured with Memory recognition at 3 months, on a scale from not reported to not reported with higher values indicating benefit

* Episodic memory measured with Visuospatial learning at 3 months, on a scale from not reported to not reported with higher values indicating benefit

* Executive functioning measured with Focused attention at 3 months, on a scale from not reported to not reported with higher values indicating benefit

* Executive functioning measured with Mental flexibility at 3 months, on a scale from not reported to not reported with higher values indicating benefit

* Working memory measured with Sustained attention at 3 months, on a scale from not reported to not reported with higher values indicating benefit

Notes

\section{Risk of bias}

\begin{tabular}{lll}
\hline Bias & Authors' judgement & Support for judgement \\
\hline $\begin{array}{l}\text { Random sequence genera- } \\
\text { tion (selection bias) }\end{array}$ & Low risk & $\begin{array}{l}\text { Judgement: adequate random sequence generation } \\
\text { Quote(s): "random number generator" }\end{array}$ \\
\hline $\begin{array}{l}\text { Allocation concealment } \\
\text { (selection bias) }\end{array}$ & Low risk & Judgement: adequate method of allocation concealment \\
& Quote(s): "encrypted codes" \\
\hline $\begin{array}{l}\text { Blinding of participants } \\
\text { (performance bias) }\end{array}$ & High risk & $\begin{array}{l}\text { Judgement: a large number of participants correctly identified their group as- } \\
\text { signment; this is assumed to be an indication of poor blinding of participants }\end{array}$ \\
& $\begin{array}{l}\text { Quote(s): ".with investigators and participants being blind to group assign- } \\
\text { ment. Participants received a CD containing either the cognitive training pro- } \\
\text { gram or the computer games program. To preserve blindness, all CDs were } \\
\text { labelled and packaged identically, and all graphics, fonts, opening screens, } \\
\text { baseline evaluations and post-training evaluations were identical on both CDs. } \\
\text { Personnel were kept unaware of the participants' group assignment, which } \\
\text { was encrypted in the code number labels on the CDs"; "'Thirty-six percent of } \\
\text { the subjects correctly identified their group assignment (21\% personalized } \\
\text { cognitive training, 15\% games)" }\end{array}$ \\
\hline
\end{tabular}

Blinding of personnel (per- Low risk formance bias)
Judgement: adequate method of therapist blinding

Quote(s): "..with investigators and participants being blind to group assignment. Participants received a CD containing either the cognitive training program or the computer games program. To preserve blindness, all CDs were labelled and packaged identically, and all graphics, fonts, opening screens, baseline evaluations and post-training evaluations were identical on both CDs. Personnel were kept unaware of the participants' group assignment, which was encrypted in the code number labels on the CDs"

Judgement: not clearly reported if outcome assessors were blinded, but all personnel were likely kept blinded to treatment assignment

Quote(s): "personnel were kept unaware of the participants' group assignment, which was encrypted in the code number labels on the CDs" 
Peretz 2011 (Continued) Incomplete outcome data High risk
(attrition bias)

All outcomes
Judgement: for the outcome episodic memory, 66 out of 84 (79\%) randomised were analysed in experimental group, and 55 out of $71(77 \%)$ randomised were analysed in control group. Statistical analyses were reported to be done according to the intent-to-treat principle. Although study authors state that they used an ITT, 18 participants in experimental group and 16 in control group did not complete the training and had no data available at baseline, follow-up, or both

Quote(s): "a total of 34 (22\%) participants (18 in the cognitive training group and 16 in the computer games group) did not complete the training; the majority of those $(n=29)$ never began the home training"

\begin{tabular}{lll}
\hline $\begin{array}{l}\text { Selective reporting (re- } \\
\text { porting bias) }\end{array}$ & Low risk & $\begin{array}{l}\text { Judgement: all outcomes indicated in the methods section are reported in the } \\
\text { results section }\end{array}$ \\
\hline Other bias & Low risk & Judgement: no other apparent risks of bias \\
\hline
\end{tabular}

Shatil 2013

\begin{tabular}{|c|c|}
\hline Methods & $\begin{array}{l}\text { - Design: 4-arm RCT with parallel-group design } \\
\text { - Recruitment period: not reported } \\
\text { - No. of centres involved: } 1 \\
\text { - Unit of randomisation: individuals } \\
\text { - No. randomised: } 180 \\
\text { - Number of arms considered in this review: } 4 \\
\text { - Maximum trial duration: } 4 \text { months } \\
\text { - Funding by non-profit organisation: Beckman Insititute } \\
\text { - Funding by commercial organisation: none reported } \\
\text { - Publication status: full-text report }\end{array}$ \\
\hline Participants & $\begin{array}{l}\text { - Patient flow: } 45 \text { randomised, } 33 \text { described at baseline in experimental group } 1 ; 48 \text { randomised, } 29 \\
\text { described at baseline in experimental group 2; } 45 \text { randomised, } 31 \text { described at baseline in experimen- } \\
\text { tal group 3; } 42 \text { randomised, } 29 \text { described at baseline in control group } \\
\text { - Number of females: } 23 \text { of } 33 \text { ( } 70 \%) \text { in experimental group } 1 ; 20 \text { of } 29(69 \%) \text { in experimental group 2; } \\
22 \text { of } 31 \text { ( } 71 \%) \text { in experimental group 3; } 19 \text { of } 29(66 \%) \text { in control group } 1 \\
\text { - Average age (SD): } 80 \text { (5.4) years in experimental group 1; } 79 \text { (5.5) years in experimental group 2;79 } \\
\text { (5.8) years in experimental group 3; } 81 \text { (5.3) years in control group } 1 \\
\text { - Average (SD) education: experimental group 1: some college and above: } 26 \text { (78,8\%); experimental } \\
\text { group 2: some college and above: } 17 \text { ( } 58,6 \%) \text {; experimental group 3: some college and above: } 28 \\
\text { (90,3\%); control group 1: some college and above: } 23(79,3 \%) \\
\text { - Baseline cognitive function: MMSE > } 24 \\
\text { - Selection criteria on cognition overall: healthy } \\
\text { - Ethnicity: not reported } \\
\text { - APOE: number of participants positive for APOE not reported }\end{array}$ \\
\hline
\end{tabular}

Interventions

Type of experimental intervention 1: computerised CT group; treatment duration of 16 weeks; intervention provided in group format, under supervision

- Details of experimental intervention: Cognifit

- Session duration: 40 minutes in experimental group

- Number of treatment sessions: 48 in experimental group

- Treatment frequency: $3 /$ week in experimental group

- Maximum treatment duration in weeks: 16 in experimental group

Computerised cognitive training for $\mathbf{1 2}$ or more weeks for maintaining cognitive function in cognitively healthy people in late life 


\section{Type of experimental intervention 2: mixed}

- Details of experimental intervention 2: cognitive training as for experimental arm 1 in combination with group-based supervised physical training, which consisted of 3 weekly 45 -minute sessions, with at least a 1-day interval between training days, during 16 weeks

- Session duration: 40 minutes in experimental group 2

- Number of treatment sessions: 48 in experimental group 2

- Treatment frequency: $3 /$ week in experimental group 2

- Maximum treatment duration in weeks: 16 in experimental group 2

Type of control intervention 1: other; treatment duration of 16 weeks; intervention provided in group format, under supervision

- Details of control intervention: this group was assigned selected book excerpts to be read at home and held one 60-minute weekly meeting during which the best ways to achieve the goals advocated in the book were discussed. This group was classified as an active control group because it was compared with the Cognifit group

- Session duration: 60 minutes in control group

- Number of treatment sessions: 16 in control group

- Treatment frequency: 1 /week in control group

- Maximum treatment duration: 16 in control group

Type of control intervention 2: other; intervention provided in group format, under supervision

- Details of control intervention 2: group-based supervised physical training. This group was classified as an inactive control group because it was compared with the mixed experimental intervention

- Session duration: 45 minutes in control group 2

- Number of treatment sessions: 48 in control group 2

- Treatment frequency: $3 /$ week in control group 2

- Maximum treatment duration in weeks: 16 in control group 2

Outcomes

- Cognitive functioning outcomes considered for both comparisons

* Speed of processing measured with SVP at 4 months, on a scale from not reported to not reported with higher values indicating benefit

* Working memory measured with AM Cognifit at 4 months, on a scale from not reported to not reported with higher values indicating benefit

- Physical functioning outcome considered: none reported

- Quality of life outcome considered: none reported

- Safety outcome considered: none reported

- Depression outcome considered: none reported

- Other outcome data on cognitive functioning, not considered in our meta-analyses

- Cognifit subtests

Notes

\section{Risk of bias}

\begin{tabular}{lll}
\hline Bias & Authors' judgement & Support for judgement \\
\hline $\begin{array}{l}\text { Random sequence genera- } \\
\text { tion (selection bias) }\end{array}$ & Unclear risk & $\begin{array}{l}\text { Judgement: method of random sequence generation not reported } \\
\text { Quote(s): "following the screening subjects were randomized to the four inter- } \\
\text { vention groups" }\end{array}$ \\
\hline
\end{tabular}

Allocation concealment Unclear risk Judgement: method of allocation concealment not reported

(selection bias) 
Quote(s): "following the screening subjects were randomized to the four intervention groups"

Blinding of participants Unclear risk Judgement: no information reported
(performance bias)

\begin{tabular}{lll}
\hline $\begin{array}{l}\text { Blinding of personnel (per- } \\
\text { formance bias) }\end{array}$ & Unclear risk & Judgement: no information reported \\
\hline $\begin{array}{l}\text { Blinding of outcome as- } \\
\text { sessment (detection bias) }\end{array}$ & Unclear risk & Judgement: blinding of outcome assessment not reported \\
$\begin{array}{l}\text { All outcomes } \\
\text { Quote(s): "to measure change in cognitive function following the interven- } \\
\text { tions, we used the CogniFit neuropsychological evaluation" }\end{array}$ \\
\hline
\end{tabular}

\begin{tabular}{|c|c|c|}
\hline $\begin{array}{l}\text { Incomplete outcome data } \\
\text { (attrition bias) }\end{array}$ & High risk & $\begin{array}{l}\text { Judgement: } 62 \text { out of } 93(67 \%) \text { randomised were analysed in experimental } \\
\text { group, and } 60 \text { out of } 87(69 \%) \text { randomised were analysed in control group }\end{array}$ \\
\hline
\end{tabular}

Quotes: "55 participants (30.5\%) left during the baseline testing period, while another battery of tests (to be reported elsewhere) were being administered; before the training interventions.."; "three participants, two in the Cognitive Training Group and one in the Physical Activity Group, left the study, due to health problems. Thus, altogether, 58 subjects ( $32.2 \%$ among the 180 enlisted study participants) withdrew from the study and 122 adhered to it"

\begin{tabular}{lll}
\hline $\begin{array}{l}\text { Selective reporting (re- } \\
\text { porting bias) }\end{array}$ & Low risk & $\begin{array}{l}\text { Judgement: all outcomes indicated in the methods section are reported in the } \\
\text { results section }\end{array}$ \\
\hline Other bias & High risk & $\begin{array}{l}\text { Judgement: potential high risk of bias because the main author (Shatil) is an } \\
\text { employee of the CogniFit Company }\end{array}$ \\
\hline
\end{tabular}

van het Reve 2014

\begin{tabular}{|c|c|}
\hline Methods & $\begin{array}{l}\text { - Design: international multi-centre 2-arm RCT with parallel-group design } \\
\text { - Recruitment period: } 2011 \text { to } 2013 \\
\text { - No. of centres involved: } 14 \\
\text { - Unit of randomisation: individuals } \\
\text { - No. randomised: } 182 \\
\text { - Number of arms considered in this review: } 2 \\
\text { - Maximum trial duration: } 3 \text { months } \\
\text { - Funding by non-profit organisation: none reported } \\
\text { - Funding by commercial organisation: none reported } \\
\text { - Publication status: full-text report }\end{array}$ \\
\hline Participants & $\begin{array}{l}\text { - Patient flow: } 84 \text { randomised, } 69 \text { described at baseline in experimental group; } 98 \text { randomised, } 76 \text { de- } \\
\text { scribed at baseline in control group } \\
\text { - Number of females: } 49 \text { of } 69(71 \%) \text { in experimental group } 1 ; 52 \text { of } 76 \text { (68\%) in control group } 1 \\
\text { - Average age (SD): } 81 \text { (8.3) years in experimental group 1; } 82(6.3) \text { years in control group } \\
\text { - Education: experimental group 1: university/college } 7(10) \text {, vocational education } 41 \text { (59), no educated } \\
\text { profession } 21(30) \text {, in a sitting position past profession } 18(26) \text {; control 1: university/college } 4(5) \text {, vo- } \\
\text { cational education } 52(68) \text {, no educated profession } 20(26) \text {, in a sitting position past profession } 15(20) \\
\text { - Baseline cognitive function: selection criteria on cognition overall: healthy } \\
\text { - Selection criteria on cognition: experimental group: MMSE score (mean } \pm \text { SD): } 27.6 \pm 2.6 \text {; control } \\
\text { group: MMSE score (mean } \pm \text { SD): } 27.7 \pm 2.9 \\
\text { - Ethnicity: not reported }\end{array}$ \\
\hline
\end{tabular}


- APOE: number of participants positive for APOE not reported*

Interventions Type of experimental intervention: computerised CT group; treatment duration of 12 weeks; intervention provided in group format, under supervision

- Details of experimental intervention: cognitive training, with the CogniPlus training programme

- Type of concomitant treatment provided: strength-balance training

- Session duration: 10 minutes in experimental group

- Number of treatment sessions: 36 in experimental group

- Treatment frequency: $3 /$ week in experimental group

- Maximum treatment duration in weeks: 12 in experimental group

Type of control intervention: other; treatment duration of 12 weeks; intervention provided in group format, under supervision

- Details of control intervention: exercise programme consisted of twice-weekly 30-minute progressive resistance training on age-adapted machines and 10-minute balance training during 12 weeks

- Type of concomitant treatment provided: strength-balance training

- Session duration: 40 minutes in control group

- Number of treatment sessions: 24 in control group

- Treatment frequency: $2 /$ week in control group

- Maximum treatment duration in weeks: 12 in control group

\section{Outcomes}

\section{- Cognitive functioning outcomes considered}

* Executive functioning measured with TMT-B at 3 months, on a scale from not reported to not reported with lower values indicating benefit

* Speed of processing measured with TMT-A at 3 months, on a scale from not reported to not reported with lower values indicating benefit

- Physical functioning outcome considered: none reported

- Quality of life outcome considered: none reported

- Safety outcome considered: none reported

- Depression outcome considered: none reported
Notes

Due to strength-balance training, which was given to both groups, we included the study in the inactive control comparison

\section{Risk of bias}

\begin{tabular}{lll}
\hline Bias & Authors' judgement & Support for judgement \\
\hline $\begin{array}{l}\text { Random sequence genera- } \\
\text { tion (selection bias) }\end{array}$ & Low risk & $\begin{array}{l}\text { Judgement: adequate random sequence generation } \\
\text { Quote(s): "to ensure allocation concealment, participants in each home were } \\
\text { enrolled by the health care staff, and randomized by the person assessing the } \\
\text { outcome measures using simple (unrestricted) randomisation.. based on a ta- } \\
\text { ble of random numbers" }\end{array}$ \\
\hline
\end{tabular}

Allocation concealment Unclear risk (selection bias)

\begin{abstract}
Judgement: unclear allocation concealment
Quote(s): "the assessor generated an unpredictable allocation sequence, which was concealed until assignment occurred. Each participant in every home received a two digit number $(01,02,03, \ldots)$ resulting in a rank order of the participants. With the help of the random numbers table the assessor decided a priori to pick a number from the table with a pencil and go through the table either from bottom-right to upper-left in a diagonal way, horizontally from left-to-right or right-to-left, etc"
\end{abstract}


van het Reve 2014 (Continued)

Blinding of participants Unclear risk Judgement: patient blinding was not reported, but it is unlikely

(performance bias)

Quote(s): "blinding of the investigator was not possible because the investigator conducted part of the assessments"

Blinding of personnel (per- High risk formance bias)
Judgement: investigators were not blinded

Quote(s): "blinding of the investigator was not possible because the investigator conducted part of the assessments"

\section{Blinding of outcome as- sessment (detection bias) \\ All outcomes}

\section{Judgement: outcome assessment was not blinded}

Quote(s): "blinding of the investigator was not possible because the investigator conducted part of the assessments"
Incomplete outcome data High risk (attrition bias)

All outcomes
Judgement: 69 out of $84(82 \%)$ randomised were analysed in the experimental group, and 76 out of $98(78 \%)$ randomised were analysed in the control group, although statistical analyses were reported to be done according to the intent-to-treat principle. In addition, 4 participants were re-assigned by investigators to the control group despite being initially randomised to the intervention group

Quote(s): "a total of 156 participants completed the intervention (137 subjects living in the homes-for-the-aged and 19 subjects living in the vicinity) resulting in 14.3\% attrition"; "Four participants that were not able to conduct the cognitive training due to vision problems were manually allocated to the SB group after randomization. Thus, we reported 98 participants in SB and 84 participants in SBC after this adaptation"

\begin{tabular}{ll}
\hline $\begin{array}{l}\text { Selective reporting (re- } \\
\text { porting bias) }\end{array}$ & Low risk \\
\end{tabular}

\begin{tabular}{ll}
\hline Other bias & Low risk \\
& Quote(s): none \\
\hline
\end{tabular}

AC: active control.

$\mathrm{AE}$ : adverse event.

APOE: apolipoprotein E.

AR: aerobics and resistance.

BDT-DT: The Baddeley Dual Task

CCI: computerised cognitive intervention.

COWAT: Controlled Oral Word Association Test.

CT: computed tomography.

CWIT: Color-Word Interference Test.

DT: dual task.

FCSRT: Free and Cued Selective Reminding Test.

GDS-Sf: short-form Geriatric Depression Scale.

HVLT: Hopkins Verbal Learning Test.

ITT: intention-to-treat.

MMRM: mixed model for repeated measures.

MMSE: Mini Mental State Examination.

MoCA: Montreal Cognitive Assessment.

RBMT: Rivermead Behavioural Memory Test.

$\mathrm{RCT}$ : randomised controlled trial.

RT: Reaction time.

SAE: serious adverse event.

SD: standard deviation.

ST: stretching and toning.

SVP: speed of visual information processing.

Computerised cognitive training for 12 or more weeks for maintaining cognitive function in cognitively healthy people in late life 
TMT: Trail Making Test.

WMS-III: Wechsler Memory Scale, Third Edition.

Characteristics of excluded studies [ordered by study ID]

\begin{tabular}{|c|c|}
\hline Study & Reason for exclusion \\
\hline Adel 2013 & Wrong study design \\
\hline Alves 2014 & Wrong intervention \\
\hline Alves 2014a & Wrong intervention \\
\hline Anderson 2014 & Intervention shorter than 12 weeks \\
\hline Ann 2012 & Wrong patient population \\
\hline Anon 2007 & Nature of intervention unclear \\
\hline Anon 2007a & Nature of intervention unclear \\
\hline Apostolo 2014 & Wrong patient population \\
\hline Baglio 2011 & Nature of intervention unclear \\
\hline Ball 2002 & Intervention shorter than 12 weeks \\
\hline Ball 2002a & Duplicate \\
\hline Ball 2006 & Intervention shorter than 12 weeks \\
\hline Ball 2013 & Intervention shorter than 12 weeks \\
\hline Ballesteros 2014 & Duplicate \\
\hline Ballesteros 2014a & Duplicate \\
\hline Ballesteros 2015 & Duplicate \\
\hline Ballesteros 2015a & Duplicate \\
\hline Ballesteros 2017 & Intervention shorter than 12 weeks \\
\hline Bamidis 2015 & Wrong study design \\
\hline Baniqued 2014 & Adult population \\
\hline Baniqued 2015 & Younger than 30 years of age \\
\hline Barban 2012 & Duplicate \\
\hline Barban 2016 & $\begin{array}{l}\text { Wrong study design: cross-over trial that reported outcome data only at the end of trial, af- } \\
\text { ter cross-over had taken place }\end{array}$ \\
\hline Barbosa 2015 & Wrong intervention \\
\hline Barcelos 2015 & Wrong intervention \\
\hline
\end{tabular}

Computerised cognitive training for 12 or more weeks for maintaining cognitive function in cognitively healthy people in late life 


\begin{tabular}{|c|c|}
\hline Study & Reason for exclusion \\
\hline Barnes 2006 & Intervention shorter than 12 weeks \\
\hline Barnes 2009 & Duplicate \\
\hline Barnes 2013 & Wrong patient population \\
\hline Basak 2016 & Intervention shorter than 12 weeks \\
\hline Beck 2013 & Wrong intervention \\
\hline Belchior 2007 & Wrong outcomes \\
\hline Belchior 2008 & Wrong outcomes \\
\hline Belleville 2006 & Wrong intervention \\
\hline Belleville 2014 & Wrong outcomes \\
\hline Berry 2010 & Intervention shorter than 12 weeks \\
\hline Bier 2015 & Wrong study design \\
\hline Binder 2016 & Intervention shorter than 12 weeks \\
\hline Bittner 2013 & Wrong study design \\
\hline Borella 2010 & Intervention shorter than 12 weeks \\
\hline Borella 2013 & Wrong intervention \\
\hline Borella 2014 & Duplicate \\
\hline Borella 2017 & Wrong intervention \\
\hline Boripuntakul 2012 & Wrong intervention \\
\hline Borness 2013 & Wrong patient population \\
\hline Bottiroli 2009 & Duplicate \\
\hline Bottiroli 2009a & Intervention shorter than 12 weeks \\
\hline Bozoki 2013 & Intervention shorter than 12 weeks \\
\hline Brehmer 2012 & Intervention shorter than 12 weeks \\
\hline Brum 2013 & Duplicate \\
\hline Buitenweg 2017 & Wrong intervention \\
\hline Buiza 2008 & Wrong intervention \\
\hline Bureš 2016 & Intervention shorter than 12 weeks \\
\hline Buschert 2011 & Wrong intervention \\
\hline
\end{tabular}

Computerised cognitive training for 12 or more weeks for maintaining cognitive function in cognitively healthy people in late life 


\begin{tabular}{|c|c|}
\hline Study & Reason for exclusion \\
\hline Buschert 2011a & Duplicate \\
\hline Buschert 2012 & Wrong intervention \\
\hline Buschert 2012a & Duplicate \\
\hline Buschkuehl 2008 & $\begin{array}{l}\text { Wrong design. Not an RCT. Quote: "pseudorandomly assigned to either the experimental or } \\
\text { the control group. Both groups were matched as closely as possible according to gender, } \\
\text { age, body weight, and selected physical performance measures" }\end{array}$ \\
\hline Calkins 2011 & Wrong intervention \\
\hline Cammarata 2011 & No outcome given \\
\hline Cancela 2015 & Wrong patient population \\
\hline Candela 2015 & Wrong intervention \\
\hline Cantarella 2017 & Intervention shorter than 12 weeks \\
\hline Cao 2016 & Wrong route of administration \\
\hline Carretti 2013 & Wrong intervention \\
\hline Casutt 2014 & Wrong outcomes \\
\hline Chapman 2015 & Wrong intervention \\
\hline Chapman 2016 & Wrong intervention \\
\hline Chapman 2017 & Wrong intervention \\
\hline Cheng 2012 & Wrong intervention \\
\hline Cheng 2018 & Wrong patient population \\
\hline Cho 2002 & Younger than 30 years of age \\
\hline Cleverley 2012 & Wrong intervention \\
\hline Cohen-Mansfield 2014 & Wrong intervention \\
\hline Cohen-Mansfield 2014a & Wrong intervention \\
\hline Cohen-Mansfield 2015 & Wrong intervention \\
\hline Cohen-Mansfield 2015a & Duplicate \\
\hline Combourieu 2014 & Wrong outcomes \\
\hline Corbett 2015 & Wrong patient population \\
\hline Costa 2015 & Wrong patient population \\
\hline Danassi 2015 & Duplicate \\
\hline
\end{tabular}




\begin{tabular}{|c|c|}
\hline Study & Reason for exclusion \\
\hline Dannhauser 2014 & Wrong study design \\
\hline de Almondes 2017 & Intervention shorter than 12 weeks \\
\hline de Macedo 2015 & Wrong outcomes \\
\hline De Vreesse 1996 & Wrong intervention \\
\hline Diamond 2015 & Intervention shorter than 12 weeks \\
\hline Dittmann-Kohli 1991 & Wrong intervention \\
\hline Djabelkhir 2017 & Wrong patient population \\
\hline Duncan 2009 & Wrong intervention \\
\hline Dwolatzky 2005 & Intervention shorter than 12 weeks \\
\hline Eckroth-Bucher 2009 & Wrong patient population \\
\hline Edwards 2005 & Intervention shorter than 12 weeks \\
\hline Edwards 2011 & Intervention shorter than 12 weeks \\
\hline Edwards 2015 & Intervention shorter than 12 weeks \\
\hline Edwards 2015a & Intervention shorter than 12 weeks \\
\hline Efthymiou 2011 & Wrong comparator \\
\hline Engvig 2014 & Wrong study design \\
\hline Fabre 2002 & Wrong intervention \\
\hline Faille 2007 & Nature of intervention unclear \\
\hline Fairchild 2010 & Wrong intervention \\
\hline Feng 2013 & Wrong intervention \\
\hline Feng 2015 & Wrong intervention \\
\hline Feng 2017 & Wrong patient population \\
\hline Fiatarone Singh 2014 & Wrong patient population \\
\hline Finn 2011 & Intervention shorter than 12 weeks \\
\hline Finn 2015 & Intervention shorter than 12 weeks \\
\hline Finn 2015a & Duplicate \\
\hline Flak 2013 & Intervention shorter than 12 weeks \\
\hline Flak 2014 & Intervention shorter than 12 weeks \\
\hline
\end{tabular}




\begin{tabular}{|c|c|}
\hline Study & Reason for exclusion \\
\hline Flak 2014a & Intervention shorter than 12 weeks \\
\hline Flak 2016 & Intervention shorter than 12 weeks \\
\hline Foerster 2009 & No outcome given \\
\hline Forloni 2012 & No outcome given \\
\hline Forster 2011 & Wrong intervention \\
\hline Fortman 2013 & Wrong comparator \\
\hline Gagnon 2012 & Wrong study design \\
\hline Gagnon 2012a & Intervention shorter than 12 weeks \\
\hline Gaitan 2013 & Wrong patient population \\
\hline Gajewski 2012 & Intervention shorter than 12 weeks \\
\hline Gajewski 2017 & Intervention shorter than 12 weeks \\
\hline Garcia-Campuzano 2013 & Nature of intervention unclear \\
\hline Gates 2011 & Study protocol \\
\hline Gill 2016 & Wrong intervention \\
\hline Gillette 2009 & No outcome given \\
\hline Giovannini 2015 & No outcome given \\
\hline Giuli 2016 & Wrong intervention \\
\hline Giuli 2017 & Wrong intervention \\
\hline Golino 2017 & Wrong intervention \\
\hline Gooding 2016 & Wrong patient population \\
\hline Haesner 2015 & Wrong study design \\
\hline Haesner 2015a & Intervention shorter than 12 weeks \\
\hline Haimov 2013 & Intervention shorter than 12 weeks \\
\hline Haimov 2013a & Intervention shorter than 12 weeks \\
\hline Haimov 2013b & Intervention shorter than 12 weeks \\
\hline Haimov $2013 c$ & Duplicate \\
\hline Haimov 2013d & Intervention shorter than 12 weeks \\
\hline Haimov 2014 & Intervention shorter than 12 weeks \\
\hline
\end{tabular}




\begin{tabular}{|c|c|}
\hline Study & Reason for exclusion \\
\hline Haimov 2014a & Intervention shorter than 12 weeks \\
\hline Hardy 2015 & Intervention shorter than 12 weeks \\
\hline Hausmann 2012 & Wrong intervention \\
\hline Hayashi 2012 & Wrong intervention \\
\hline Hayslip B Jr 2016 & Intervention shorter than 12 weeks \\
\hline Heinzel 2014 & Intervention shorter than 12 weeks \\
\hline Herrera 2012 & Wrong patient population \\
\hline Hudak 2013 & Intervention shorter than 12 weeks \\
\hline Hughes 2014 & Wrong population: participants with mild cognitive impairment \\
\hline Hötting 2013 & Intervention shorter than 12 weeks \\
\hline Ignjatovic 2015 & Younger than 30 years of age \\
\hline Irigaray 2012 & Wrong intervention \\
\hline Israel 1997 & Nature of intervention unclear \\
\hline ISRCTN70130279 & Wrong intervention \\
\hline Jackson 2012 & Nature of intervention unclear \\
\hline Jansen 2012 & Wrong intervention \\
\hline Jean 2010 & Intervention shorter than 12 weeks \\
\hline Jeong 2016 & Wrong intervention \\
\hline Jobe 2001 & Intervention shorter than 12 weeks \\
\hline Jones 2013 & Intervention shorter than 12 weeks \\
\hline Kampanaros 2010 & Wrong intervention \\
\hline Kholin 2010 & Intervention shorter than 12 weeks \\
\hline Kim 2012 & Wrong outcomes \\
\hline Kim 2013 & Intervention shorter than 12 weeks \\
\hline Kim 2013a & Wrong outcomes \\
\hline Kim 2015 & Intervention shorter than 12 weeks \\
\hline Kim 2015a & Intervention shorter than 12 weeks \\
\hline Kim 2015b & Duplicate \\
\hline
\end{tabular}

Computerised cognitive training for 12 or more weeks for maintaining cognitive function in cognitively healthy people in late life 


\begin{tabular}{|c|c|}
\hline Study & Reason for exclusion \\
\hline Kivipelto 2014 & Wrong intervention \\
\hline Klusmann 2009 & Duplicate \\
\hline Klusmann 2010a & Duplicate \\
\hline Klusmann 2011 & Younger than 30 years of age \\
\hline Kudelka 2014 & Intervention shorter than 12 weeks \\
\hline Kwak 2015 & Natue of intervention unclear \\
\hline Kwak 2017 & Nature of intervention unclear \\
\hline Kwok 2013 & Intervention shorter than 12 weeks \\
\hline Kwok 2013a & Wrong patient population \\
\hline Lampit 2013 & Wrong study design \\
\hline Lavretsky 2016 & Nature of intervention unclear \\
\hline Law 2014 & Intervention shorter than 12 weeks \\
\hline Law 2014a & Duplicate \\
\hline Lee 2013 & Intervention shorter than 12 weeks \\
\hline Lee 2013a & Intervention shorter than 12 weeks \\
\hline Lee $2013 b$ & Intervention shorter than 12 weeks \\
\hline Lee 2014 & Intervention shorter than 12 weeks \\
\hline Lee 2015 & Intervention shorter than 12 weeks \\
\hline León 2015 & Wrong comparator \\
\hline Li 2010 & Intervention shorter than 12 weeks \\
\hline Linde 2014 & Nature of intervention unclear \\
\hline Mace 2015 & Intervention shorter than 12 weeks \\
\hline Mahncke 2006 & Intervention shorter than 12 weeks \\
\hline Maillot 2012 & $\begin{array}{l}\text { Wrong intervention. RCT meeting all inclusion criteria but those for the intervention: ex- } \\
\text { ergames, which we considered to be a combined intervention of physical exercise and } \\
\text { computerised cognitive training; persons in the control group received no intervention }\end{array}$ \\
\hline Man 2012 & Wrong comparator \\
\hline Mann 2012 & Wrong patient population \\
\hline Margrett 2006 & Wrong patient population \\
\hline
\end{tabular}




\begin{tabular}{|c|c|}
\hline Study & Reason for exclusion \\
\hline Mayas 2014 & Intervention shorter than 12 weeks \\
\hline McAvinue 2013 & Intervention shorter than 12 weeks \\
\hline McDaniel 2014 & Intervention shorter than 12 weeks \\
\hline McDougall 2012 & Intervention shorter than 12 weeks \\
\hline Middleton 2012 & Wrong intervention \\
\hline Miller 2013 & Intervention shorter than 12 weeks \\
\hline Mohs 1998 & Wrong intervention \\
\hline Mombelli 2012 & No outcome given \\
\hline Moon 2013 & Intervention shorter than 12 weeks \\
\hline Mowszowski 2014 & Intervention shorter than 12 weeks \\
\hline Mowszowski 2014a & Duplicate \\
\hline Mozolic 2010 & Intervention shorter than 12 weeks \\
\hline Mozolic 2011 & Intervention shorter than 12 weeks \\
\hline Muller 2011 & Nature of intervention unclear \\
\hline Na 2013 & Duplicate \\
\hline Na 2014 & Nature of intervention unclear \\
\hline Naismith 2014 & Duplicate \\
\hline Navarro 2006 & Intervention shorter than 12 weeks \\
\hline NCT02417558 2015 & Nature of intervention unclear \\
\hline NCT02462135 2014 & No outcome given \\
\hline NCT02480738 2012 & No outcome given \\
\hline NCT02512627 2015 & No outcome given \\
\hline NCT02747784 2016 & Wrong patient population \\
\hline NCT02774083 2015 & Wrong comparator \\
\hline NCT02785315 2016 & Wrong intervention \\
\hline NCT02808676 2016 & Wrong intervention \\
\hline Neely 2013 & Nature of intervention unclear \\
\hline Ng 2015 & Wrong intervention \\
\hline
\end{tabular}




\begin{tabular}{|c|c|}
\hline Study & Reason for exclusion \\
\hline Ngandu 2015 & Wrong intervention \\
\hline Ngandu 2015a & Wrong intervention \\
\hline Nishiguchi 2015 & Wrong intervention \\
\hline Nouchi 2012 & Intervention shorter than 12 weeks \\
\hline Nouchi 2013 & Intervention shorter than 12 weeks \\
\hline Nozawa 2015 & Intervention shorter than 12 weeks \\
\hline O'Caoimh 2015 & Intervention shorter than 12 weeks \\
\hline Oei 2013 & Intervention shorter than 12 weeks \\
\hline Oliveira 2013 & Intervention shorter than 12 weeks \\
\hline Optale 2010 & Wrong patient population \\
\hline Otsuka 2015 & Wrong study design \\
\hline Park 2009 & Nature of intervention unclear \\
\hline Park 2014 & Intervention shorter than 12 weeks \\
\hline Payne 2012 & Wrong intervention \\
\hline Payne 2017 & Intervention shorter than 12 weeks \\
\hline Rahe 2015 & Intervention shorter than 12 weeks \\
\hline Rahe 2015a & Intervention shorter than 12 weeks \\
\hline Rebok 2013 & Intervention shorter than 12 weeks \\
\hline Rebok 2014 & Intervention shorter than 12 weeks \\
\hline Redick 2013 & Younger than 30 years of age \\
\hline Requena 2016 & Wrong intervention \\
\hline Rizkalla 2015 & Intervention shorter than 12 weeks \\
\hline Rojas 2013 & Wrong intervention \\
\hline Rose 2015 & Intervention shorter than 12 weeks \\
\hline Rosen 2011 & Intervention shorter than 12 weeks \\
\hline Rozzini 2007 & Wrong patient population \\
\hline Ryu 2013 & Wrong study design \\
\hline Sakka 2015 & Wrong study design \\
\hline
\end{tabular}




\begin{tabular}{|c|c|}
\hline Study & Reason for exclusion \\
\hline Santos 2011 & Wrong comparator \\
\hline Schoene 2015 & Duplicate \\
\hline Schoene 2015a & Duplicate \\
\hline Schumacher 2013 & Intervention shorter than 12 weeks \\
\hline Shah 2012 & Wrong patient population \\
\hline Shatil 2014 & Intervention shorter than 12 weeks \\
\hline Shatil 2014a & Duplicate \\
\hline Sisco 2013 & Intervention shorter than 12 weeks \\
\hline Slegers 2009 & Wrong intervention \\
\hline Smith 2009 & Intervention shorter than 12 weeks \\
\hline Smith-Ray 2014 & Intervention shorter than 12 weeks \\
\hline Smith-Ray 2015 & Intervention shorter than 12 weeks \\
\hline Smith-Ray 2015a & Duplicate \\
\hline Solomon 2014 & Wrong comparator \\
\hline Song 2009 & Wrong intervention \\
\hline Stepankova 2014 & Intervention shorter than 12 weeks \\
\hline Stine-Morrow 2014 & Intervention shorter than 12 weeks \\
\hline Strenziok 2013 & Duplicate \\
\hline Strenziok 2014 & Intervention shorter than 12 weeks \\
\hline Sturz 2011 & Wrong patient population \\
\hline Sturz 2011a & Nature of intervention unclear \\
\hline Sturz 2015 & Duplicate \\
\hline Styliadis 2015 & Intervention shorter than 12 weeks \\
\hline Styliadis $2015 a$ & Duplicate \\
\hline Suo 2012 & Wrong outcomes \\
\hline Szelag 2012 & Intervention shorter than 12 weeks \\
\hline Talib 2008 & Intervention shorter than 12 weeks \\
\hline Tappen 2014 & Wrong intervention \\
\hline
\end{tabular}

Computerised cognitive training for 12 or more weeks for maintaining cognitive function in cognitively healthy people in late life 


\begin{tabular}{|c|c|}
\hline Study & Reason for exclusion \\
\hline Tennstedt 2013 & Study protocol \\
\hline Tesky 2012 & Wrong intervention \\
\hline Tsai 2008 & Wrong study design \\
\hline Tsolaki 2013 & Nature of intervention unclear \\
\hline Tucker-Drob 2009 & Wrong study design \\
\hline van den Berg 2016 & Intervention shorter than 12 weeks \\
\hline van der Ploeg 2016 & Wrong study design \\
\hline Vance 2007 & Intervention shorter than 12 weeks \\
\hline Vidovich 2009 & Intervention shorter than 12 weeks \\
\hline Vidovich 2015 & Intervention shorter than 12 weeks \\
\hline Vidovich 2015a & Duplicate \\
\hline von Bastian 2013 & Intervention shorter than 12 weeks \\
\hline Wadley 2007 & Wrong study design \\
\hline Walton 2015 & Intervention shorter than 12 weeks \\
\hline Wang 2013 & Wrong intervention \\
\hline Weicker 2013 & Intervention shorter than 12 weeks \\
\hline Wild-Wall 2012 & Wrong outcomes \\
\hline Williams 2014 & Intervention shorter than 12 weeks \\
\hline Willis 1986 & Intervention shorter than 12 weeks \\
\hline Willis 2006 & Intervention shorter than 12 weeks \\
\hline Willis 2006a & Duplicate \\
\hline Willis 2007 & Duplicate \\
\hline Willis 2013 & Intervention shorter than 12 weeks \\
\hline Wojtynska 2011 & Intervention shorter than 12 weeks \\
\hline Wolinsky 2006 & Intervention shorter than 12 weeks \\
\hline Wolinsky 2006a & Intervention shorter than 12 weeks \\
\hline Wolinsky 2010 & Intervention shorter than 12 weeks \\
\hline Wolinsky 2010a & Intervention shorter than 12 weeks \\
\hline
\end{tabular}




\begin{tabular}{ll}
\hline Study & Reason for exclusion \\
\hline Wolinsky 2013 & Intervention shorter than 12 weeks \\
\hline Wolinsky 2015 & Intervention shorter than 12 weeks \\
\hline Yam 2014 & Wrong intervention \\
\hline Yassuda 2015 & Intervention shorter than 12 weeks \\
\hline Yip 2012 & Intervention shorter than 12 weeks \\
\hline Yoonmi 2012 & Intervention shorter than 12 weeks \\
\hline Youn 2011 & Intervention shorter than 12 weeks \\
\hline Zelinski 2011 & Wrong study design \\
\hline Zelinski 2011 a & Intervention shorter than 12 weeks \\
\hline Zhuang 2013 & Wrong patient population \\
\hline Zimmermann 2014 & Intervention shorter than 12 weeks \\
\hline
\end{tabular}

Characteristics of studies awaiting assessment [ordered by study ID]

Boot 2013

\begin{tabular}{ll}
\hline Methods & Country: USA \\
- Design: 3 -arm randomised controlled pilot trial with parallel-group design \\
- Ro. of centres involved: 1 \\
- Unit of randomisation: individuals \\
- No. randomised: 62 \\
- Number of arms considered in this review: 3 \\
- Maximum trial duration: 12 weeks \\
- Funding by non-profit organisation: National Institute on Aging, NIA 3 PO1 AG017211, Project \\
- Funding by commercial organisation: none reported \\
- Publication status: full-text report
\end{tabular}

Participants

- Participant profile: independent living Caucasian elderly, 90\% retired, mean near visual acuity of 20/32

- Patient flow: 21 randomised, 21 described at baseline in experimental group; 21 randomised, 21 described at baseline in control group 1;20 randomised, 20 described at baseline in control group 2

- Number of females: 14 of $21(67 \%)$ in experimental group; 11 of $21(52 \%)$ in control group 1; 11 of $20(55 \%)$ in control group 2

- Average age (SD): 74 (1.2) years in experimental group; 75 (1.5) years in control group 1; 72 (1.4) in control group 2

- Average (SD) education: not reported

- Baseline cognitive function: MMSE mean 29, SD 1.04 
- Selection criteria on cognition: minimum score of 25 on the MMSE; $\leq 2$ errors on Short Portable Mental Status Questionnaire; no significant memory deficits using the Wechsler Memory Scale, 3rd edition (Logical Memory subscale; age-adjusted criterion)

- Ethnicity: 100\% Caucasian

- APOE: not reported

Interventions

- Type of experimental intervention: computerised CT, treatment duration 12 weeks; intervention provided as individual training at home, without supervision

- Details of experimental intervention: Brain Fitness group. Video game intervention using the Nintendo DS Lite gaming system, Brain Age 2, with focus on memory, reaction time, language, and mathematical ability

- Type of concomitant treatment provided: none

- Session duration: 60 minutes in experimental group (planned); mean of 56 minutes (SD 6) in practice

- Number of treatment sessions: 60 in experimental group

- Treatment frequency: $5 /$ week in experimental group

- Maximum treatment duration: 12 weeks in experimental group

- Type of control intervention 1: other; treatment duration 12 weeks; intervention provided as group training, under supervision

- Details of control intervention 1: video game intervention using the Nintendo DS Lite gaming system, Mario Kart DS

- Session duration: 60 minutes in control group (planned); mean of 22 minutes (SD 5) in practice

- Number of treatment sessions: 60 in control group

- Treatment frequency: $5 /$ week in control group

- Maximum treatment duration: 12 weeks in control group

- Type of control intervention 2: no intervention

- Details of control intervention 2: no contact group

- Session duration: not applicable

- Number of treatment sessions: not applicable

- Treatment frequency: not applicable

- Maximum treatment duration: not applicable

- Physical functioning outcome to be considered: none measured

\section{Quality of life outcome}

- Depression outcome to be considered: none measured

- Safety outcome to be considered: none measured

Notes *Values across the 6 subscales will be averaged

This trial was identified thanks to a communication with Dr. Lampit and will be included in the meta-analysis in the next update of this review

Stern 2011

\begin{tabular}{ll}
\hline Methods & Design: 3-arm randomised controlled pilot trial with parallel-group design \\
& - Recruitment period: not reported \\
- No. of centres involved: 1 \\
- Unit of randomisation: individual \\
- No. randomised: 60 (of which 40 considered in this review) \\
\hline
\end{tabular}

Computerised cognitive training for 12 or more weeks for maintaining cognitive function in cognitively healthy people in late life 
Stern 2011 (Continued)

- Number of arms considered in this review: 3

- Maximum trial duration: 6 months

- Funding by non-profit organisation

- Funding by commercial organisation

- Publication status: full-text report

Participants

Interventions
- Type of participants: cognitive healthy elderly with (corrected-to) normal vision, with no past or current medical, neurological, or psychiatric disorder

- Patient flow: 20 randomised, 17 described at baseline in experimental group; 20 randomised, 18 described at baseline in experimental group 2; 20 randomised, 19 described at baseline in control group

- Number of females: 10 of 17 (59\%) in experimental group 1; 9 of $18(50 \%)$ in experimental group 2; 11 of $19(58 \%)$ in control group

- Average age (SD): 66 (4.5) years in experimental group 1; 66 (4.0) years in experimental group 2; 67 (4.2) years in control group

- Average (SD) education: 15.65 (2.55) years in experimental group; 16.28 (2.61) years in experimental 2 group; 15.74 (2.54) years in control group

- Baseline cognitive function: DRS total score 140.7 (SD 2.88) in experimental group 1; 140.7 (SD 2.33) in experimental group 2; and 140.2 (SD 2.76) in control group

- Selection criteria on cognition: Mattis Dementia Rating Scale (DRS) total score 135 or higher included. Neuropsychological test data from baseline assessment battery were subsequently reviewed to ensure absence of dementia or $\mathrm{MCl}$

- Ethnicity: not reported

- APOE: not reported

Type of experimental intervention 1: computerised CT, treatment duration 12 weeks; intervention provided as individual training, under supervision

- Details of experimental intervention: Space Fortress, played with emphasis on attention*

- Type of concomitant treatment provided: none reported

- Session duration: 60 minutes in experimental group

- Number of treatment sessions: 36 in experimental group

- Treatment frequency: $3 /$ week in experimental group

- Maximum treatment duration: 12 weeks in experimental group

Type of experimental intervention 2: computerised CT, treatment duration 12 weeks; intervention provided as individual training, under supervision

- Details of experimental intervention: Space Fortress, played with standard instructions*

- Type of concomitant treatment provided: none reported

- Session duration: 60 minutes in experimental group

- Number of treatment sessions: 36 in experimental group

- Treatment frequency: $3 /$ week in experimental group

- Maximum treatment duration: 12 weeks in experimental group

Type of control intervention 1: passive; treatment duration 12 weeks

- Details of control intervention: no intervention

- Session duration: not applicable in control group

- Number of treatment sessions: not applicable in control group

- Treatment frequency: not applicable in control group

- Maximum treatment duration: not applicable in control group
Cognitive functioning outcomes

- Physical functioning outcome to be considered: none measured

- Quality of life outcome to be considered: none measured

Computerised cognitive training for 12 or more weeks for maintaining cognitive function in cognitively healthy people in late life 
Stern 2011 (Continued)

- Depression outcome to be considered: none measured

- Safety outcome to be considered: none measured

Notes

* In the systematic review by Lampit 2014a, the trial arm playing Space Fortress under specific experimental conditions (emphasis change) was not included. Instead, the trial arm playing Space Fortress with standard instructions was included

This trial was identified thanks to a communication with Dr. Lampit and will be included in the meta-analysis in the next update of this review

\section{DATA AND ANALYSES}

\section{Comparison 1. Computerised cognition-based training versus active control}

\begin{tabular}{|c|c|c|c|c|}
\hline Outcome or subgroup title & $\begin{array}{l}\text { No. of } \\
\text { studies }\end{array}$ & $\begin{array}{l}\text { No. of } \\
\text { partici- } \\
\text { pants }\end{array}$ & Statistical method & Effect size \\
\hline 1 Global cognitive function & 2 & & $\begin{array}{l}\text { Std. Mean Difference (Random, } \\
95 \% \mathrm{Cl} \text { ) }\end{array}$ & Subtotals only \\
\hline 1.2 End of intervention period (12 weeks) & 2 & 232 & $\begin{array}{l}\text { Std. Mean Difference (Random, } \\
95 \% \mathrm{Cl} \text { ) }\end{array}$ & $-0.31[-0.57,-0.05]$ \\
\hline $\begin{array}{l}\text { 1.3 End of follow-up ( } 12 \text { months after interven- } \\
\text { tion) }\end{array}$ & 1 & 77 & $\begin{array}{l}\text { Std. Mean Difference (Random, } \\
95 \% \mathrm{Cl} \text { ) }\end{array}$ & $-0.21[-0.66,0.24]$ \\
\hline 2 Episodic memory & 4 & & $\begin{array}{l}\text { Std. Mean Difference (Random, } \\
95 \% \mathrm{Cl} \text { ) }\end{array}$ & Subtotals only \\
\hline 2.1 End of intervention period ( 12 to 17 weeks) & 4 & 439 & $\begin{array}{l}\text { Std. Mean Difference (Random, } \\
95 \% \mathrm{Cl} \text { ) }\end{array}$ & $0.06[-0.14,0.26]$ \\
\hline 3 Speed of processing & 2 & & $\begin{array}{l}\text { Std. Mean Difference (Random, } \\
95 \% \mathrm{Cl} \text { ) }\end{array}$ & Subtotals only \\
\hline 3.1 End of intervention period ( 12 to 16 weeks) & 2 & 138 & $\begin{array}{l}\text { Std. Mean Difference (Random, } \\
95 \% \mathrm{Cl} \text { ) }\end{array}$ & $-0.63[-1.14,-0.12]$ \\
\hline 4 Executive function & 3 & & $\begin{array}{l}\text { Std. Mean Difference (Random, } \\
95 \% \mathrm{Cl} \text { ) }\end{array}$ & Subtotals only \\
\hline 4.1 End of intervention period (12 to 17 weeks) & 3 & 230 & $\begin{array}{l}\text { Std. Mean Difference (Random, } \\
95 \% \mathrm{Cl} \text { ) }\end{array}$ & $-0.04[-0.61,0.53]$ \\
\hline 5 Working memory & 3 & & $\begin{array}{l}\text { Std. Mean Difference (Random, } \\
95 \% \mathrm{Cl} \text { ) }\end{array}$ & Subtotals only \\
\hline 5.1 End of intervention period ( 12 to 16 weeks) & 3 & 392 & $\begin{array}{l}\text { Std. Mean Difference (Random, } \\
95 \% \mathrm{Cl} \text { ) }\end{array}$ & $-0.17[-0.36,0.02]$ \\
\hline
\end{tabular}


Analysis 1.1. Comparison 1 Computerised cognition-based training versus active control, Outcome $1 \mathrm{Global}$ cognitive function.

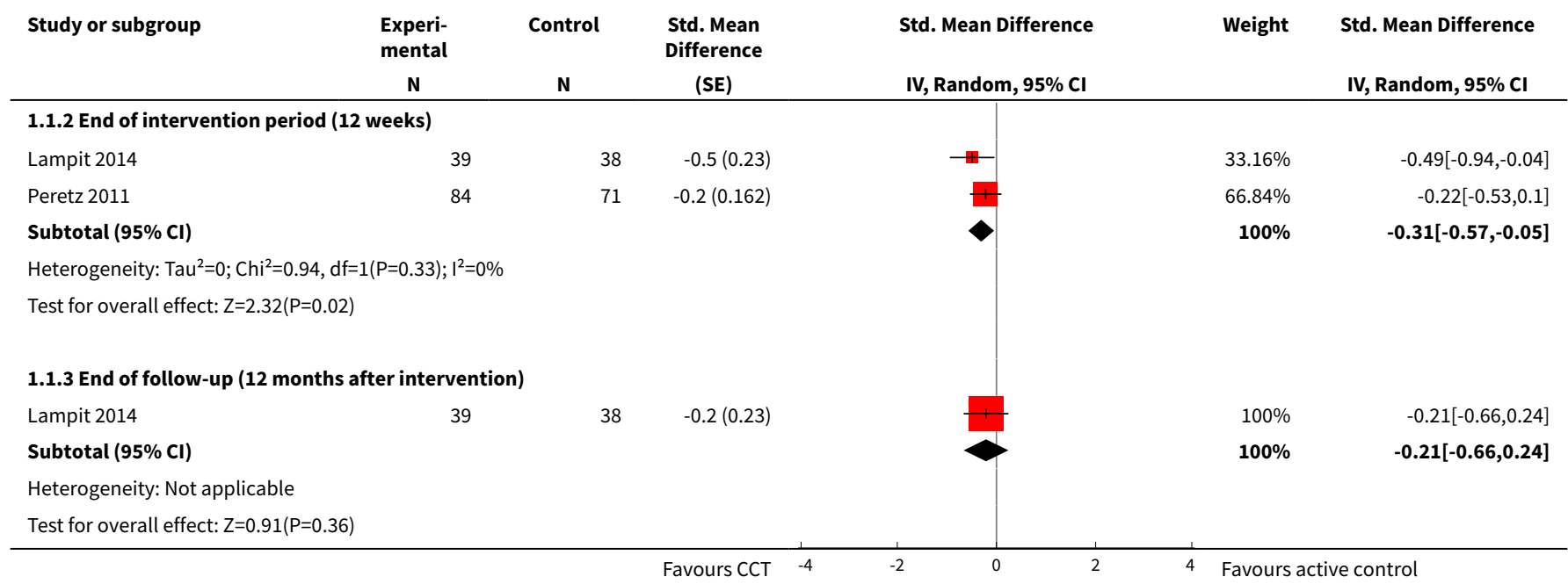

\section{Analysis 1.2. Comparison 1 Computerised cognition-based training versus active control, Outcome 2 Episodic memory.}

\begin{tabular}{|c|c|c|c|c|c|c|}
\hline Study or subgroup & $\begin{array}{c}\text { Experi- } \\
\text { mental } \\
\mathbf{N}\end{array}$ & $\begin{array}{l}\text { Control } \\
\text { N }\end{array}$ & $\begin{array}{l}\text { Std. Mean } \\
\text { Difference } \\
\text { (SE) }\end{array}$ & $\begin{array}{l}\text { Std. Mean Difference } \\
\text { IV, Random, } 95 \% \mathrm{Cl}\end{array}$ & Weight & $\begin{array}{l}\text { Std. Mean Difference } \\
\text { IV, Random, } 95 \% \mathrm{CI}\end{array}$ \\
\hline \multicolumn{7}{|c|}{ 1.2.1 End of intervention period ( 12 to 17 weeks) } \\
\hline Desjardins-Crépeau 2016 & 42 & 34 & $0.2(0.231)$ & + & $17.79 \%$ & $0.19[-0.26,0.64]$ \\
\hline Legault 2011 & 16 & 17 & $0.5(0.353)$ & * & $8.12 \%$ & $0.46[-0.23,1.15]$ \\
\hline Leung 2015 & 109 & 100 & $0.1(0.139)$ & $\#$ & $41.24 \%$ & $0.1[-0.18,0.37]$ \\
\hline Peretz 2011 & 66 & 55 & $-0.2(0.161)$ & 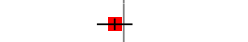 & $32.85 \%$ & $-0.16[-0.48,0.16]$ \\
\hline Subtotal $(95 \% \mathrm{CI})$ & & & & 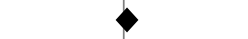 & $100 \%$ & $0.06[-0.14,0.26]$ \\
\hline \multicolumn{7}{|c|}{ Heterogeneity: $\mathrm{Tau}^{2}=0.01 ; \mathrm{Chi}^{2}=3.51, \mathrm{df}=3(\mathrm{P}=0.32) ; \mathrm{I}^{2}=14.45 \%$} \\
\hline \multicolumn{7}{|c|}{ Test for overall effect: $Z=0.56(P=0.57)$} \\
\hline
\end{tabular}

Analysis 1.3. Comparison 1 Computerised cognition-based training versus active control, Outcome 3 Speed of processing.

\begin{tabular}{|c|c|c|c|c|c|c|}
\hline Study or subgroup & $\begin{array}{c}\text { Experi- } \\
\text { mental } \\
\mathbf{N}\end{array}$ & Control & $\begin{array}{c}\text { Std. Mean } \\
\text { Difference } \\
\text { (SE) }\end{array}$ & Std. Mean Difference & Weight & $\begin{array}{l}\text { Std. Mean Difference } \\
\text { IV, Random, } 95 \% \mathrm{CI}\end{array}$ \\
\hline \multicolumn{7}{|c|}{ 1.3.1 End of intervention period ( 12 to 16 weeks) } \\
\hline Desjardins-Crépeau 2016 & 42 & 34 & $-0.4(0.233)$ & + & $53.28 \%$ & $-0.39[-0.85,0.07]$ \\
\hline Shatil 2013 & 33 & 29 & $-0.9(0.268)$ & $\because$ & $46.72 \%$ & $-0.91[-1.43,-0.38]$ \\
\hline Subtotal $(95 \% \mathrm{Cl})$ & & & & & $100 \%$ & $-0.63[-1.14,-0.12]$ \\
\hline \multicolumn{7}{|c|}{ Heterogeneity: $\mathrm{Tau}^{2}=0.07 ; \mathrm{Chi}^{2}=2.12, \mathrm{df}=1(\mathrm{P}=0.15) ; \mathrm{I}^{2}=52.82 \%$} \\
\hline Test for overall effect: $Z=2$ & & & & & & \\
\hline
\end{tabular}

Computerised cognitive training for $\mathbf{1 2}$ or more weeks for maintaining cognitive function in cognitively healthy people in late life 
Analysis 1.4. Comparison 1 Computerised cognition-based training versus active control, Outcome 4 Executive function.

\begin{tabular}{|c|c|c|c|c|c|c|}
\hline Study or subgroup & $\begin{array}{c}\text { Experi- } \\
\text { mental } \\
\mathbf{N}\end{array}$ & $\begin{array}{c}\text { Control } \\
\text { N }\end{array}$ & $\begin{array}{c}\text { Std. Mean } \\
\text { Difference } \\
\text { (SE) }\end{array}$ & $\begin{array}{l}\text { Std. Mean Difference } \\
\text { IV, Random, } 95 \% \text { CI }\end{array}$ & Weight & $\begin{array}{l}\text { Std. Mean Difference } \\
\text { IV, Random, } 95 \% \mathrm{Cl}\end{array}$ \\
\hline \multicolumn{7}{|c|}{ 1.4.1 End of intervention period ( 12 to 17 weeks) } \\
\hline Desjardins-Crépeau 2016 & 42 & 34 & $-0.4(0.233)$ & $\rightarrow$ & $34.61 \%$ & $-0.39[-0.84,0.07]$ \\
\hline Legault 2011 & 16 & 17 & $0.8(0.363)$ & $\mp$ & $26.37 \%$ & $0.81[0.1,1.52]$ \\
\hline Peretz 2011 & 66 & 55 & $-0.3(0.162)$ & \# & $39.02 \%$ & $-0.31[-0.63,0.01]$ \\
\hline \multicolumn{7}{|c|}{ Heterogeneity: $\mathrm{Tau}^{2}=0.19 ; \mathrm{Chi}^{2}=8.83, \mathrm{df}=2(\mathrm{P}=0.01) ; \mathrm{I}^{2}=77.35 \%$} \\
\hline Test for overall effect: $Z=0$. & & & & & & \\
\hline
\end{tabular}

\section{Analysis 1.5. Comparison 1 Computerised cognition-based} training versus active control, Outcome 5 Working memory.

\begin{tabular}{|c|c|c|c|c|c|c|}
\hline Study or subgroup & $\begin{array}{c}\text { Experi- } \\
\text { mental } \\
\mathbf{N}\end{array}$ & $\begin{array}{l}\text { Control } \\
\text { N }\end{array}$ & $\begin{array}{l}\text { Std. Mean } \\
\text { Difference } \\
\text { (SE) }\end{array}$ & $\begin{array}{l}\text { Std. Mean Difference } \\
\text { IV, Random, } 95 \% \mathrm{CI}\end{array}$ & Weight & $\begin{array}{l}\text { Std. Mean Difference } \\
\text { IV, Random, } 95 \% \mathrm{CI}\end{array}$ \\
\hline \multicolumn{7}{|c|}{ 1.5.1 End of intervention period ( 12 to 16 weeks) } \\
\hline Leung 2015 & 109 & 100 & $-0.2(0.139)$ & \# & $48.96 \%$ & $-0.2[-0.47,0.07]$ \\
\hline Peretz 2011 & 66 & 55 & $-0.2(0.161)$ & \# & $36.49 \%$ & $-0.15[-0.47,0.16]$ \\
\hline Shatil 2013 & 33 & 29 & $-0.1(0.255)$ & $\rightarrow$ & $14.55 \%$ & $-0.12[-0.62,0.38]$ \\
\hline \multicolumn{7}{|c|}{ Heterogeneity: Tau $^{2}=0 ; \mathrm{Chi}^{2}=0.1, \mathrm{df}=2(\mathrm{P}=0.95) ; \mathrm{I}^{2}=0 \%$} \\
\hline Test for overall effect & & & & & & \\
\hline
\end{tabular}

Comparison 2. Computerised cognition-based training versus inactive control

\begin{tabular}{|c|c|c|c|c|}
\hline Outcome or subgroup title & $\begin{array}{l}\text { No. of } \\
\text { studies }\end{array}$ & $\begin{array}{l}\text { No. of } \\
\text { partici- } \\
\text { pants }\end{array}$ & Statistical method & Effect size \\
\hline 1 Episodic Memory & 1 & & $\begin{array}{l}\text { Mean Difference (IV, Random, } \\
95 \% \mathrm{CI} \text { ) }\end{array}$ & Subtotals only \\
\hline 1.1 End of intervention period ( 6 months) & 1 & 150 & $\begin{array}{l}\text { Mean Difference (IV, Random, } \\
95 \% \mathrm{CI} \text { ) }\end{array}$ & $-0.90[-1.73,-0.07]$ \\
\hline 2 Executive function & 2 & & $\begin{array}{l}\text { Std. Mean Difference (Random, } \\
95 \% \mathrm{Cl} \text { ) }\end{array}$ & Subtotals only \\
\hline $\begin{array}{l}2.1 \text { End of intervention period ( } 12 \text { weeks to } 6 \\
\text { months) }\end{array}$ & 2 & 292 & $\begin{array}{l}\text { Std. Mean Difference (Random, } \\
95 \% \mathrm{Cl} \text { ) }\end{array}$ & $-0.08[-0.31,0.15]$ \\
\hline 3 Speed of processing & 2 & & $\begin{array}{l}\text { Std. Mean Difference (Random, } \\
95 \% \mathrm{Cl} \text { ) }\end{array}$ & Subtotals only \\
\hline
\end{tabular}




\begin{tabular}{|c|c|c|c|c|}
\hline Outcome or subgroup title & $\begin{array}{l}\text { No. of } \\
\text { studies }\end{array}$ & $\begin{array}{l}\text { No. of } \\
\text { partici- } \\
\text { pants }\end{array}$ & Statistical method & Effect size \\
\hline $\begin{array}{l}\text { 3.1 End of intervention period ( } 12 \text { to } 16 \\
\text { weeks) }\end{array}$ & 2 & 204 & $\begin{array}{l}\text { Std. Mean Difference (Random, } \\
95 \% \mathrm{Cl} \text { ) }\end{array}$ & $-0.28[-0.82,0.26]$ \\
\hline 4 Working memory & 1 & 60 & $\begin{array}{l}\text { Mean Difference (IV, Random, } \\
95 \% \mathrm{CI})\end{array}$ & $-0.08[-0.43,0.27]$ \\
\hline 4.1 End of intervention period ( 16 weeks) & 1 & 60 & $\begin{array}{l}\text { Mean Difference (IV, Random, } \\
95 \% \mathrm{CI})\end{array}$ & $-0.08[-0.43,0.27]$ \\
\hline 5 Verbal fluency & 1 & 150 & $\begin{array}{l}\text { Mean Difference (IV, Random, } \\
95 \% \mathrm{CI} \text { ) }\end{array}$ & $-0.11[-1.58,1.36]$ \\
\hline 5.1 End of intervention period ( 6 months) & 1 & 150 & $\begin{array}{l}\text { Mean Difference (IV, Random, } \\
95 \% \mathrm{Cl} \text { ) }\end{array}$ & $-0.11[-1.58,1.36]$ \\
\hline
\end{tabular}

Analysis 2.1. Comparison 2 Computerised cognition-based training versus inactive control, Outcome 1 Episodic Memory.

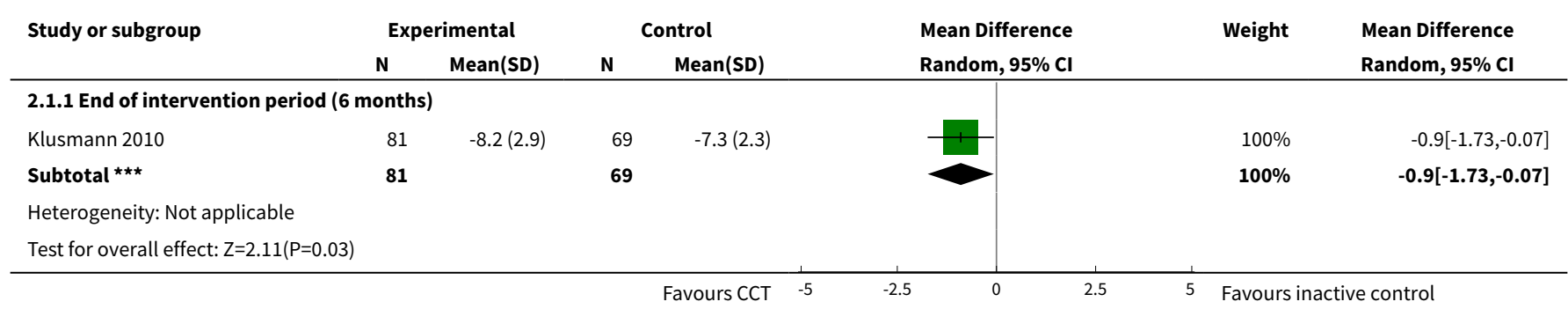

Analysis 2.2. Comparison 2 Computerised cognition-based training versus inactive control, Outcome 2 Executive function.

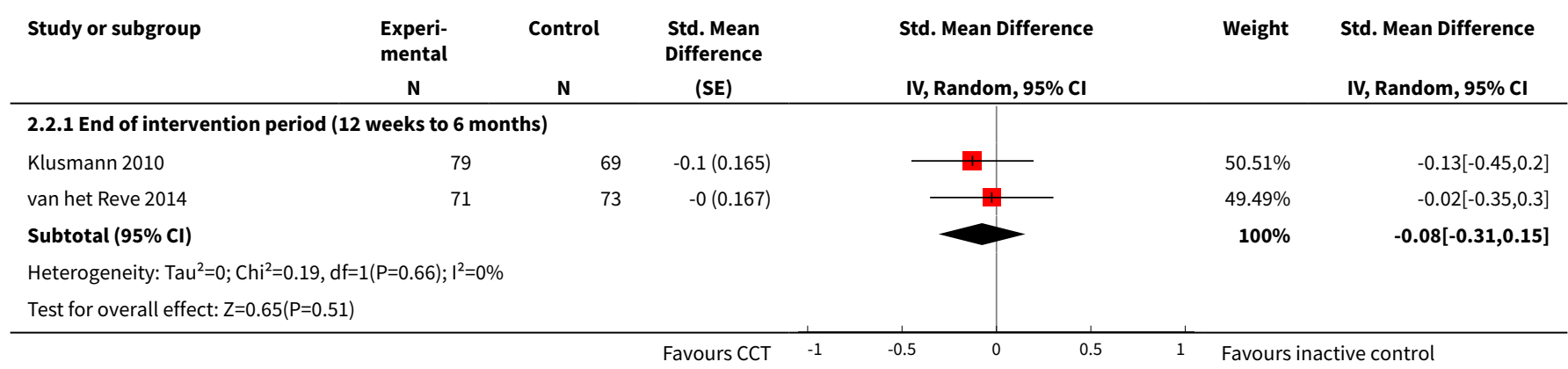


Analysis 2.3. Comparison 2 Computerised cognition-based training versus inactive control, Outcome 3 Speed of processing.

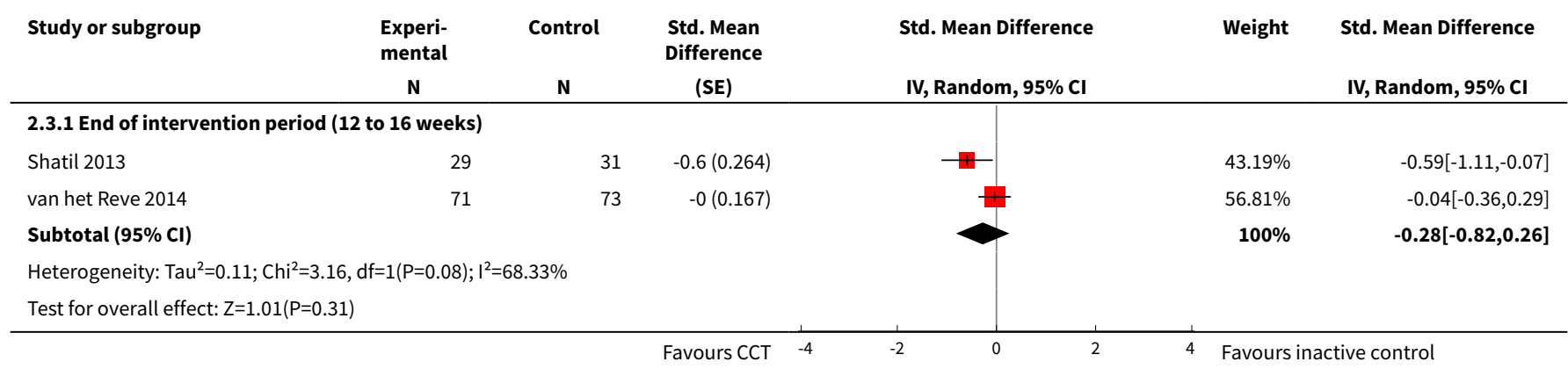

Analysis 2.4. Comparison 2 Computerised cognition-based training versus inactive control, Outcome 4 Working memory.

\begin{tabular}{|c|c|c|c|c|c|c|c|}
\hline \multirow[t]{2}{*}{ Study or subgroup } & \multicolumn{2}{|c|}{ Experimental } & \multicolumn{2}{|c|}{ Control } & \multirow{2}{*}{$\begin{array}{l}\text { Mean Difference } \\
\text { Random, } 95 \% \mathrm{Cl}\end{array}$} & \multirow[t]{2}{*}{ Weight } & \multirow{2}{*}{$\begin{array}{l}\text { Mean Difference } \\
\text { Random, } 95 \% \mathrm{Cl}\end{array}$} \\
\hline & $\mathbf{N}$ & Mean(SD) & $\mathbf{N}$ & Mean(SD) & & & \\
\hline \multicolumn{8}{|c|}{ 2.4.1 End of intervention period ( 16 weeks) } \\
\hline Shatil 2013 & 29 & $0(0.7)$ & 31 & $0.1(0.6)$ & & $100 \%$ & $-0.08[-0.43,0.27]$ \\
\hline 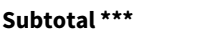 & 29 & & 31 & & & $100 \%$ & $-0.08[-0.43,0.27]$ \\
\hline \multicolumn{8}{|c|}{ Heterogeneity: Not applicable } \\
\hline \multicolumn{8}{|c|}{ Test for overall effect: $Z=0.45(P=0.66)$} \\
\hline Total ${ }^{\star \star \star}$ & 29 & & 31 & & & $100 \%$ & $-0.08[-0.43,0.27]$ \\
\hline \multicolumn{8}{|c|}{ Heterogeneity: Not applicable } \\
\hline \multicolumn{8}{|c|}{ Test for overall effect: $Z=0.45(P=0.66)$} \\
\hline
\end{tabular}

\section{Analysis 2.5. Comparison 2 Computerised cognition-based training versus inactive control, Outcome 5 Verbal fluency.}

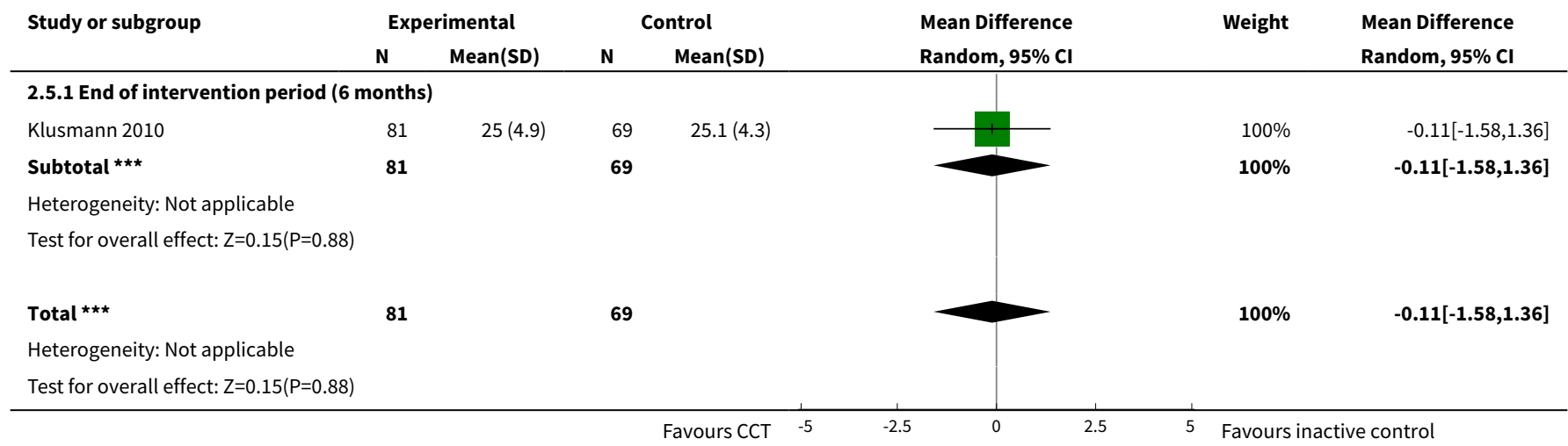




\section{APPENDICES}

\section{Appendix 1. Sources searched and search strategies}

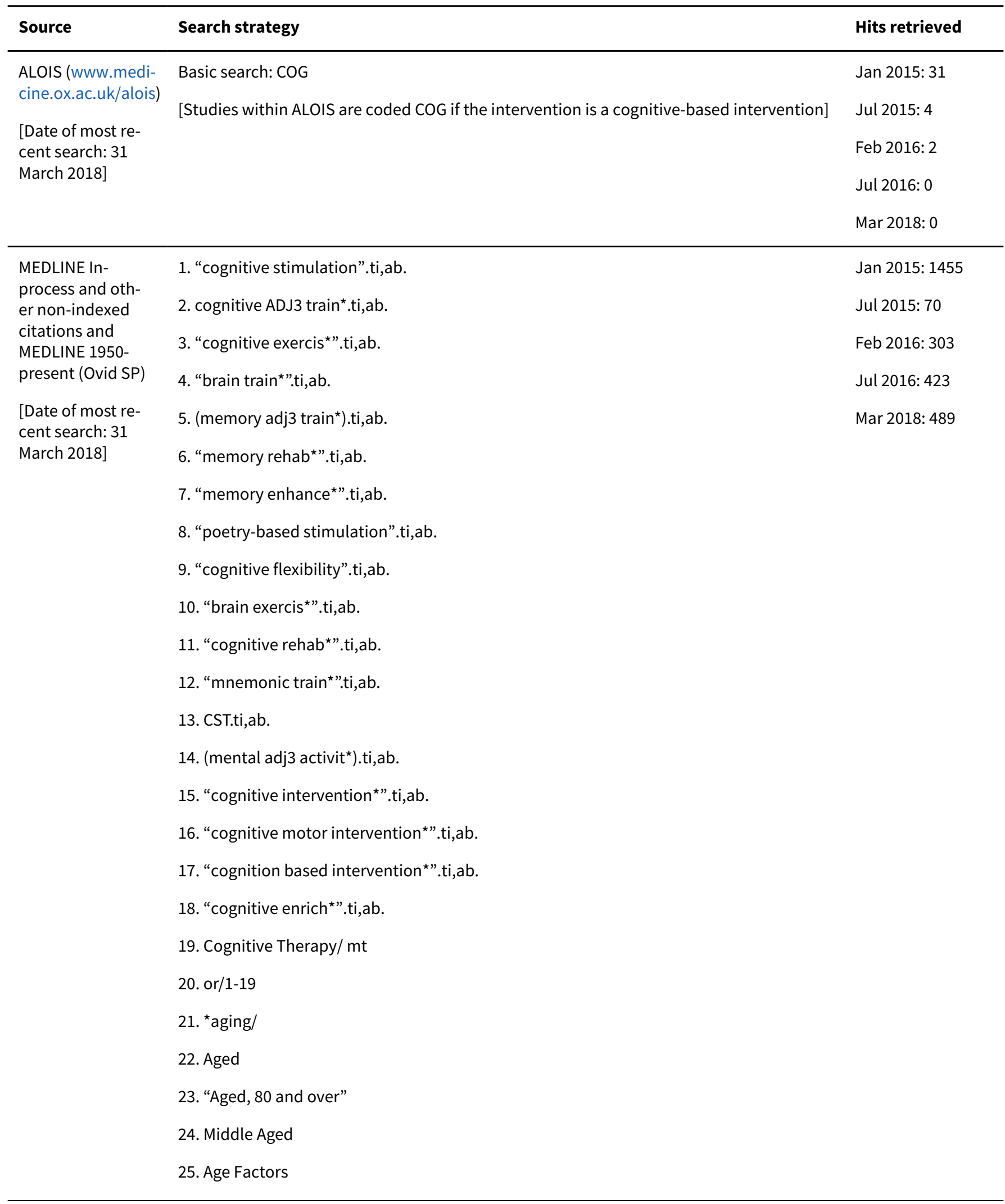

Computerised cognitive training for 12 or more weeks for maintaining cognitive function in cognitively healthy people in late life 


\section{6. *Cognition/ \\ 27. *Cognition Disorders/}

28. Memory/

29. Memory Disorders/

30. Brain/

31. Mild Cognitive Impairment/

32. Executive Function/

33. (cognit* ADJ3 (func* OR declin* OR reduc* OR impair ${ }^{\star}$ OR improve* OR deficit* OR progress ${ }^{\star} 34$. OR perform $\left.{ }^{\star}\right)$ ).ti,ab.

35. "mental perform*”.ti,ab.

36. memory.ti,ab.

37. "executive function"..ti,ab.

38. MCl.ti,ab.

39. AAMI.ti,ab.

40. ACMI.ti,ab.

41. ARCD.ti,ab.

42. CIND.ti,ab.

43. (nMCI OR aMCI OR mMCI OR MCla).ti,ab.

44. Dementia/

45. Alzheimer Disease/

46. dement ${ }^{\star}$.ti,ab.

47. alzheimer ${ }^{\star} . t i, a b$.

48. "old* age*”.ti,ab.

49. elderly.ti,ab.

50. “middle age ".ti,ab.

51. "old*adults".ti,ab.

52. seniors.ti,ab.

53. "senior citizens".ti,ab.

54. "community dwelling”.ti,ab.

55. pensioners.ti,ab.

56. or/21-55

57. randomized controlled trial.pt.

58. controlled clinical trial.pt.

59. randomized.ab.

60. placebo.ab.

61. drug therapy.fs.

62. randomly.ab. 
(Continued)

\author{
63. trial.ab. \\ 64. groups.ab. \\ 65. or/57-64 \\ 66. exp animals/ not humans.sh. \\ 67. 65 NOT 66 \\ 68. 67 AND 56 AND 20 [all results] \\ 69. ("cognitive stimulation" OR "cognitive training").ti. \\ 70. *Cognition \\ 71. *Aging/ \\ 72. and/69-71
}

73. 72 AND 57 ['no brainer' results - directly sent to core author team]

74. 68 NOT 73 [results minus 'no brainer' results - for the crowd to screen]

\begin{tabular}{|c|c|c|}
\hline Embase & 1. aging/ & Jan 2015: 1289 \\
\hline 1974-24 January & 2 aged/ & 101 100150 \\
\hline 2018 (Ovid SP) & 2. dgea/ & Jul $2013: 163$ \\
\hline & 3. middle aged/ & Feb 2016: 380 \\
\hline $\begin{array}{l}\text { [Date of most re- } \\
\text { cent search: } 31\end{array}$ & 4. mild cognitive impairment/ & Jul 2016: 268 \\
\hline March 2018] & 5. elderly.ti,ab. & Mar 2018: 640 \\
\hline & 6. MCl.ti,ab. & \\
\hline & 7. AAMI.ti,ab. & \\
\hline & 8. ACMI.ti,ab. & \\
\hline & 9. ARCD.ti,ab. & \\
\hline & 10. CIND.ti,ab. & \\
\hline & 11. ( $\mathrm{nMCl}$ or $\mathrm{aMCl}$ or $\mathrm{mMCl}$ or $\mathrm{MCla}) . t i, a b$. & \\
\hline & 12. "old* age*".ti,ab. & \\
\hline & 13. elderly.ti,ab. & \\
\hline & 14. "middle age*".ti,ab. & \\
\hline & 15. "old* aadults".ti,ab. & \\
\hline & 16. seniors.ti,ab. & \\
\hline & 17. "senior citizens".ti,ab. & \\
\hline & 18. "community dwelling".ti,ab. & \\
\hline & 19. pensioners.ti,ab. & \\
\hline & 20. ("aged sample" or "aged population" or "older sample" or "older population").ti,ab. & \\
\hline & 21. "CDR 0.5".ti,ab. & \\
\hline & $\begin{array}{l}\text { 22. (cognit* adj3 }\left(\text { func }^{\star} \text { or declin }{ }^{\star} \text { or reduc } \text { or impair }^{\star} \text { or improve }{ }^{\star} \text { or deficit* or progress* }\right. \\
\left.\text { or perform }{ }^{\star} \text { or abilit }{ }^{\star}\right) \text {.ti,ab. }\end{array}$ & \\
\hline & 23. or/1-22 & \\
\hline & 24. * cognition/ & \\
\hline
\end{tabular}

Computerised cognitive training for 12 or more weeks for maintaining cognitive function in cognitively healthy people in late life 
25. memory/ or episodic memory/

26. executive function/

27. attention/

28. "mental perform".ti,ab.

29. memory.ti,ab.

30. dementia/

31. Alzheimer disease/

32. dement ${ }^{\star}$.ti,ab.

33. alzheimer*.ti,ab.

34. or/24-33

35. randomized controlled trial/

36. controlled clinical trial/

37. (randomly adj2 allocat $\left.{ }^{\star}\right) \cdot a b$.

38. (randomly adj2 divide $\left.{ }^{\star}\right)$.ab.

39. randomi?ed.ab.

40. (controlled adj7 (study or design or trial)).ti,ab.

41. "double-blind*".ti,ab.

42. "single blind*".ti,ab.

43. groups.ab.

44. or/35-43

45. "cognitive stimulation".ti,ab.

46. (cognitive adj3 train*).ti,ab

47. "cognitive exercis ${ }^{\star}$.ti,ab.

48. "brain train*".ti,ab.

49. (memory adj3 train*).ti,ab.

50. "memory enhance*".ti,ab.

51. "memory rehab*".ti,ab.

52. "brain exercis*".ti,ab.

53. "cognitive rehab*".ti,ab.

54. "cognitive rehab*".ti,ab.

55. "mnemonic train*".ti,ab.

56. CST.ti,ab.

57. (mental adj3 activit*).ti,ab.

58. "cognitive intervention*".ti,ab. 


\section{RCT.ti,ab.}

23. "double-blind*".ti,ab.

24. "single blind*".ti,ab.

25. "randomi?ed trial".ab.

26. "randomi?ed control* trial".ab.

27. "random allocation".ab.

28. "controlled clinical trial".ti,ab.

29. (controlled adj4 (study or design or trial)).ti,ab.

30. or/19-29

31. "cognitive stimulation".ti,ab.

32. (cognitive adj3 train $\left.^{\star}\right) . t i, a b$.

33. "cognitive exercis*".ti,ab.

34. "brain train*".ti,ab.

35. (memory adj3 train*).ti,ab.

36. "memory enhance*".ti,ab.

37. "memory rehab*".ti,ab.

38. "brain exercis*".ti,ab.

39. "cognitive rehab*".ti,ab.

40. "cognitive rehab*".ti,ab.

41. "mnemonic train*".ti,ab.

42. CST.ti,ab.

43. (mental adj3 activit $\left.^{\star}\right)$.ti,ab.

44. "cognitive intervention*".ti,ab.

45. "cognitive motor intervention*".ti,ab.

46. "cognition based intervention*".ti,ab.

47. "cognitive enrich".ti,ab.

48. "reality orientation".ti,ab.

49. (memory adj2 game ${ }^{\star}$ ).ti,ab.

50. or/31-49

51. 18 and 30 and 50

52. *Cognition/

53. ( $\mathrm{MCl}$ or "mild cognitive impairment" or elderly or "old* adults" or "middle age*").ti.

54. ("cognitive stimulation" or "cognitive training").ti,ab.

55.19 or 20 or 21 
CINAHL (EBSCO-

host)

Jan 2015: 390

[Date of most re-

Jul 2015: 13

cent search: 31

Feb 2016: 57

March 2018]

Jul 2016: 12

Mar 2018: 125

\section{ISI Web of Science} [includes: Web of Science (1945present); BIOSIS Previews (1926present); MEDLINE (1950-present); Journal Citation Reports]; BIOSIS Previews

[Date of most recent search: 31 March 2018] ("mild cognitive impairment" OR elderly OR "age* subjects" OR "old* adult*" OR "middle age*" OR MCI) AND TOPIC: ("randomly allocated" OR "random allocation" OR randomised OR randomized OR RCT OR "controlled trial" OR "double blind" OR "single blind") AND TOPIC: ("cognit* stim*" OR "cognit* train*" OR puzzle OR "brain train*" OR "cognit* exercis" ${ }^{\star}$ OR "brain exercis*" OR "memory exercis" " OR "brain gam*" OR "cognit* gam*" OR "memory gam ${ }^{\star}$ OR sudoku OR crossword* OR "reality orientation") AND TOPIC: (cognition OR dementia OR memory OR "executive function" OR alzheimer ${ }^{\star}$ )

Timespan: All years.

Search language=Auto
Jan 2015: 333

Jul 2015: 44

Feb 2016: 108

Jul 2016: 35

Mar 2018: 268

\section{LILACS (BIREME)}

Jan 2015: 4

[Date of most re-

Jul 2015: 0

cent search: 31

March 2018]

Feb 2016: 0

Jul 2016: 0

Mar 2018: 0

\section{CENTRAL (via CRSO)}

[Date of most recent search: 31 March 2018]
\#1 MeSH descriptor: [Aged, 80 and over] explode all trees

Jan 2015: 274

\#2 MeSH descriptor: [Aged] explode all trees

Jul 2015: 11

\#3 MeSH descriptor: [Middle Aged] explode all trees

Feb 2016: 57

\#4 MeSH descriptor: [Mild Cognitive Impairment] explode all trees

Jul 2016: 4

\#5 "cognit* impair*" or MCl

Mar 2018: 125

\#6 elderly

\#7 "old* adults"

\#8 "old* age*"

\#9 "old* sample"

\#10 senior citizens

\#11 pensioners

\#12 seniors

$\# 13 \# 1$ or \#2 or \#3 or \#4 or \#5 or \#6 or \#7 or \#8 or \#9 or \#10 or \#11 or \#12 
\#14 MeSH descriptor: [Cognition] explode all trees

\#15 MeSH descriptor: [Dementia] explode all trees

\#16 cognit ${ }^{\star}$

\#17 memory

\#18 "executive function*"

\#19 processing

\#20 "mental perform*"

\#21 dement ${ }^{\star}$

\#22 alzheimer

$\# 23 \# 14$ or \#15 or \#16 or \#17 or \#18 or \#19 or \#20 or \#21 or \#22

\#24 "cognitive stimulation"

\#25 "cognitive training"

\#26 "brain train*"

\#27 "brain gam*"

\#28 "memory train*" or "memory game*"

\#29 puzzle*

\#30 crossword $^{*}$

\#31 sudoku*

\#32 "mental game*"

\#33 "mental agil*"

\#34 "cognitive exercis*"

\#35 "mental exercis*"

$\# 36 \# 24$ or \#25 or \#26 or \#27 or \#28 or \#29 or \#30 or \#31 or \#32 or \#33 or \#34 or \#35

$\# 37 \# 13$ and \#23 and \#36

Clinicaltrials.gov

Jan 2015: 17

(www.clinicaltrial-

s.gov)

Jul 2015: 4

[Date of most re-

Feb 2016: 2

cent search: 31

March 2018]

Jul 2016: 0

Mar 2018: 4

ICTRP Search

Jan 2015: 22

Portal (http://

apps.who.int/tri-

Jul 2015: 3

alsearch) [in-

cludes: Australian

Feb 2016: 1

New Zealand Clini-

Jul 2016: 0

cal Trials Registry;

Mar 2018: 4

Computerised cognitive training for 12 or more weeks for maintaining cognitive function in cognitively healthy people in late life 
(Continued)

ISRCTN; Chinese

Clinical Trial Reg-

istry; Clinical Tri-

als Registry - In-

dia; Clinical Re-

search Informa-

tion Service - Re-

public of Korea;

German Clinical

Trials Register;

Iranian Registry

of Clinical Trials;

Japan Primary

Registries Net-

work; Pan African

Clinical Trial Reg-

istry; Sri Lanka

Clinical Trials Reg-

istry; The Nether-

lands National Tri-

al Register]

[Date of most re-

cent search: 31

March 2018]

TOTAL before de-duplication

Jan 2015: 3981

Jul 2015: 332

Feb 2016: 935

Jul 2016: 754

Mar 2018: 1725

TOTAL: 7727

TOTAL after de-duplication

TOTAL: 5832

TOTAL after first assessment by the Crowd and CDCIG Information Specialists

Jan 2015: 604

Jul 2015: 60

Feb 2016: 164

Jul 2016: 73

Mar 2018: 189

TOTAL: 1090

Appendix 2. Definitions of design, patient, and intervention characteristics as applied in the stratified analyses exploring between-trial variations in intervention effects

\begin{tabular}{ll}
\hline Item & Definition \\
\hline Design-related characteristics* & \\
\hline \hline
\end{tabular}

Computerised cognitive training for 12 or more weeks for maintaining cognitive function in cognitively healthy people in late life

Copyright @ 2020 The Cochrane Collaboration. Published by John Wiley \& Sons, Ltd. 
(Continued)

Concealment of allocation (avoiding selection bias)
Guidance from the Cochrane Handbook for Systematic Reviews of Interventions will be used to judge bias related to sequence generation and concealment of allocation using the 2 Cochrane 'Risk of bias' items (Higgins 2011). From these, the statistician will derive a single variable to be used in the stratified analysis: allocation concealment will be judged at low risk of bias if the investigators responsible for patient selection were unable to suspect, before allocation, which treatment was next. Concealment will be downgraded to high risk of bias if there is evidence of inadequate sequence generation (Rutjes 2012)
Blinding of patients and personnel (avoiding performance bias)
Low risk of bias will be judged:

- if a credible sham procedure was used; or if a placebo supplement or pill was used that was reported to be identical in appearance from the experimental intervention, and the specific outcome or group of outcomes is/are likely to be influenced by lack of blinding; or

- if blinding is absent or suboptimal and the specific outcome, such as mortality, is not likely to be influenced by lack of blinding

Blinding of outcome assessment (avoiding detection bias)
For self-reported/partner-reported outcomes

Low risk of bias will be judged if:

- self-report outcomes were assessed AND blinding of patients was considered adequate AND there was no information to suggest that there was an investigator involved during the process of outcome assessment; $\mathrm{OR}$ if blinding of investigators performing the outcome assessment was reported AND an attempt to blind patients was reported

\section{For other outcomes}

- Outcome assessment was considered to be blinded if the outcome assessment was reported to be blinded
Statistical analyses (avoiding attrition bias)

\section{For continuous outcomes}

Low risk of bias will be judged if:

- at least $90 \%$ of randomised participants were analysed AND the difference in percentage of participants not analysed was $5 \%$ or lower across trial arms; or

- for trials using imputations to handle missing data: the percentage of participants with missing data did not exceed $20 \%$ AND the difference in percentage of participants with imputed data was $5 \%$ or lower across trial arms AND applied imputation methods were judged to be appropriate. Multiple imputation techniques will be considered appropriate, and simple methods such as "last observation carried forward" or "baseline carried forward" will be considered inappropriate

\section{For binary outcomes of rare events}

Low risk of bias will be judged if:

- the event rate is low (e.g. incidence of dementia) AND at least $95 \%$ of randomised participants were analysed AND there is no evidence of differential reasons for missing data that may alter the estimate AND the rate of missing data does not exceed the expected event rates

For binary outcomes of non-rare events

Low risk of bias will be judged if:

- at least $90 \%$ of randomised participants were analysed AND the difference in percentage of participants not analysed was 5\% or lower across trial arms AND there is no evidence of differential reasons for missing data that may alter the estimate AND the rate of missing data does not exceed the expected event rates

Trial size
The cut-off to distinguish small from larger trials will be determined by a sample size calculation on the primary outcome 
(Continued)

Publication status Full journal article vs other type or unpublished material

Follow-up duration

For the cognitive outcomes, we will group studies according to these follow-up cut-offs to describe immediate results (up to 12 weeks), short-term (up to 1 year), medium-term (1 to 2 years), and longer-term results (more than 2 years)

\title{
Treatment-related characteristics
}

\author{
Treatment and control The analyses will be stratified by: \\ Treatment duration \\ - control intervention (placebo vs no intervention vs usual care, where no intervention refers to \\ RCTs with standardised concurrent treatments in both experimental and control arms); \\ - training in multiple domains (yes/no); or \\ - mode of delivery \\ * training supervision (yes /no); or \\ * group training (yes/no)
}

The analyses will be stratified into $>3$ sessions per week (yes/no), length of training sessions $>30$ minutes (yes/no) based upon previous findings (Lampit 2014) and total number of sessions

The minimum treatment duration of 3 months is considered short-term, 3 to 12 months as medium-term, and 12 months as long-term

\section{Participant-related characteristics}

Participant-related criteria Gender, level of education (in years)

* The descriptions depicted in this Table are provided in addition to the guidance available in the Cochrane Handbook for Systematic Reviews of Interventions (Higgins 2011). Stratified analyses are performed only for the primary outcome and only if about 10 RCTs contribute to the analyses.

\section{FEEDBACK}

\section{Included studies, 16 December 2019}

\section{Summary}

Feeback submitted by Henry Mahncke

Comment : To the Editors,

We read with great interest your recently published review "Computerised cognitive training for maintaining cognitive function in cognitively healthy people in late life." The review could have been a timely evidence-based analysis that helped to clarify key issues in the field of computerised cognitive training (CCT). However, the decision to include only studies that employed 12 or more weeks of cognitive training unfortunately renders the review of very limited scientific or clinical value.

The choice to include only studies employing 12 or more weeks of cognitive training is problematic for multiple reasons:

First, the decision itself does not have a scientific basis, as the authors of the review themselves state. The decision is mentioned briefly in several places in the Cochrane review: 1 . In the introduction, with the statement "The inclusion criterion of an intervention duration of 12 or more weeks is consistent with cognitive training recommendations (Lampit 2015)." No other reference to the literature supporting the decision is provided. The reference Lampit 2015(1) appears to be to a single randomized controlled trial, of a single CCT intervention that is specifically titled "a pilot study." In that reference, 12 weeks of cognitive training is used, but no specific justification for that length of time is discussed, nor is a general recommendation made that this is the minimum required amount of cognitive training for efficacy. It seems possible from the pattern of citations that the authors intended to cite the Lampit 2014a meta-analysis here. However that meta-analysis also does not support the review's statement and in fact makes no analysis of duration of training in weeks and specifically concludes that shorter and longer training doses are statistically equivalently effective. 
2. In the methods, with the statement "The minimum treatment duration was set at 12 weeks to evaluate the effects of training on meaningful long-term outcomes..." However, requiring training duration of 12 or more weeks does not relate the meaningful long-term outcomes - that goal would have been accomplished by requiring follow-up assessments at 12 or more weeks.

3. The statement continues "...and to make a comment about the minimum 'dose' of training that may be required to effect an enduring change." However, no comment can be made on the minimum 'dose' of training that may be required to effect an enduring change if short duration trials are excluded - that goal would have been accomplished by including trials of various durations, and conducting an analysis to evaluate the effect of training duration (or more correctly, delivered dose) on outcomes.

4. "Previous research suggests that acute brain changes can be seen following eight weeks of training (Engvig 2014); however, we are unable to find any evidence that such brain changes endure." This is a peculiar statement. It is quite well accepted in modern neuroscience that plastic brain changes are the mechanism by which learning and memory work - including memory for skills trained earlier than 8 weeks ago. Perhaps the authors mean to say that longitudinal brain imaging studies of cognitive training are lacking, which is a limitation in the field but does not relate to how the inclusion criteria for a meta-analysis of behavioral results should be defined.

5. "We therefore made an arbitrary judgement that at least 12 weeks of regular cognitive training would be required for an enduring effect of intervention." The arbitrariness of this decision proves fatal for the fundamental purpose of the review to synthesize the entirety of the evidence.

We are aware of no published evidence that trials with training duration under 12 weeks are ineffective and those with training duration over 12 weeks are effective, likely because analyzing trials by weeks of duration (instead of total hours of training) is generally not accepted as a reasonable basis for distinguishing trials.

We see no reasonable scientific basis for this inclusion criterion in the Cochrane review - and neither do the authors, who describe their judgement in the review itself as "arbitrary."

Second, the criterion does not achieve its stated goal - and in fact achieves a nonsensical result. A duration of twelve weeks of training reveals very little about how much training was delivered. As written, the review would exclude an 8 week trial requiring 5 hours per week of cognitive training ( 40 hours total) and include a trial of 12 weeks requiring 1 hour per week of cognitive training ( 12 hours total) with the intension "to make a comment about the minimum 'dose' of training that may be required to effect an enduring change."

This issue directly affects the quality of the results in the review. As a straightforward example, the IMPACT study(2) (N=487, requiring 5 hours of training per week for 8 weeks for a total of 40 hours) was excluded, however a study explicitly described as an independent replication(3) of IMPACT ( $N=209$, requiring 3 hours of training per week for 13 weeks for a total of 39 hours) was included. These trials delivered equivalent doses of cognitive training, yet one is included in the Cochrane review and one is not.

Simply looking at the 8 trials included in the review reveals a startling range of total number of hours of cognitive training delivered over 12 week periods. A quick check of the methods sections shows that over a three month period the trials included in the Cochrane review deliver anywhere from 6(4) to 60(5) hours of training.

Furthermore, while a study(4) with only 6 hours of cognitive training is included in the Cochrane review (under the belief that 12 weeks of training at 30 minutes per week is an adequate dose), multiple studies are excluded that provided a significantly higher dose of cognitive training in under 12 weeks that include follow-up assessments that extend the total trial duration to greater than 12 weeks (e.g., 10 hours of training with a 10-year of follow-up(6), 30 hours of training with a 1-year follow-up(7), 40 hours of training with a 6-month follow-up(2); see next section for further details). This is a clearly nonsensical result.

Overall, the use of this criterion fails to achieve the Cochrane review's stated goal of including trials that deliver at least a "minimum dose of training."

Third, the criterion results in the elimination of virtually all published clinical trials from the review.

This has two significant consequences:

Removal of the vast majority of published trials: The inclusion table from the review counts 114 publications as excluded for $<12$ weeks of cognitive training duration - almost 15 times as many as were included in the review. While careful inclusion criteria regarding trial design and execution metrics are admirable in a meta-analysis, a tremendous number of the studies excluded are randomized controlled trials that would otherwise meet the inclusion criteria of the Cochrane review - with the sole exception that the cognitive training period was $<12$ weeks.

If a single inclusion criterion for a clinical trial results in the exclusion of the vast majority of the otherwise eligible patients, it would be appropriate to state that the trial design is ungeneralizable and the results cannot be interpreted for the patient population at it exists in the real world. The Cochrane review suffers precisely this flaw. 
Removal of the largest and most carefully designed and executed published trials: The four largest and most carefully designed/executed trials of cognitive training are comprehensively excluded because each employed training durations of $<12$ weeks. These trials include 6,921 participants - almost 6 times as many as were included in the Cochrane review.

1. ACTIVE: The Advanced Cognitive Training for Independent and Vital Elderly (ACTIVE) study was the first study explicitly designed as a pivotal study to evaluate the efficacy of cognitive training in healthy older adults. It enrolled 2,832 healthy older adults, evaluated outcomes at 2(8), 5(9), and 10-year(6) follow-up visits, and documented improvements in directly trained cognitive domains $(6,8,9)$ and generalization to a variety of functional $(10,11)$ and real-world measures(12).

2. IHAMS: The lowa Healthy and Active Minds Study was designed as a sequel to ACTIVE to replicate the core results from speed training with three main design differences: use of an active control, involvement of a broader age range of participants, and comparison of training location models. IHAMS enrolled 681 healthy older adults, followed outcomes over a one-year period, and documented improvements in directly trained cognitive function and generalization to real-world measures $(13,14)$.

3. IMPACT: The Improvement in Cognition with Plasticity-based Adaptive Cognitive Training study was designed as a pivotal trial for an auditory speed training program. IMPACT enrolled 487 healthy older adults, followed outcomes over a six-month period, and documented improvements in directly trained measures, composite cognitive function measures, and self-report measures $(2,15)$.

4. BGTT: This study was designed as an evaluation of brain training in collaboration with the British television show Bang Goes The Theory. This trial enrolled 2,921 healthy older adults, followed outcomes over a six-month period, and documented improvements in directly trained measures, composite cognitive function measures, and functional measures(7).

Each of these trials is a gold-standard randomized controlled trial, with an a priori data analysis plan, and intent-to-treat analysis, and careful randomization and blinding procedures. As a result, these publications have had a real impact on the field - with a combined total of well over 2,500 citations to the initial publications for each study.

Overall, the Cochrane review has excluded a) most of the RCT evidence on CCT and b) the highest quality scientific literature on CCT. As a result, it is difficult to interpret the conclusions of Cochrane review as generalizable to the scientific field or to clinical practice.

Other reviews of CCT have not chosen to suffer from this limitation. Three examples include

1. Lampit(16) identified 52 trials meeting inclusion criteria similar to the Cochrane review, including all studies with 4 or more total hours of cognitive training delivered.

2. Mewborn(17) identified 97 trials meeting inclusion criteria similar to the Cochrane review (except including both computerized and noncomputerized interventions, and including healthy aging and $\mathrm{MCl}$ populations), including studies without limitation regarding dose.

3. Edwards(18) identified 17 trials meeting inclusion criteria similar to the Cochrane review in a review a single type of CCT (speed training), including trials with 10 hours of cognitive training delivered over 5 weeks.

Notably, each of these reviews comes to the opposite conclusion of the Cochrane review - stating that their respective meta-analyses document that cognitive training results in statistically and clinically significant improvement.

As a result of these issues, every single sentence of the authors plain language summary on page 3 is incorrect and misleading to its audience:

1. "It is not yet possible to say for certain whether or not computerised cognitive training can help older people to maintain good cognitive function." The authors chose to exclude more than 100 publications, including those from the four largest and most carefully designed and well conducted studies of cognitive training, each of which documented that computerized cognitive training can help older people to maintain good cognitive function. Unsurprisingly the authors then find it difficult to come to a conclusion. In fact, it is "yet possible to say for certain whether or not computerized cognitive training can help older people to maintain good cognitive function" - the authors could do so by including the available well-designed and well-conducted studies. This precise question has been answered in multiple careful meta-analyses each of which was available to prior to the publication of the Cochrane review16-18.

2. "Although we excluded very short trials ( $<3$ months) from this review, the trials that we found were still quite short for examining longterm effects as people age." The authors chose to exclude multiple large scale trials with follow-up periods ranging from 3 months to 10 years. It is misleading and not scientifically appropriate to exclude multiple studies that evaluate long-term effects and then state that the authors were not able to find trials that could examine long-term effects.

3. "We think it is important to do more research to find out whether longer periods of training work better, and whether training can produce lasting effects." While this may be the authors' personal beliefs, and of course further research is always appealing, there is simply nothing in the review that justifies the belief that longer periods of training might work better. The authors did not find positive effects because they excluded studies with $<12$ weeks of cognitive training - not because studies of $>12$ weeks have not yet been done. In addition, Multiple studies already have been done with multi-month and multi-year follow-ups to evaluate whether "training can produce lasting effects" however, those studies were excluded from the review.

Computerised cognitive training for 12 or more weeks for maintaining cognitive function in cognitively healthy people in late life 
Cochrane's first goal is "To produce high-quality, relevant, up-to-date systematic reviews and other synthesized research evidence to inform health decision making." Unfortunately, the current review does not achieve its goal due to this crucial design error.

It is difficult to see how this review can be amended or corrected given this fundamental flaw. Any conclusion - even that insufficient evidence existed to evaluate the efficacy of the included studies - would have note that that vast majority of studies, including the largest studies, studies with higher doses of cognitive training of cognitive training, and studies with longer follow-up periods, were all excluded.

In an effort to be helpful, we suggest: "We found little evidence from the included studies to suggest that 12 or more weeks of CCT improves cognition in healthy older adults. However, our limited confidence in the results reflects the exclusion of more than 100 publications with cognitive training periods of under 12 weeks, including multiple studies with substantially larger patient populations, substantially higher doses of cognitive training, and substantially longer follow-up periods than the studies included in this review. The possibility that each of these variables could affect the results of the analysis remains to be more fully explored."

More appropriately, we suggest that this review should be retracted, and re-conducted with appropriate inclusion criteria.

Contributors:

Henry W. Mahncke, Ph.D Posit Science, CEO

Michael M. Merzenich, Ph.D. University of California San Francisco, Professor Emeritus in the Department of Otolaryngology; Posit Science, Co-Founder and Chairperson and Chief Scientific Officer

Karlene K. Ball, Ph.D. University of Alabama, Professor in the Department of Neurobiology and Director of the UAB Edward R. Roybal Center for Research on Applied Gerontology

Jerri Edwards, Ph.D. University of South Florida, Professor in the College of Medicine Psychiatry and Behavioral Neurosciences References

\section{References}

1. Lampit A, Hallock H, Suo C, Naismith SL, Valenzuela M. Cognitive training-induced short-term functional and long-term structural plastic change is related to gains in global cognition in healthy older adults: a pilot study. Front Aging Neurosci. 2015;7(14):1-13.

2. Smith GE, Housen P, Yaffe K, et al. A cognitive training program based on principles of brain plasticity: Results from the Improvement in Memory with Plasticity-based Adaptive Cognitive Training (IMPACT) study. J Am Geriatr Soc. 2009;57(4):594-603.

3. Leung NT, Tam HM, Chu LW, et al. Neural plastic effects of cognitive training on aging brain. Neural Plast. 2015;2015(535618):1-9.

4. van Het Reve E, de Bruin ED. Strength-balance supplemented with computerized cognitive training to improve dual task gait and divided attention in older adults: a multicenter randomized-controlled trial. BMC Geriatr. 2014;14(1):134.

5. Klusmann V, Evers A, Schwarzer R, et al. Complex mental and physical activity in older women and cognitive performance: a 6-month randomized controlled trial. J Gerontol A Biol Sci Med Sci. 2010;65A(6):680-688.

6. Rebok GW, Ball K, Guey LT, et al. Ten-year effects of the Advanced Cognitive Training for Independent and Vital Elderly cognitive training trial on cognition and everyday functioning in older adults. J Am Geriatr Soc. 2014;62(1):16-24.

7. Corbett A, Owen A, Hampshire A, et al. The effect of an online cognitive training package in healthy older adults: an online randomized controlled trial. J Am Med Dir Assoc. 2015;16(11):990-997.

8. Ball K, Berch DB, Helmers KF, et al. Effects of cognitive training interventions with older adults: a randomized controlled trial. J Am Med Assoc. 2002;288(18):2271-2281.

9. Willis SL, Tennstedt SL, Marsiske M, et al. Long-term effects of cognitive training on everyday functional outcomes in older adults. JAMA J Am Med Assoc. 2006;296(23):2805-2814.

10. Wolinsky FD, Vander Weg MW, Martin R, et al. The effect of speed-of-processing training on depressive symptoms in ACTIVE. J Gerontol A Biol Sci Med Sci. 2009;64(4):468-472.

11. Wolinsky FD, Unverzagt FW, Smith DM, Jones R, Wright E, Tennstedt SL. The effects of the ACTIVE cognitive training trial on clinically relevant declines in health-related quality of life. J Gerontol B Psychol Sci Soc Sci. 2006;61(5):S281-287.

12. Ball K, Edwards JD, Ross LA, McGwin Jr. G. Cognitive training decreases motor vehicle collision involvement of older drivers. J Am Geriatr Soc. 2010;58(11):2107-2113.

13. Wolinsky FD, Vander Weg MW, Howren MB, Jones MP, Dotson MM. A randomized controlled trial of cognitive training using a visual speed of processing intervention in middle aged and older adults. PLoS ONE. 2013;8(5):e61624. 
14. Wolinsky FD, Weg MWV, Howren MB, Jones MP, Dotson MM. The effect of cognitive speed of processing training on the development of additional IADL difficulties and the reduction of depressive symptoms results from the IHAMS randomized controlled trial. J Aging Health. 2015;27(2):334-354.

15. Zelinski EM, Spina LM, Yaffe K, et al. Improvement in Memory with Plasticity-based Adaptive Cognitive Training (IMPACT): Results of the 3-month follow-up. J Am Geriatr Soc. 2011;59:258-265.

16. Lampit A, Hallock H, Valenzuela M. Computerized cognitive training in cognitively healthy older adults: a systematic review and metaanalysis of effect modifiers. PLOS Med. 2014;11(11):e1001756.

17. Mewborn CM, Lindbergh CA, Miller LS. Cognitive interventions for cognitively healthy, mildly impaired, and mixed samples of older adults: A systematic review and meta-analysis of randomized-controlled trials. Neuropsychol Rev. July 2017:1-37. doi:10.1007/ s11065-017-9350-8

18. Edwards JD, Fausto BA, Tetlow AM, Corona RT, Valdés EG. Systematic review and meta-analyses of useful field of view cognitive training. Neurosci Biobehav Rev. 2018;84:72-91. doi:10.1016/j.neubiorev.2017.11.004

\section{Declaration of Interest}

Do you have any affiliation with or involvement in any organisation with a financial interest in the subject matter of your comment?

$\mathrm{HM}$ and MM are employed at and hold stock in Posit Science, a company that develops cognitive training programs. KB holds stock in Posit Science. JE has no conflict of interest.

\section{Reply}

We thank Dr. Mahncke and colleagues for their comments regarding the Cochrane Review: 'Computerised cognitive training for maintaining cognitive function in cognitively healthy people in late life.'

Dr. Mahncke and colleagues' primary criticism is of our decision to require a 12-week minimum duration of the computerised cognitive training (CCT) intervention, which led to exclusion of a large number of trials with shorter intervention periods.

Regarding the use of the two references 'Lampit 2015' and 'Lampit 2014a' as background to this decision, we agree that these are referenced incorrectly and we apologise for this mistake. We agree that these papers do not support the minimum 12-week exposure criterion.

This review was conceived as part of a set of reviews concerned with lifestyle modifications which could help to maintain cognitive function in later life and, in particular, contribute to preventing or delaying the onset of dementia. The reviews were intended to focus on sustainable interventions and to look for enduring effects. One of the intervention domains identified as being of interest was increasing cognitive activity and, with an eye to sustainability, a decision was made to restrict the focus to computer-delivered interventions (computerised cognitive training, CCT).

Trials of any intervention which measure cognitive outcomes in cognitively healthy adults fall along a spectrum. At one end are cognitive enhancement trials. Cognitive enhancement is typically the aim of interventions directed at younger adults. The interventions are often short and can be of high intensity. At the other end are trials looking to prevent cognitive decline or dementia. These trials are most often conducted in older adults, although we know that the duration of neurodegenerative diseases is such that mid-life may also be a key period for neuroprotection. Indeed, for cognitive activity, the evidence on education as a protective factor against dementia suggests that wholelife timescales may be relevant.

The distinction between cognitive enhancement (or improvement from baseline) and prevention of cognitive decline and dementia is an important one and, in recent years, the policy of the Cochrane Dementia and Cognitive Improvement Group has to been to regard these as sufficiently distinct topics to merit separate reviews.

We would maintain that the majority of the trials excluded from this review on the basis of duration of intervention $<12$ weeks are best viewed as cognitive enhancement trials and are not directly relevant to the question this review seeks to address. As acknowledged above, this is a spectrum, not a dichotomy, but - in order to avoid producing a review dominated by cognitive enhancement effects - some threshold had to be chosen, which inevitably had to be a matter of judgment.

We understand Dr. Mahncke and colleagues to be suggesting that, if a threshold is to be imposed, then dose (total hours delivered and/or frequency) would be a better basis for that threshold than overall duration of intervention. We agree that this is an alternative approach and that it was misleading to refer in the review to "a minimum dose of intervention" rather than to a minimum duration. However, selecting a dose cut-off would have been equally arbitrary. Certainly there is no clear dose-response relationship in the literature. For example, Lampit 2014 , in a subgroup analysis in their review, found no evidence of benefit from training $>3$ times/week compared to less frequent training.

Dr. Mahncke and colleagues also make the point that the objectives of the review would be better addressed by concentrating on duration of follow-up, not duration of exposure to the intervention. We think this is a valid argument. The review is being updated with new lead 
authors and the inclusion criteria will be amended in the update so that all CCT trials which assess outcomes 12 weeks or longer after randomisation will be eligible, regardless of total dose of CCT or duration of exposure.

As far as this edition of the review is concerned, we published a peer-reviewed protocol in which the PICO elements, including the 12week threshold for duration of eligible interventions were clearly stated. This criterion was repeated several times in the abstract of the review, the Plain Language Summary and the Discussion, where it was clearly stated that the conclusions did not apply to shorter training programmes. In the amended version of the review published with this response, we have - for even greater transparency - also inserted the duration criterion into the title and further emphasised the restriction of scope in other sections, in order that the findings are not over-generalised. We accept that the rationale for the duration criterion could have been better explained, but not that the review was misleading. Mahncke and colleagues may not consider that the review asked the best question, but it did address the question asked.

\section{References}

1. Lampit A, Hallock H, Valenzuela M. Computerized cognitive training in cognitively healthy older adults: a systematic review and metaanalysis of effect modifiers. PLOS Med. 2014;11(11):e1001756

\section{Contributors}

Dr G Martinez, Dr R Vernooij, Dr A Rutjes (authors)

Dr J McCleery, Dr T Quinn (CDCIG Coordinating Editors)

\section{WHAT'S NEW}

\begin{tabular}{lll}
\hline Date & Event & Description \\
\hline 11 February 2020 & $\begin{array}{l}\text { New citation required and conclusions } \\
\text { have changed }\end{array}$ & $\begin{array}{l}\text { Comments/feedback received and errors corrected in response. } \\
\text { Title changed to reflect this. Conclusions changed }\end{array}$ \\
\hline 11 February 2020 & Amended & $\begin{array}{l}\text { Errors corrected in response to comments received. Title } \\
\text { changed to reflect this. Conclusions changed }\end{array}$ \\
\hline
\end{tabular}

\section{CONTRIBUTIONSOF AUTHORS}

Completion of the protocol: Nicola Gates, Anne Rutjes, Marcello Di Nisio, Salman Karim, Jennifer Ware, Lee Yee Chong, Evrim March, Robin Vernooij.

Screening of references: Students For Best Evidence (title/abstract screening).

Full-text screening: Nicola Gates, Salman Karim, Evrim March, Robin Vernooij, Gabriel Martínez.

Acquisition of data: Nicola Gates, Anne Rutjes, Marcello Di Nisio, Salman Karim, Evrim March, Robin Vernooij, Gabriel Martínez.

Risk of bias assessments: Nicola Gates, Anne Rutjes, Marcello Di Nisio, Salman Karim, Evrim March, Robin Vernooij, Gabriel Martínez.

SoF and GRADE-ing: Robin Vernooij, Anne Rutjes.

Statistical analysis: Anne Rutjes.

Overall interpretation of data: Nicola Gates, Anne Rutjes, Marcello Di Nisio, Evrim March, Robin Vernooij, Gabriel Martínez.

Manuscript preparation: Nicola Gates, Anne Rutjes, Robin Vernooij, Gabriel Martínez.

\section{DECLARATIONSOF INTEREST}

Nicola J Gates: none known.

Anne WS Rutjes: Dr. Rutjes declares partial funding by a grant for the project 'OPERAM: OPtimising therapy to prevent Avoidable hospital admissions in the Multi-morbid elderly', supported by the European Union's Horizon 2020 research and innovation programme under the grant agreement No. 6342388, and by the Swiss State Secretariat for Education, Research, and Innovation (SERI) under contract number 15.0137.

Marcello Di Nisio: Di Nisio declares partial funding by a grant for the project 'OPERAM: OPtimising therapy to prevent Avoidable hospital admissions in the Multi-morbid elderly', supported by the European Union's Horizon 2020 research and innovation programme under the grant agreement No 6342388. Di Nisio reports participation in Advisory Boards for Daiichi-Sankyo, Aspen, and Pfizer, and consultancy fees for Daiichi-Sankyo, Bayer Health Care, and Leo Pharma outside the submitted work.

Salman Karim: none known.

Lee-Yee Chong: none known.

Evrim March: none known.

Gabriel Martínez: none known. 
Robin WM Vernooij: none known.

\section{SOURCES OF SUPPORT}

\section{Internal sources}

- No sources of support supplied

\section{External sources}

- National Institute for Health Research (NIHR), UK.

This protocol was supported by the NIHR, via a Cochrane Programme Grant to the Cochrane Dementia and Cognitive Improvement Group. The views and opinions expressed herein are those of the authors and do not necessarily reflect those of the Systematic Reviews Programme, NIHR, National Health Service (NHS), or the Department of Health.

- SERI and Horizon 2020, Other.

The authors AR and MdN are partially funded by a grant for the project 'OPERAM: OPtimising therapy to prevent Avoidable hospital admissions in the Multi-morbid elderly' supported by the European Union's Horizon 2020 research and innovation programme under the grant agreement No 6342388, and by the Swiss State Secretariat for Education, Research and Innovation (SERI) under contract number 15.0137. The opinions expressed and arguments employed herein are those of the authors and do not necessarily reflect the official views of the EC and the Swiss government.

\section{DIFFERENCES BETWEEN PROTOCOLANDREVIEW}

Appendix 2 describes the features we planned to use in stratified analyses to explore between-trial heterogeneity. We also planned to explore bias associated with small study size, such as publication bias, in funnel plot analyses. As our protocol required the inclusion of 10 trials for such analyses to be meaningful, we omitted stratified and funnel plot analyses. We also omitted the protocol-defined sensitivity analysis for the primary outcome. Latter analyses would include high-quality trials only, with high quality planned to be defined using results of the stratified analyses. As stratified analyses could not be performed, we omitted this sensitivity analyses. We also planned to perform sensitivity analyses according to the definitions used for $\mathrm{MCl}$ or dementia, namely, restricting analyses to trials applying internationally accepted definitions. As none of the trials reported such outcomes, we could not perform any analyses for this patient relevant outcome. We used a hierarchy to select instruments from which we would analyse the outcome data. We made the decision to use the hierarchy before we began to extract data.

\section{N DEX TERMS}

\section{Medical Subject Headings (MeSH)}

${ }^{\star}$ Cognition; ${ }^{\star}$ Computer-Assisted Instruction; ${ }^{\star}$ Healthy Aging; Age Factors; Cognitive Dysfunction [ ${ }^{*}$ prevention \& control]; Dementia [prevention \& control]; Memory, Episodic; Randomized Controlled Trials as Topic; Time Factors

\section{MeSH check words}

Aged; Aged, 80 and over; Humans; Middle Aged 